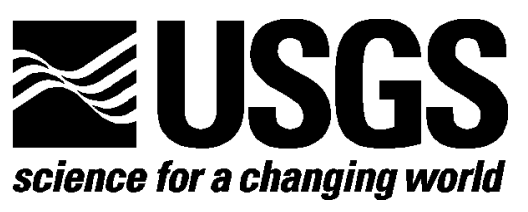

\title{
Relationship of faults in basin sediments to the gravity and magnetic expression of their underlying fault systems
}

By Christopher A. Baldyga ${ }^{1}$

Open-File Report 01-502

2001

This report is preliminary and has not been reviewed for conformity with U.S. Geological Survey editorial standards or with the North American Stratigraphic Code. Any use of trade, product or firm names is for descriptive purposes only and does not imply endorsement by the U.S. Government.

\section{U. S. DEPARTMENT OF THE INTERIOR U.S. GEOLOGICAL SURVEY}

1U.S. Geological Survey, Tucson, Arizona. This Master's Thesis was funded by the Southwest Mineral and Environmental Investigations Project, Mineral Resources Program, Geologic Division, U.S. Geological Survey. 


\title{
STATEMENT BY AUTHOR
}

This thesis has been submitted in partial fulfillment of requirements for advanced degree at the University of Arizona and is deposited in the University Library to be made available to borrowers under the rules of the Library.

Brief quotations from this thesis are allowable without special permission, provided that accurate acknowledgement of source is made. Requests for permission for extended quotation from or reproduction of this manuscript in whole or in part may be granted by the head of the major department or the Dean of the Graduate College when in his or her judgement the proposed use of the material is in the interests of scholarship. In all other instances, however, permission must be obtained by the author.

\section{SIGNED:}

\section{APPROVAL BY THE THESIS DIRECTOR}

The thesis has been approved on the date shown below:

Mary M. Poulton

Date

Associate Professor, Geological Engineering

Mark E. Gettings

Date

\author{
Adjunct Professor, Geophysics
}




\section{ACKNOWLEDGEMENTS}

I would like to thank several people who have helped me in the past three years financially, intellectually and spiritually. My family and friends, thank you for getting me to this point, I could not have done it without you. Mary Poulton and Karl Glass, who served on my thesis committee, thank you for the challenges that come with higher education, your knowledge and support has motivated and elevated me to goals I thought once impossible. Thank you to the USGS and WAIME for funding me through my period here at the University. Special thanks goes to my mentor and thesis advisor, Mark Gettings, your endless patience, kindness and knowledge will remain with me forever. Thank you. 


\section{ACKNOWLEDGEMENTS}

I would like to thank several people who have helped me in the past three years financially, intellectually and spiritually. My family and friends, thank you for getting me to this point, I could not have done it without you. Mary Poulton and Karl Glass, who served on my thesis committee, thank you for the challenges that come with higher education, your knowledge and support has motivated and elevated me to goals I thought once impossible. Thank you to the USGS and WAIME for funding me through my period here at the University. Special thanks goes to my mentor and thesis advisor, Mark Gettings, your endless patience, kindness and knowledge will remain with me forever. Thank you. 


\section{TABLE OF CONTENTS}

LIST OF FIGURES................................................................

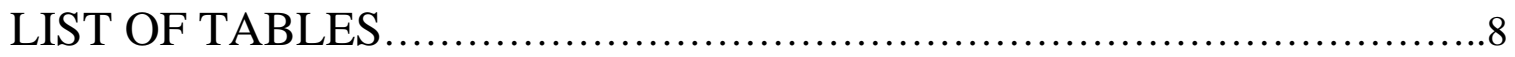

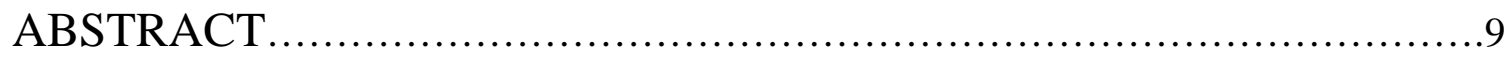

INTRODUCTION ............................................................

GEOLOGIC SETTING......................................................

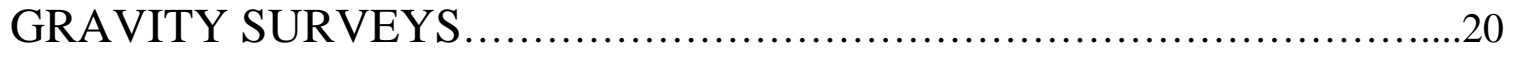

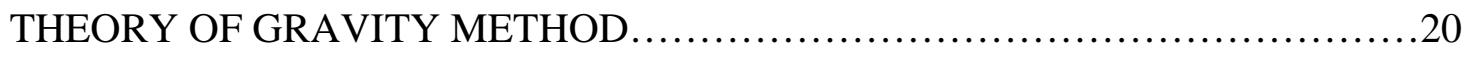

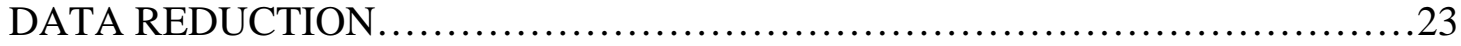

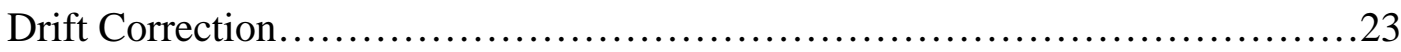

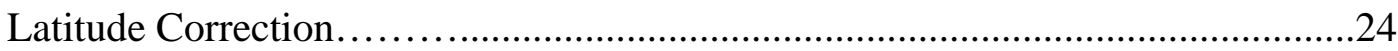

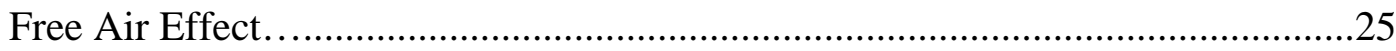

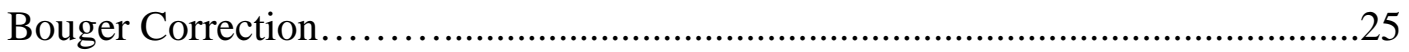

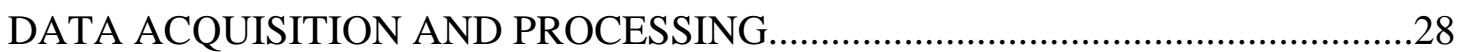

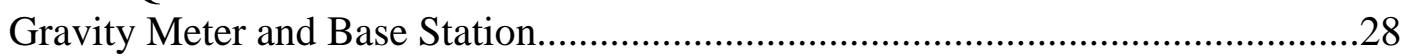

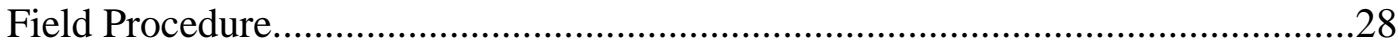

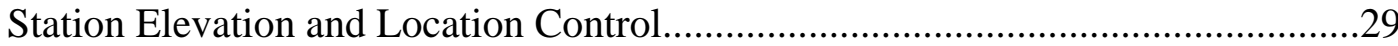

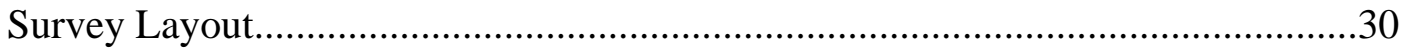

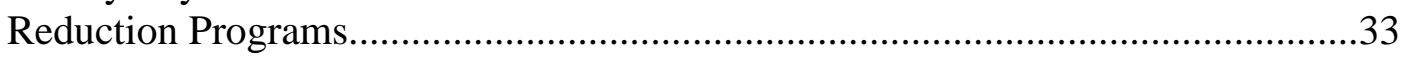

MAGNETIC SURVEYS ..................................................... 38

THEORY OF MAGNETIC METHOD ......................................... 38

MAGNETIC DATA ACQUISITION AND PROCESSING .......................43

Instrument and Procedure ...........................................................

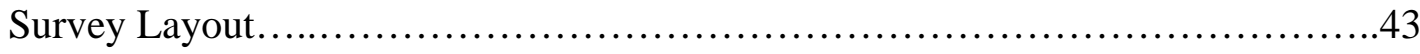

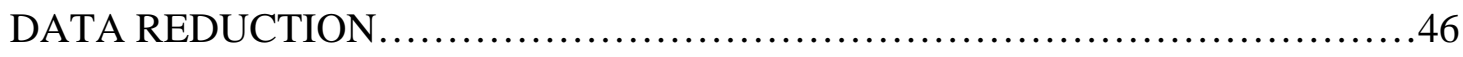




\section{TABLE OF CONTENTS - continued}

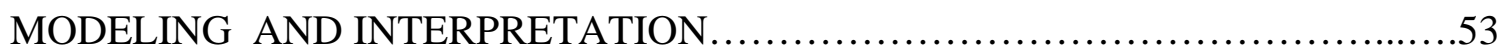

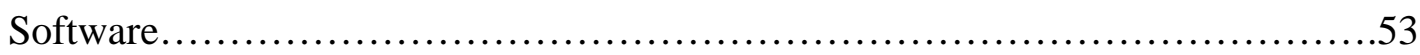

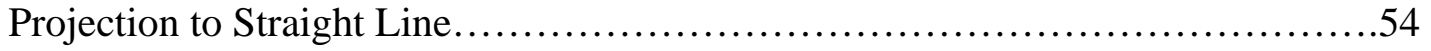

REX RANCH PROFILE.................................................... 57

NORTHERN COTTONWOOD CANYON PROFILE ..........................68

SOUTHERN COTTONWOOD CANYON PROFILE.............................75

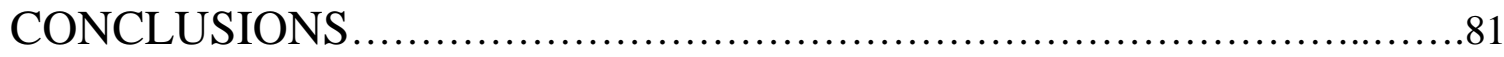

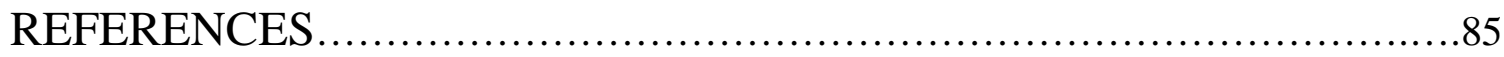

APPENDIX A: GRAVITY DATA......................................87

APPENDIX B: TRUCK MAGNETIC DATA............................

APPENDIX C: AEROMAGNETIC DATA................................105 


\section{LIST OF FIGURES}

Figure 1 Location map of survey area .........................................11

Figure 2 Aerial photograph of Rex Ranch fault..................................12

Figure 3 Aerial photograph of Cottonwood Canyon fault...........................12

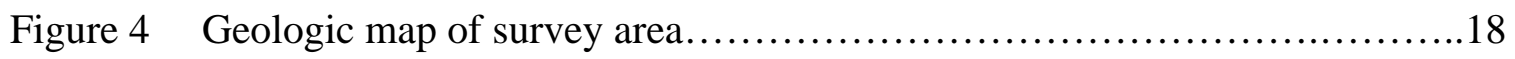

Figure 5 Drift curve for Northern Cottonwood Canyon profile......................23

Figure $6 \quad$ Location of gravity survey lines....................................... 32

Figure 7 Complete Bouguer gravity anomaly data for Rex Ranch profile...............35

Figure 8 Complete Bouguer gravity anomaly data for Northern Cottonwood Canyon profile.................................................................

Figure 9 Complete Bouguer gravity anomaly data for Southern Cottonwood Canyon

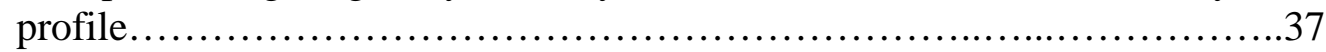

Figure 10 Location of magnetic survey lines.......................................4

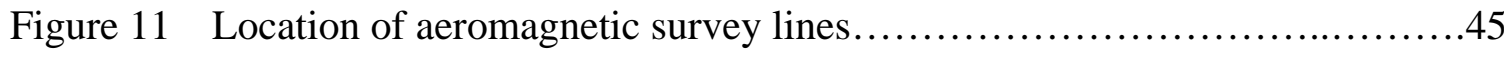

Figure 12 Rex Ranch magnetic anomaly profile..................................47

Figure 13 Northern Cottonwood Canyon magnetic anomaly profile ...................48

Figure 14 Southern Cottonwood Canyon magnetic anomaly profile ....................49

Figure 15 Rex Ranch aeromagnetic anomaly profile..............................50

Figure 16 Northern Cottonwood Canyon aeromagnetic anomaly profile...............51

Figure 17 Southern Cottonwood Canyon aeromagnetic anomaly profile.................52

Figure 18 Location of original lines and projected lines for Rex Ranch profile..........55 


\section{LIST OF FIGURES - continued}

Figure 19 Location of original lines and projected lines for Cottonwood Canyon

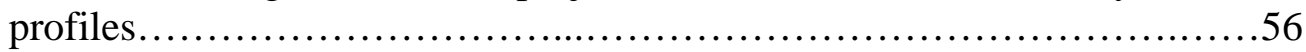

Figure 20 Model of brittle/ductile behavior in sediments...........................59

Figure 21 Magnification of Rex Ranch Model......................................60

Figure 22 Offset in peaks due to the profiles crossing the trace of the fault at different

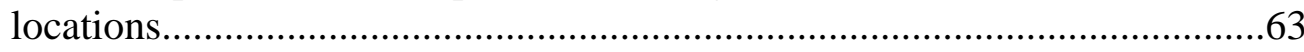

Figure 23 Modeled gravity and magnetic profile for Rex Ranch.....................66

Figure 24 Modeled gravity and aeromagnetic profile for Rex Ranch.................67

Figure 25 Magnification of Northern Cottonwood model............................69

Figure 26 Modeled gravity and magnetic profile for Northern Cottonwood Canyon...73

Figure 27 Modeled gravity and aeromagnetic profile for Northern Cottonwood Canyon...................................................................

Figure 28 Magnification of Southern Cottonwood Canyon model.....................75

Figure 29 Modeled gravity and magnetic profile for Southern Cottonwood Canyon ...79

Figure 30 Modeled gravity and aeromagnetic profile for Southern Cottonwood

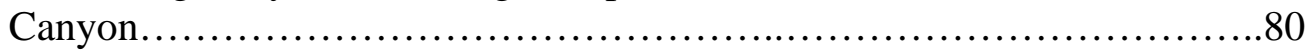




\section{LIST OF TABLES}

Table 1 Rock units and symbols for geologic map of survey area...................19

Table 2 Description of modeled rock units.................................65 


\begin{abstract}
Gravity and magnetic surveys were performed along the western flanks of the Santa Rita Mountain range located in southeastern Arizona to develop an understanding of the relationship between surface fault scarps within the basin fill sediments and their geophysical response of the faults at depth within the bedrock. Data were acquired for three profiles, one of them along the northern terrace of Montosa Canyon, and the other two along the northern and southern terraces of Cottonwood Canyon. A total of 122 gravity stations were established as well as numerous magnetic data collected by a truckmounted cesium-vapor magnetometer. In addition, aeromagnetic data previously acquired were interpreted to obtain a geologically sound model, which produced a good fit to the data.

Gravity anomalies associated with faults exhibiting surface rupture were more pronounced than the respective magnetic anomalies. More credence was given to the gravity data when determining fault structures and it was found in all three profiles that faults at depth projected through alluvium at a steeper dip than the bedrock fault indicating brittle behavior within the overlying sediments. The gravity data also detected a significant horst and graben structure within Cottonwood Canyon. The aeromagnetic data did not provide any insight into the response of the minor faults but rather served to verify the regional response of the whole profile.
\end{abstract}




\section{INTRODUCTION}

The objective of this project was to gain a better understanding of the relationship between the gravitational and magnetic expressions of faults at depth in bedrock and the geometry and character of their fault scarps through methods of forward geophysical modeling. Existing aeromagnetic data were also modeled to help understand the subsurface geology. Previous gravity work done by U.S. Geological Survey (M.E. Gettings, unpublished), Mary Hegmann (1998) and Khalid Tanbal (1987) combined with the data acquired for this project were used to create gravity contour maps of the areas of study. Tanbal (1987) conducted gravity surveys to identify the position and displacement of Quaternary faults located north of the present study area.

The survey was conducted in Santa Cruz County, Arizona, along the west flank of the Santa Rita Mountains near Elephant Head. The Santa Rita Mountains are located about $55 \mathrm{~km}$ south of Tucson and trend NW - SE. They begin near Pantano Wash and extend southward to Sonoita Creek, which is $19 \mathrm{~km}$ north of the Mexico border. Fig. 1 shows the location of the field area. Figs. 2 and 3 are aerial photographs of the Rex Ranch and Cottonwood Canyon areas showing the surface fault scarps and profile lines. 


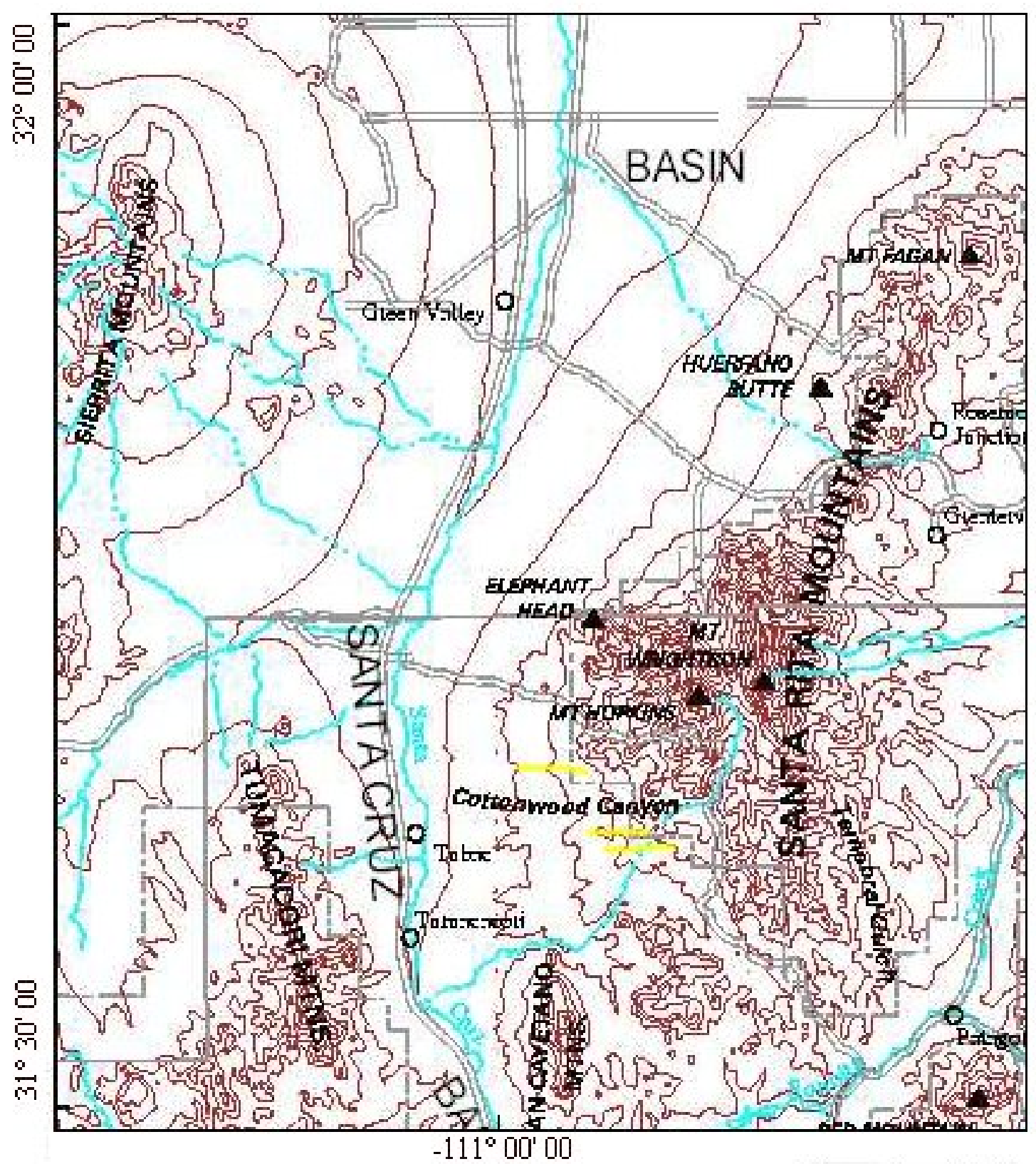

Figure 1. Map location of fie ld are a with profiles marked in solid yellow lines.

KILOMETERS

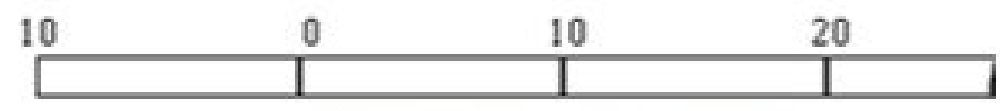

Contour interval is 100 meters

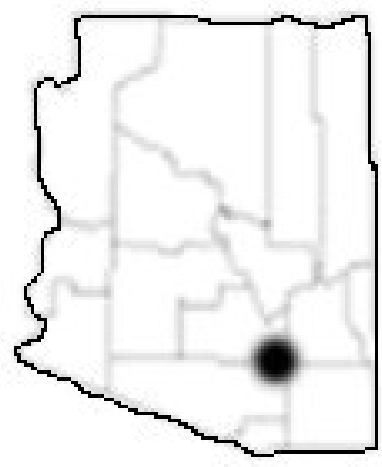




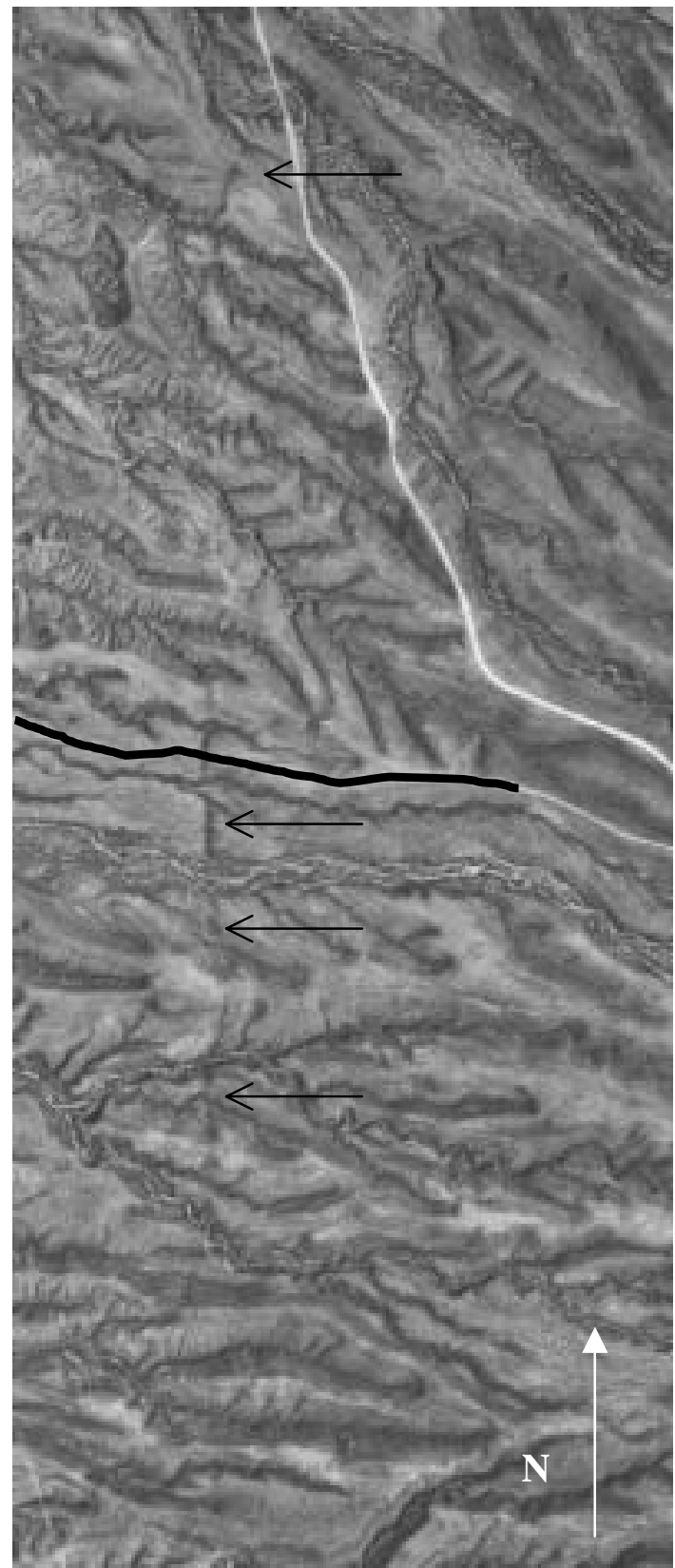

Figure 2. Aerial photograph of Rex Ranch fault as indicated by arrows. Solid lines indicate the gravity and magnetic profiles.

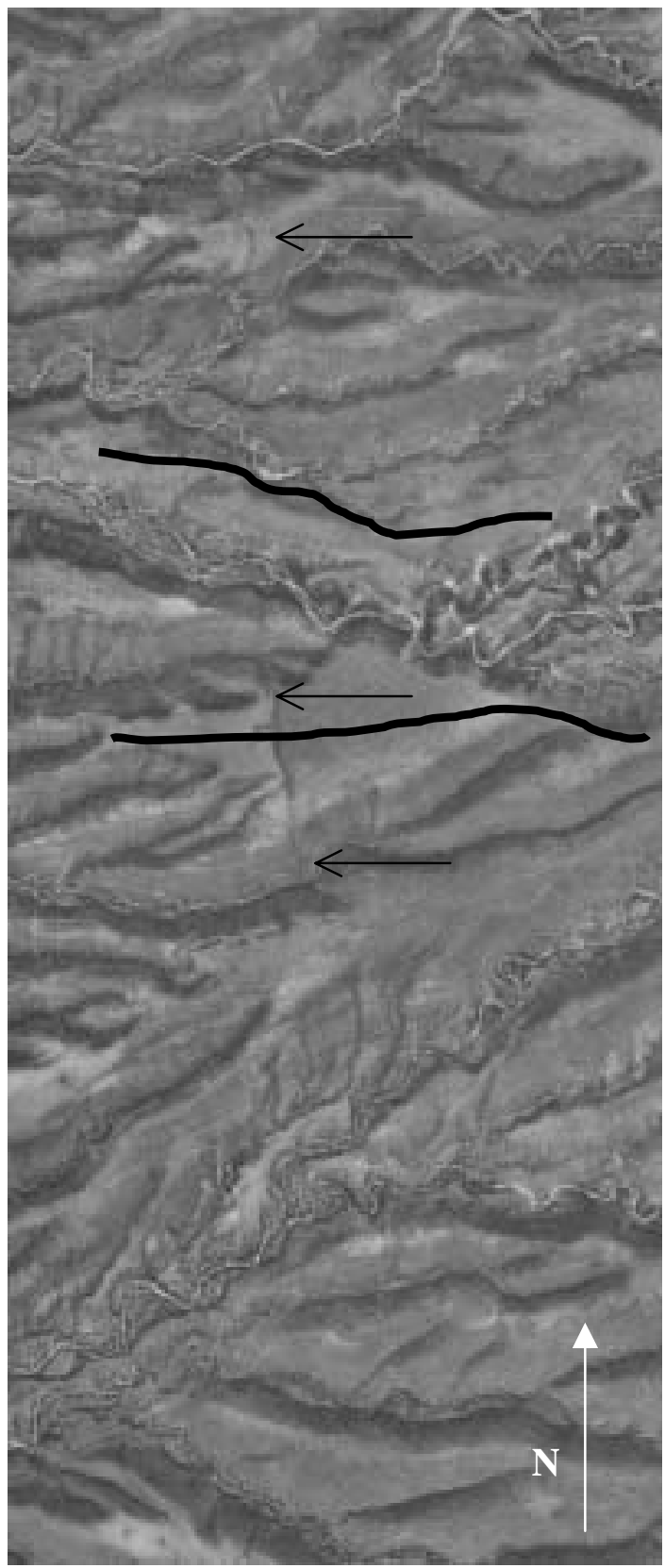

Figure 3. Aerial photograph of Cottonwood Canyon as indicated by arrows. Solid lines indicate the gravity and magnetic profiles.

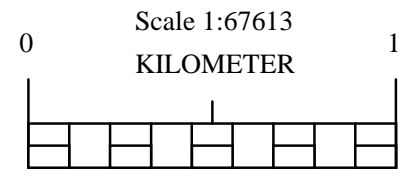




\section{GEOLOGICAL SETTING}

The project area lies in the Southern Basin and Range Province on the western flank of the Santa Rita Mountains (see Fig. 1). The Santa Ritas have been extensively studied because of their unusually complete stratigraphic and structural record. An extensive sequence of sedimentary, intrusive, extrusive and metamorphic rocks ranging from Precambrian to Holocene in age compose the Santa Rita Mountain Range. The majority of basement rock, known as the Continental Granodiorite is a coarse-grained porphyritic granodiorite and quartz monzonite (Drewes, 1976). It has been radiometrically dated to be at least 1.45 b.y. old. The Continental Granodiorite of the Santa Rita Mountain range has been intruded by stocks of Triassic monzonites, Jurassic granitic stocks, and a host of Tertiary Volcanics (Drewes, 1976).

The Precambrian rocks are overlain by a section of shallow marine rocks deposited during the Paleozoic. This section is dominated by limestone and dolomite with clastic rocks present at the top and bottom of the section representing a history of marine transgressions and regressions, until the Middle of the Permian Period when the area was uplifted and exposed to continental conditions (Drewes, 1976).

Throughout the Mesozoic Era southeastern Arizona was part of a continental margin volcanic arc along the North American Cordillera from Mexico to Alaska (Coney, 1987). Three major sequences of volcanic rocks were deposited over Precambrian and Paleozoic rocks. During the Triassic, rhyodacite and andesite as well as some eolian sandstone and conglomerates were deposited as two different formations, the Mt. Wrightson Formation overlain by the Gardner Canyon Formation. Between mid- 
Permian and mid-Triassic significant uplift associated with the Sonoran Orogeny occurred in the present area of the Santa Rita Mountain Range. Subsequent erosion stripped away nearly $1.5 \mathrm{~km}$ of Paleozoic rocks and exposed the Precambrian rocks to further erosion and deposition as detritus into the Mt. Wrightson Formation. Evidence for block faulting is coupled with the fact that the linear distribution of Triassic volcanics was the result of deposition in the block-faulted troughs (Drewes, 1971). Near the end of the Triassic Period the Piper Gulch Monzonite intruded through the Santa Rita fault scar. Of significant importance is the Squaw Gulch Granite that intruded through Precambrian, Paleozoic and Triassic rocks sometime during the Jurassic Period. The volcanic rocks intruded by this granitic batholith are contact metamorphosed. Near to the project area, the Squaw Gulch granite intruded and actually recrystallized the Continental Granodiorite. The contact between the two formations is concealed and postulated to be sharp and irregular. In exposures closer to Cottonwood Canyon, the contact of the Squaw granite with Paleozoic rocks is sharp and dips irregularly. The host rock forms either xenoliths or roof pendants within the batholith, rather than acting as wallrock to the batholith. Faulting and subsequent erosion occurred after the emplacement of the granite batholith. During Early Cretaceous time the Temporal Formation, Bathtub Formation and Bisbee Group consisting of rhyolitic and andesitic volcanic material, as well as arkosic rocks and conglomerates were deposited. In the latest of the three volcanic sequences are of Late Cretaceous age and consist of arkose and conglomerate overlain by dacitic and rhyodacitic volcanic rocks. The volcanic rocks deposited during the 
Mesozoic have been well preserved and only slightly metamorphosed, however, due to repeated deformation they have been fragmented through faulting.

The rocks that compose the present day Santa Rita Mountains have a long history of deformation. During the Precambrian and Paleozoic Eras there was mostly epierogenic activity with little orogenic activity. During the Mesozoic and Cenozoic Eras, however, tectonism increased in both strength and frequency. The Laramide Orogeny, left a pronounced effect lasting from the Late Cretaceous through the Early Tertiary, 90 to 52 mya.

There were two phases of deformation during the Laramide Orogeny separated by a period of tectonic quiescence. The first phase, called the Piman Phase, lasted from 90 to 63 mya, and the second phase, known as the Helvetian Phase, lasted from 57 to 52 mya. The Piman Phase was defined by basement-cored block uplift (Drewes, 1972). The direction of compression was along an axis oriented northeast - southwest. Northeasterly thrust faulting and associated tear faulting was also prevalent during this phase. A transition from volcanism to plutonic emplacement marked the end of the Piman Phase.

A period of quiescence during the Middle of the Laramide lasted from 63 to 57 mya (Drewes, 1972). The direction of compression slowly changed and probably created a tensional environment. The existence of intrusive rocks such as the Cottonwood Dike Swarm provides evidence for the existence of extensional conditions. Also, nearby volcanism deposited the Gringo Gulch and Red Mountain volcanics.

The Helvetian Phase of the Laramide Orogeny began in the Late Paleocene and is associated with less severe tectonics relative to the earlier phase. Compressional forces 
re-oriented about 90 degrees from the Piman Phase. Minor northwest thrust faulting was activated as well as reactivation of earlier faults systems, however, in a fashion much different from the original. Stocks appropriately named the Helvetian Stocks were emplaced. Intrusion of quartz latite porphyries marked the close of the Helvetian Phase of the Laramide Orogeny.

Post-Laramide deformation is characterized by normal faulting and drag folding resulting from tensional stresses or possibly the relaxation of compressional forces (Drewes, 1972). Faulting was relatively shallow, although some older faults were reactivated. The primary orientation of faults was northeast to east. From the Paleocene to Oligocene, quartz veins were emplaced to the south and rhyolitic and andesitic volcanics were deposited to the north. Magmatic activity began again in the Late Oligocene with the deposition of the Grosvenor Hill volcanics, primarily rhyolitic in composition, and extruded as flows and tuffs. Feeder dikes and laccoliths commonly intruded the Grosvenor volcanics (Drewes, 1971b).

During the Miocene, about 17 mya, extensional forces dominated when the spreading ridge of the Pacific plate was subducted under the North American plate causing the movement of the two plates to become strike-slip as opposed to subduction (Coney, 1987). Block faulting began to reform the present day Santa Rita Mountains. Extension was directed along an east-northeast/west-southwest axis. Reactivation of older Mesozoic faults occurred but due to the different direction of compression a zigzag pattern of basin and ranges subsequently formed. Extensive deposits of gravel, sand and conglomerates called the Nogales Formation, filled the basins adjacent to the uplifted 
Santa Ritas (Drewes, 1972). The Nogales comprised of volcanic detritus was indurated and then deformed by normal faulting, resulting in blocks dipping $10-25$ degrees towards the mountains. From the Pliocene until present day several formations, separated by unconformities, have been deposited. The sediments are mainly derived from formations above in the Santa Rita Mountains.

Figure 4 shows the geology around the Cottonwood Canyon area, the Rex Ranch profile is to the northwest of the Cottonwood Canyon area, however, it is not shown in this figure. There are no bedrock exposures near the Rex Ranch profile and it is completely covered by Holocene gravel. Table 1 describes some of the exposed rocks especially those used in the modeling. 


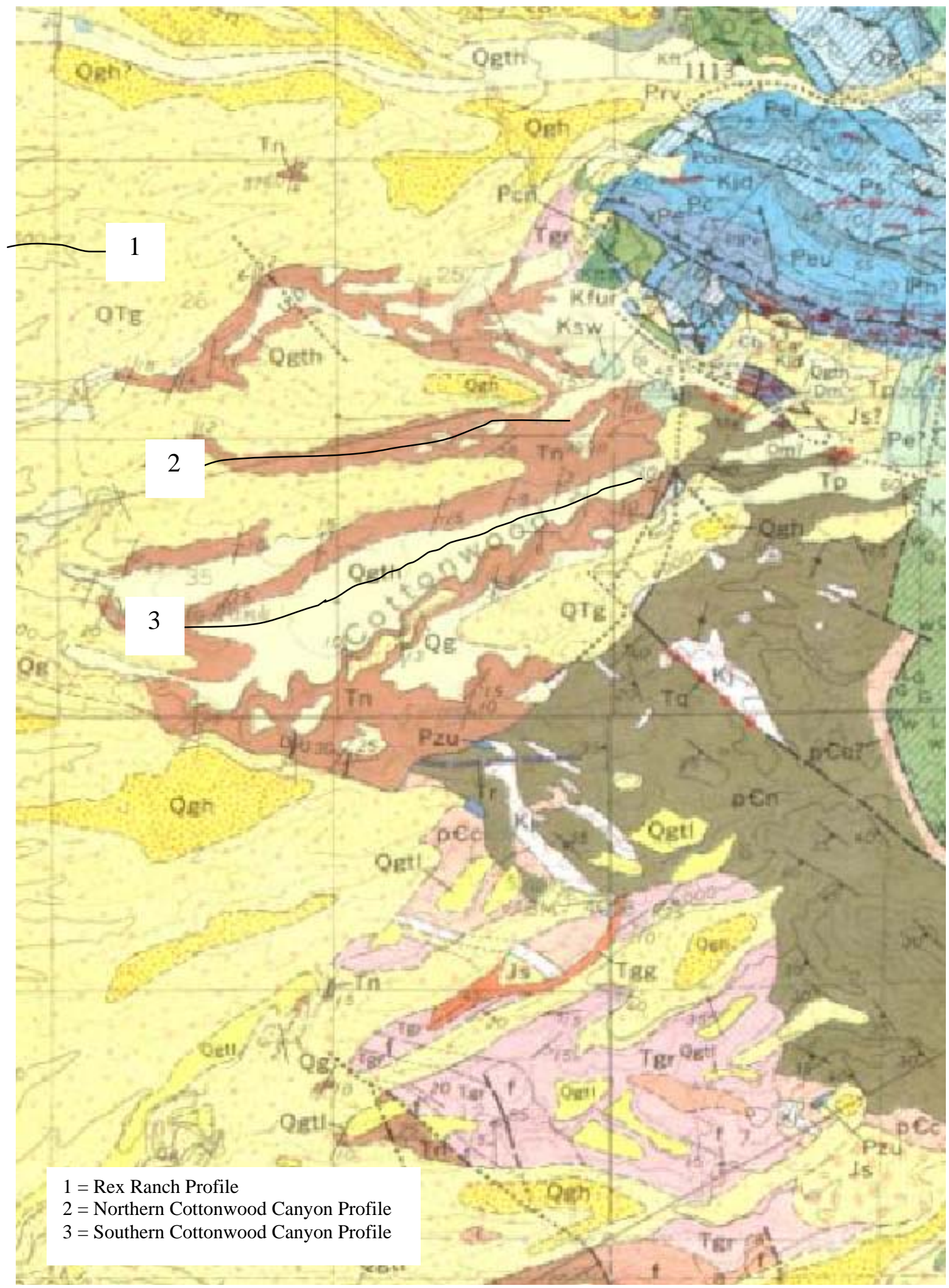

Figure 4. Geologic map of field area (Drewes, 1971a) with location of profiles. 
Table 1: Description of modeled rock units (Drewes, 1971a)

\begin{tabular}{|c|c|c|c|}
\hline Symbol & Unit Name & Geologic Age & Unit Description \\
\hline Qg & Gravel & Holocene & Alluvium of streams draining the Santa Rita Mountains \\
\hline Qgth & Terrace Gravel & Late Pleistocene & Alluvium capping higher terraces, carrying a well-developed soil \\
\hline Qgh & Gravel & Early Pleistocene & Alluvium caps high surfaces \\
\hline $\operatorname{Tn}$ & Gravel at Nogales & Miocene & Gravel, conglomerate, and sand comprised of abundant volcanic detritus \\
\hline Tgr & Rhyolite Member & Oligocene & Largely undifferentiated tuff breccia (Grosvenor Hills Volcanics) \\
\hline $\mathrm{Kj}$ & Josephine Canyon Diorite & Late Cretaceous & Moderately coarse-grained quartz diorite phase \\
\hline Kse & Exotic Block Member & Late Cretaceous & Undifferentiated tuffaceous sandstone, conglomerate and tuff breccia \\
\hline Js & Squaw Gulch Granite & Jurassic & Pink coarse grained granite and quartz monzonite, includes some lamprophyre dikes. \\
\hline Ps & Scherre Formation & Permian & Fine-grained quartzitic sandstone and a medial dolomite unit \\
\hline $\mathrm{pCn}$ & Gneiss & Precambrian & Hornblende gneiss and granite gneiss, possibly part of Pinal Schist \\
\hline
\end{tabular}




\section{GRAVITY SURVEY}

\section{Theory of Gravity Method}

In 1687, Isaac Newton came forth with the Universal Law of Gravitation. Newton's law is a mathematical description of one of the most fundamental phenomena of nature. This law states that each particle of matter in the universe attracts all others with a force directly proportional to its mass and inversely proportional to the square of its distance of separation (Telford, Geldhart, Sheriff and Keys, 1976).

In cartesian coordinates, the mutual force between a particle of mass $m$ centered at point $\mathrm{Q}=\left(\mathrm{x}^{\prime}, \mathrm{y}, \mathrm{z}^{\prime}\right)$ and a particle mass of $m_{o}$ at $P=(\mathrm{x}, \mathrm{y}, \mathrm{z})$ is given by:

$$
\mathrm{F}:=\gamma \cdot \frac{\mathrm{m} \cdot \mathrm{m}_{0}}{\mathrm{r}^{2}}
$$

where

$$
r=\left[\left(x-x^{\prime}\right)^{2}+\left(y-y^{\prime}\right)^{2}+\left(z-z^{\prime}\right)^{2}\right]^{1 / 2},
$$

and where $\gamma$ is Newton's gravitational constant. Allowing the mass $m_{o}$ to be a test particle with unit magnitude, then dividing the force of gravity by $m_{o}$ results in the gravitational attraction produced by mass $m$ at the location of the test particle:

$$
g(P):=-\gamma \cdot \frac{m}{r^{2}} \cdot r
$$

where $\mathrm{r}$ is a unit vector directed from the mass $m$ to the observation point $P$. This value is negative because $\mathbf{r}$ is directed from the source to the observation point, opposite in sense to the gravitational attraction. 
So, the gravitational acceleration $\mathbf{g}$ can be described as the gradient of the scalar potential

$$
\mathbf{g}(P)=\nabla \mathrm{U}(P)
$$

where

$$
\mathrm{U}(\mathrm{P}):=\gamma \cdot \frac{\mathrm{m}}{\mathrm{r}}
$$

The convention used here defines the gravitational potential as the work done on a test particle and is the negative of the particle's potential energy, hence $U(P)$ is positive. Acceleration is seen to be a function only of the mass of the Earth and the distance from the center of it to the gravity station. The unit of gravitational acceleration is called the Gal and is equivalent to $1 \mathrm{~cm} / \mathrm{sec}^{2}$ (Telford et al, 1976)

Gravitational potential obeys the principle of superposition and so the net force on a test particle is the vector sum of the forces due to all of the masses in space. This principle can be applied to the gravitational attraction in the limit of a continuous distribution of matter whose mass can be thought of as an infinite number of very small masses $d m=\rho(x, y, z) d v$, where $\rho(x, y, z)$ is the density distribution. Applying the principle of superposition yields

$$
\mathrm{U}(\mathrm{P})=\int \gamma \cdot \frac{\rho(\mathrm{Q})}{\mathrm{r}} \mathrm{dv}
$$

where integration is over $\mathrm{V}$, the volume occupied by the mass. $P$ is still the point of observation, $\mathrm{Q}$ is the point of integration, and $\mathrm{r}$ is distance separating $P$ and $\mathrm{Q}$. However, only the vertical component of the gravity is measured by the gravimeter in the 


\section{DATA REDUCTION}

It is necessary to correct for all of the factors that are not due to the density contrasts in the subsurface, such that the:

\section{Gravity Anomaly = Observed Gravity - Earth Model Gravity}

The Earth model is a function of several effects such as the latitude correction, the free air correction and finally the Bouger correction. And the observed gravity is a function of the conversion factor for that specific meter, drift correction and tidal correction.

\section{Drift Correction}

A phenomenon known as drift occurs in every gravimeter. Drift is defined as the change in the elasticity of the springs over time and is different for every gravimeter. Correction to the observed gravity readings for instrument drift requires one to occupy a base station several times during the day of the survey. It is important to take readings

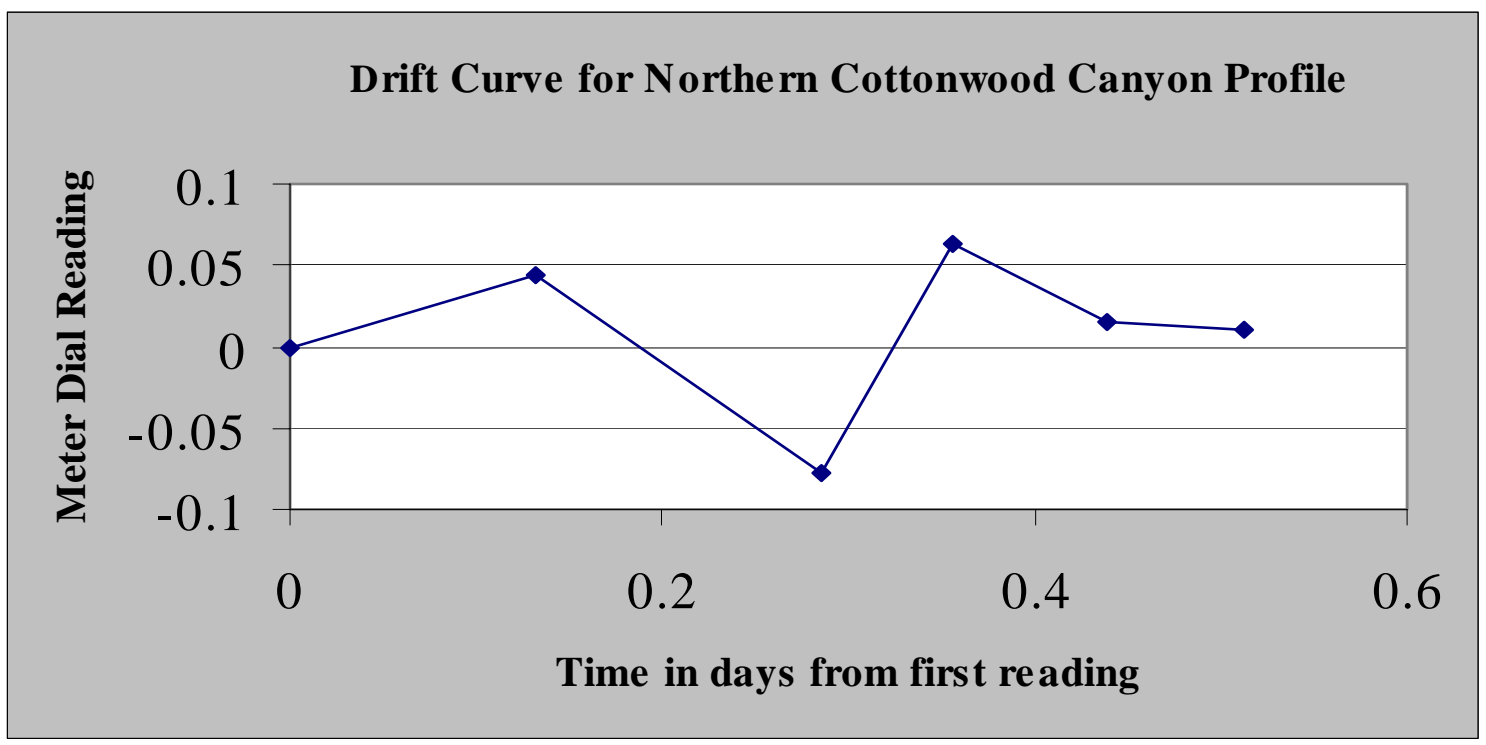

Figure 5. Showing a drift curve for the Northern Cottonwood Canyon profile 
periodically because of the erratic nature of drift. The meter reading is plotted against time and it is assumed that drift is linear between re-occupations. The drift correction is then subtracted for each station. Fig. 5 shows an example of a drift curve used for the Northern Cottonwood Canyon profile.

Observed gravity readings at a fixed location will change with time due to the periodic motion of the sun and the moon. The moon, despite its smaller mass than the sun, has a larger gravitational attraction because of its proximity to earth. The same gravitational attraction which causes tidal effects at sea also cause the solid earth to react in the same way. These solid Earth tides can cause the gravity station to vary in elevation by a few centimeters, thus increasing the distance to the center of the Earth causing a maximum change of 0.3 mGals in a minimum period of 12 hours. In a high precision survey, these tidal variations must be corrected for by reoccupying the base station at an interval less than the period of Earth tides. The tidal effect is then removed during the drift correction, which was discussed earlier.

\section{$\underline{\text { Latitude Correction }}$}

There are two factors that contribute to the latitude correction (1) spinning of the Earth and (2) its slight equatorial bulge. The centripetal acceleration of the Earth's rotation varies with latitude such that it is at a minimum near the poles and a maximum at the equator. Consequently, the negative radial component generated by this rotation decreases the gravity from the poles to the equator. The radius of the Earth measured through the equator is approximately $21 \mathrm{~km}$ larger the radius of the Earth measured through the poles. So, gravity decreases from the poles to the equator because of the 
increase in the distance to the center of the Earth. The international formula for the latitude effect is:

$$
\mathrm{g}=978031.846\left(1+0.005278895 \sin ^{2} \phi+0.000023462 \sin ^{4} \phi\right) \quad \text { mGals }
$$

where $\phi$ is the angle of latitude.

\section{$\underline{\text { Free Air Effect }}$}

The second correction to the Earth model is known as the free air effect, which accounts for the difference in elevation between the gravity station and the surface of the geoid. The free air correction is added to the observed gravity because the observed gravity would be lower at an elevation higher than the geoid surface. There is an approximate change of $-0.094 \mathrm{mGal} / \mathrm{ft}$ due to elevation differences. The formula for the free air correction is (Telford et al, 1976):

$$
\text { FAC }=\left(0.09411549-0.137789 \sin ^{2} \phi\right) h-0.67 \times 10^{-8} h^{2} \quad \text { mGals }
$$

where $\mathrm{h}$ is the elevation of the gravity station.

\section{$\underline{\text { Bouger Correction }}$}

The third correction for gravity to the Earth model, known as the Bouger correction, takes into account the material between the gravity station and the geoid surface. There are three parts to this correction. The first part assumes an infinite horizontal slab of rock of uniform density whose thickness is the elevation difference between the gravity station and the geoid surface. The density is equivalent to the mean density of bedrock found in the region. Generally, for the purpose of comparison to other surveys this density is $2.67 \mathrm{gm} / \mathrm{cm}^{3}$. Observed gravity readings are increased by the rock 
mass between the station and the datum, therefore, the Bouger correction is subtracted when the station is above the geoid surface. The Bouger correction is:

$$
\mathrm{BC}=0.012774 \rho \mathrm{h} \quad \mathrm{mGal}
$$

Where $\rho$ is the density of the slab and $h$ is the thickness of the slab.

The second part of the Bouger correction adjusts the slab to account for the curvature of the Earth's surface. This modification changes the horizontal slab to a slab with a spherical cap with a radius of $167 \mathrm{~km}$. The formula for this correction is:

$$
\begin{aligned}
& C C=4.462 \times 10^{-4} h-3.282 \times 10^{-8} h^{2}+1.27 \times 10^{-15} h^{3} \quad \text { mGal } \\
& 0.3048 \quad(0.3048)^{2} \quad(0.3048)^{3}
\end{aligned}
$$

The concept of a horizontal infinite slab existing between the station and the datum is not really valid due to local variations around the station in topography. Regions that exist above the Bouger slab and therefore not accounted for in the Bouger correction, exert an upward pull at the station thus decreasing the observed gravity reading. It is necessary to add a positive terrain correction to compensate for this upward attraction. Depressional features are accounted for in the Bouger slab, however, they do not contain mass. The Bouger correction therefore overcompensates for these regions and so a positive terrain correction is needed to restore the slab to a flat area. Therefore, for both hills and valleys the terrain correction is added back to the gravity readings.

Once corrections have been made to the observed gravity values, the result would reflect the variations of geology within the Earth model. This is called the Complete Bouger Gravity Anomaly (CBGA) and is represented below:

CBGA $=$ gobserved - glatitude $_{\text { }}$ FAC - BC + TC - CC 
CBGA values are the standard for Earth gravity models and are used for modeling all of the profiles in this survey (Keary et al, 1991). 


\section{GRAVITY DATA ACQUISITION AND PROCESSING}

\section{Gravity Meter and Base Station}

During this gravity survey, measurements were made in the field using a LaCoste and Romberg Model G Land Gravity Meter (Serial No. G-551). The gravity response of this instrument is based on the use of a zero-length spring. This meter measures the vertical change of gravitational force acting up a fixed mass in such a manner that the actual length of the zero-length spring is proportional to the tension acting on it. The LaCoste and Romberg G-meter is designed to measure the changes in the Earth's gravitational field from station to station. This method of relative measurement requires the survey to open and close with a gravity reading at a primary base station where an absolute value has already been established. Later on, the absolute readings for the field stations can be calculated. For this survey, the primary base station is located in the basement of the USGS Southwest Field Office at the University of Arizona and is tied to International Gravity Standardization Network 1971 (IGSN 71). The absolute value has been determined to be 979240.507 milligals (Don Pool, pers. comms., 2000).

\section{Field Procedure}

There are several steps during the gravity surveys to ensure repeatable and consistent readings. The gravimeter is transported from station to station and set upon a base plate where it is then leveled. The clamp, which holds the zero-length spring down during transportation, is then released. The observed gravity values were displayed on a counter wheel with hundredths of units shown and thousandths of units estimated. For consistent readings, the meter dial is rotated so the needle always approaches the null 
reading from the right. If the dial is overturned and the needle passes by the null reading then the process is repeated. Once the needle has settled on the null reading, the meter reading is then recorded in the field book. The G-551 meter's sensitivity is 0.005 scale divisions, which corresponds roughly to $0.005 \mathrm{mGals}$. The operating temperature of the instrument is $53.0^{\circ} \mathrm{C}$ and is powered by a portable battery. The instrument is sensitive to expansion and contraction from exposure to direct sunlight, therefore the time and meter readings are then double-checked before the spring is clamped down. After the survey, the meter dial readings are converted to milligals by a conversion factor specific to the G551 meter.

\section{$\underline{\text { Station Elevation and Location Control }}$}

The horizontal and vertical coordinates for all of the gravity stations were obtained by using a Trimble differential Global Positioning System (GPS) unit. A benchmark described by the United States Coast and Geodetic Survey in 1953 was used as the primary base station to set up secondary base stations in the Rex Ranch, and the Cottonwood Canyon profiles. The benchmark was located in the town of Amado, AZ, along the Southern Pacific Company Railroad, at the water tank, in the top of the concrete foundations east of the track about $2 \mathrm{ft}$ higher than the track. The Permanent Identifier for this station is CG0375. The National Geodetic Survey provided the horizontal coordinates in the North America Datum 1983 (NAD 83), and the vertical coordinates in the North American Vertical Datum 1988 (NAVD 88). The horizontal coordinates were scaled from a topographic map and have an estimated accuracy of $+/-6$ seconds. The NAVD 88 height was computed by applying the VERTCON shift value to 
the NGVD 29 height value taken in 1953. Software from Trimble, GPSurvey Version 2.30a, was used to perform coordinate transformations from NAD 83 to NAD 27, as well as from WGS 84 to NAD 27. All gravity stations were transformed to NAD 27 geographical coordinates, or to NAD 27 UTM (Zone 12 North) coordinates, for reduction, plotting, modeling, and contouring purposes. Information for this benchmark was obtained from the following website:

\section{http://www.ospl.state.nc.us/geodetic/ngsdb.html}

\section{$\underline{\text { Survey Layout }}$}

There were three gravity profiles collected for this survey. The profiles are referred to as the Rex Ranch, Northern Cottonwood Canyon, and Southern Cottonwood Canyon profiles. The northern and southern profiles were collected along the terraces above the canyon floor. Whenever possible, stations were positioned along the available roads except in cases where it was necessary to keep on a straight line. All of the profiles are perpendicular to the strike of the surface fault scarp of interest in this project. The fault scarps for each of the Cottonwood Canyon profiles were not easily distinguishable due to erosion and weathering. Aerial photographs provided by Brenda Houser (Figs. 2 and 3) aided in locating the fault trace. A handheld Magellan 2000 XL GPS unit was employed to help measure the spacing between stations. Generally, there was about 100 $\mathrm{m}$ between stations near the ends of the profiles, then $50 \mathrm{~m}$ spacing for intermediate areas and then $20-25 \mathrm{~m}$ over the fault scarps. 
Fig. 6 shows the plan view of the three gravity profiles. The Rex Ranch profile consisted of 40 gravity stations along an east-west line that extends for nearly $2 \mathrm{~km}$. Most of the stations were collected just north or south of the access roads in the field area. The spacing of the stations ranged from $100 \mathrm{~m}$ near the ends of the profile to $5 \mathrm{~m}$ near the fault scarp. The fault scarp was clearly evident on the surface. The naming convention for this profile was rr-01 through rr-40. This profile was collected over a period of several days.

The Northern Cottonwood Canyon profile consisted of 33 gravity stations primarily along an east-west line that extended for nearly $2.3 \mathrm{~km}$. A dirt road was present for half of the profile, however, only 5 stations were directly on the road. The spacing of stations ranged from $130 \mathrm{~m}$ near the ends of the profile to $20 \mathrm{~m}$ near the fault scarp. The naming convention for this profile was $\mathrm{cw}-01$ at the east end through $\mathrm{cw}-33$ at the west end.

The Southern Cottonwood Canyon profile consisted of 43 gravity stations over $2.7 \mathrm{~km}$. The spacing ranged from $170 \mathrm{~m}$ to $20 \mathrm{~m}$ depending on the proximity to the fault scarp. All of the stations were collected along the road, primarily because of the steep terrain on either side of the access road. The stations were cc-01 through cc-43. For the Southern and Northern Cottonwood Canyon profiles, new gravity stations were added to either extend the profile or to obtain higher detailed gravity information around the fault location. Information about all of the gravity stations is provided in the appendices. 


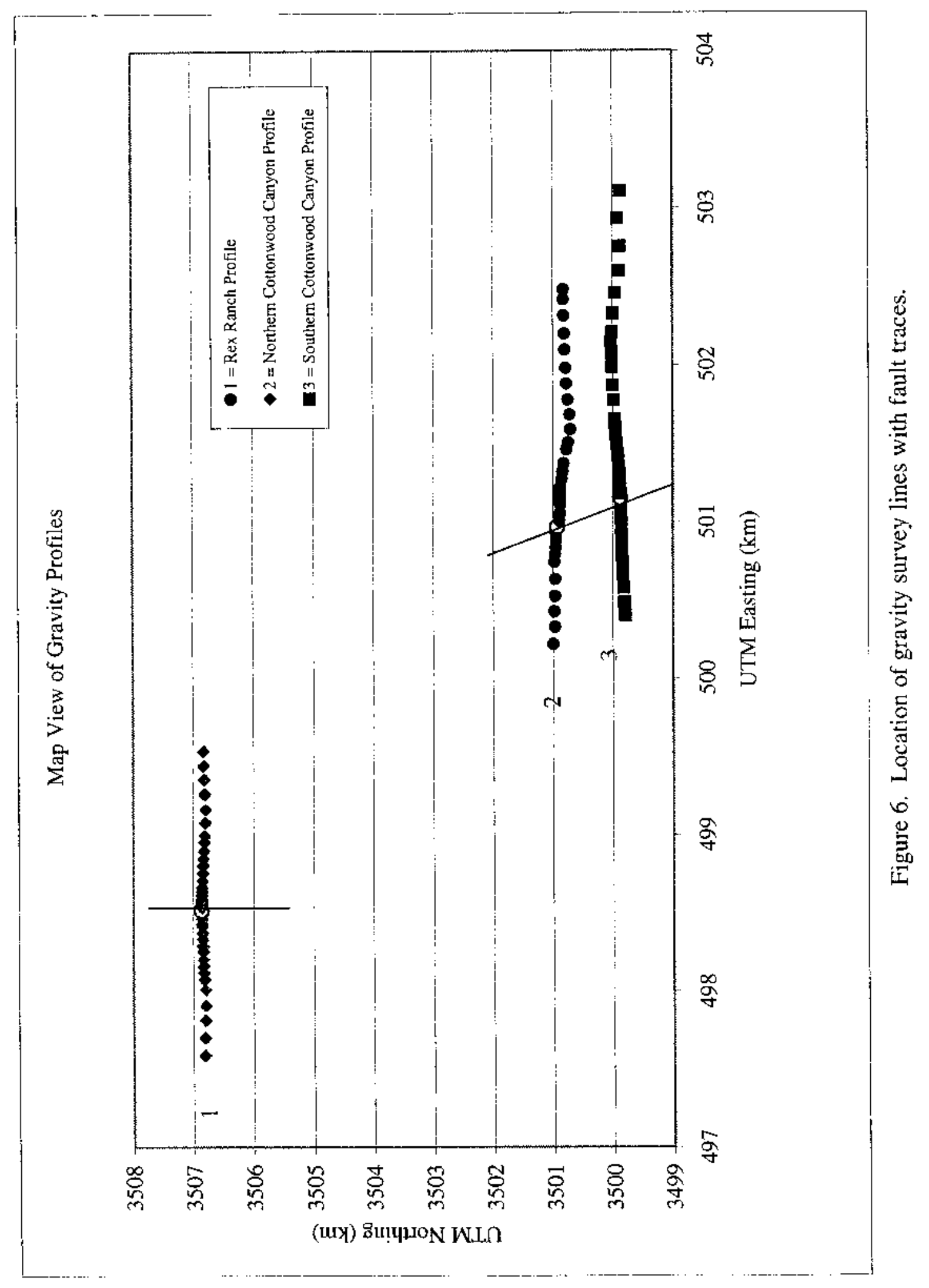




\section{$\underline{\text { Reduction Programs }}$}

Once the field data were collected they were entered into several gravity reduction programs provided by the USGS. The first program, grvrdn, was written by M. E. Gettings. The input to this program consists of the station id, the latitude and longitude, the elevation, the time and date, the designation of the station being a base station or just a gravity station, and the meter reading. The program converts the meter reading into observed gravity by taking into account the drift correction, the Earth tide correction, and the specific calibration factor for the G-551 meter. The first run of this program establishes the absolute value of gravity for the stations, if the station was used as a reoccupation then the all of the absolute values are averaged for that station. That average value is entered into a file where base station information is stored and referred to by grvrdn. The designation of that secondary base station is changed in the input file to denote that it is now a base station. The program is re-run and the drift correction was then applied. During this survey, the NGS established the absolute value for the primary base station located in the basement of the USGS Southwest Field Office building to be 979240.507 mGals. Because of timing issues, however, the absolute value for the base station located in the basement of the Gould-Simpson Building at the University of Arizona was used for reduction purposes. Upon access of the absolute value for the true base station the gravity data were adjusted by the appropriate factor. This pseudo-base station, called tucgs87, had an absolute value of 979241.136 mGals.

During the survey, at each station, the local variations in topography where noted and sketched in the field book. Slope angles were measured with an Abney level, 
elevation of hills and valleys were estimated, or in some cases measured. Anything of significant mass excess or deficiency within $68 \mathrm{~m}$ of the station was noted. This information was used in programs such as hhslope, bhslope and sect written by P.E. Gettings, to calculate the inner zone terrain correction which corresponds to the HayfordBowie AB correction (Robbins and Oliver, 1970). These corrections were entered into the observed gravity file and then it was run through terrain_correct to compute the total terrain correction to a radius of $167 \mathrm{~km}$ from the gravity station. This program references a digitized elevation database to compute the terrain correction to $167 \mathrm{~km}$ and then adds the innerzone correction. The output of terrain_correct is used in the program called pfact, which computes the free-air anomaly, the simple and complete Bouger anomalies using the reduction density of $2.67 \mathrm{gm} / \mathrm{cm}^{3}$ and other densities. The following graphs show the CBGA values plotted against the projected downline distances. The fault scarp location is also plotted on each profile. 


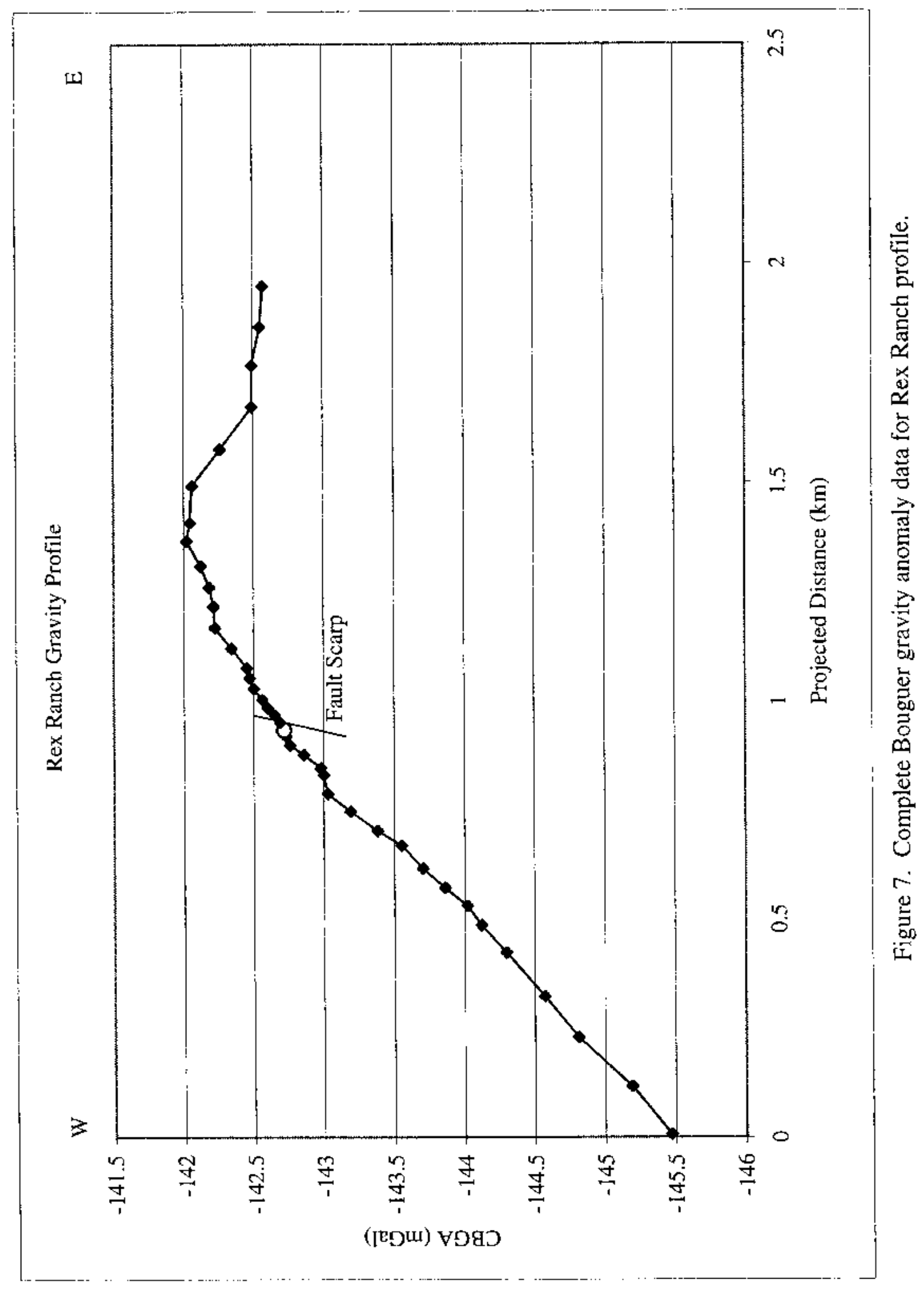




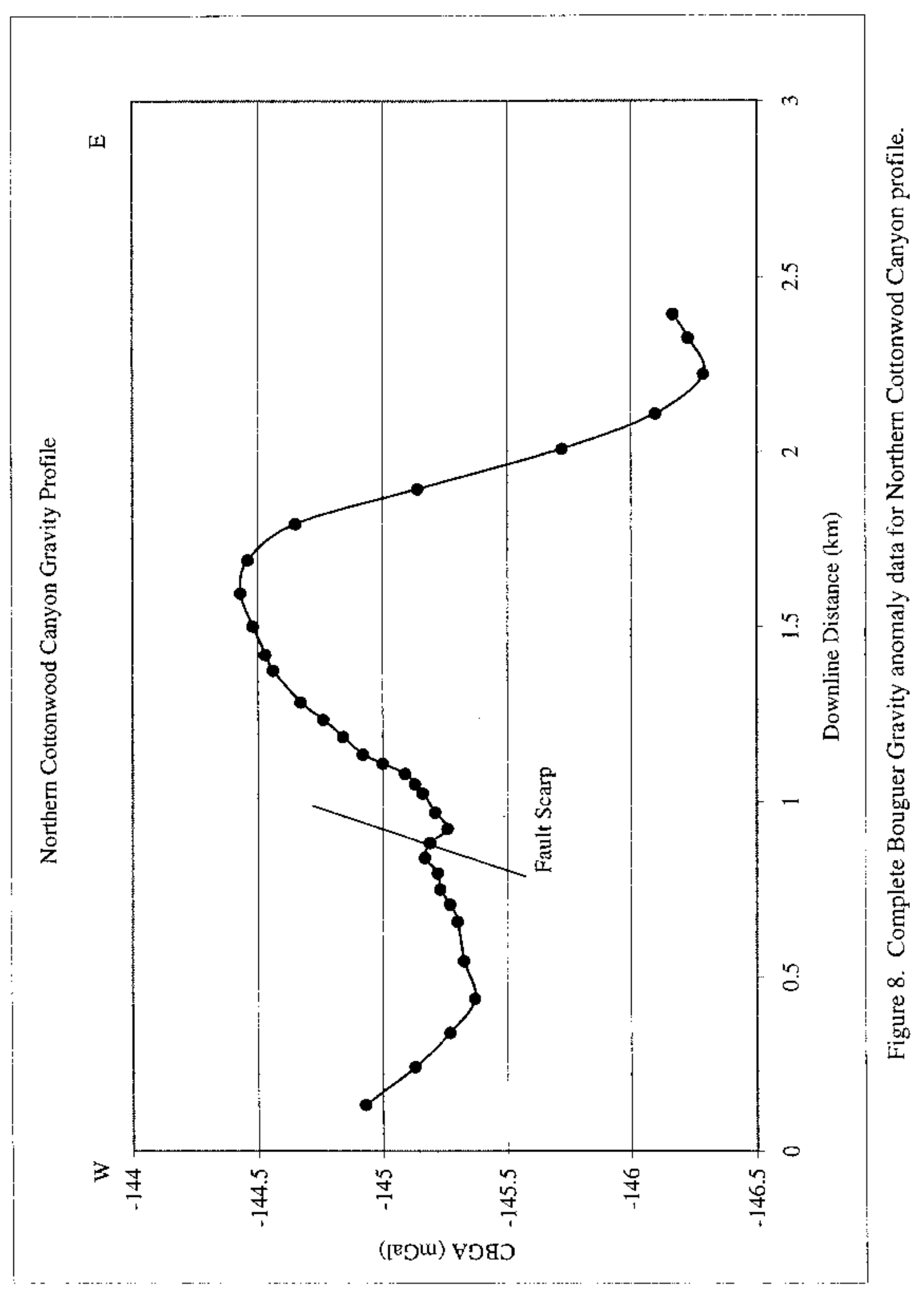




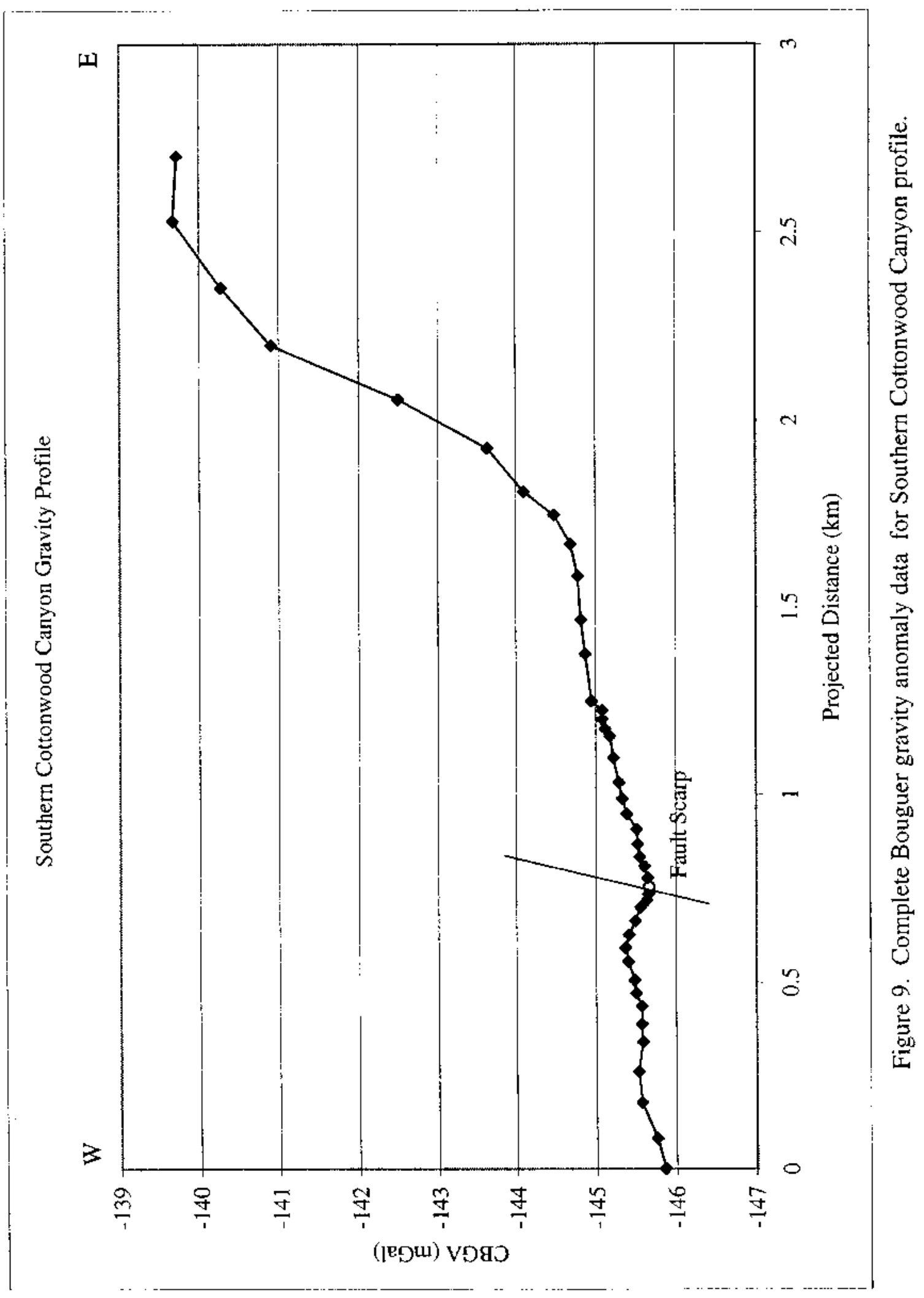




\section{MAGNETIC SURVEYS \\ THEORY OF MAGNETIC METHOD}

The discussion of gravitational potential began by examining the mutual attraction between two point masses. The case for magnetism is similar in that we now consider the mutual attraction of two small loops of electric currents instead of two point masses. Magnetic dipoles can also interact with one another at distance, by means of their magnetic fields. The force between two magnetic poles of strength $m_{1}$ and $m_{2}$ separated by a distance $r$ is given by

$$
F=\frac{\mu_{0} m_{1} m_{2}}{4 \pi \mu_{R} r^{2}}
$$

where $\mu_{\mathrm{o}}$ and $\mu_{\mathrm{R}}$ are constants corresponding to the magnetic permeability of vacuum and the magnetic permeability of the medium separating the poles, respectively. The force is attractive if the poles are of opposite sign and repulsive if they are of like sign. The magnetic field strength, $H$, is a more practical form of $F$, is defined as the magnetic force on a unit pole.

$$
H=\frac{F}{m}
$$

where m' is essentially the instrument used in measurement (Telford et al, 1976). The magnetic field $B$ due to a pole of strength $m$ at a distance $r$ from the pole is defined as the force exerted on a unit positive pole at that point

$$
B=\frac{\mu_{o} m}{4 \pi \mu_{R} r^{2}}
$$


However, magnetic poles always exist as pairs in nature and are called dipoles. The magnetic moment is defined as $M$ :

$$
M=m l
$$

with $m$ being the strength of the poles and $l$ the distance separating them. As opposed to the gravitational field, the magnetic field varies both in magnitude and direction. Also, the magnetic field has a large alternating component that depends on time, whereas, the gravitational field predictably varies with time. The Earth acts like a great spherical magnet, in that it is surrounded by a magnetic field. The Earth's magnetic field resembles, in general, the field generated by a dipole magnet (i.e., a straight magnet with a north and south pole) located at the center of the Earth. The axis of the dipole is offset from the axis of the Earth's rotation by approximately 11.5 degrees. This means that the north and south geographic poles and the north and south magnetic poles are not located in the same place. At any point, the Earth's magnetic field is characterized by a direction and intensity, which can be measured. Often the parameters measured are the magnetic declination, D, the horizontal intensity, H, and the vertical intensity, Z. From these elements, all other parameters of the magnetic field can be calculated. These components may be measured in units of Oersted ( 1 oersted=1 gauss) but are generally reported in nanoTesla $(1 \mathrm{nT} * 100,000=1$ 0ersted $)$. The Earth's magnetic field intensity is roughly between 25,000 - 65,000 nT (.25 - .65 oersted) (Kearey and Brooks, 1991). All magnetic anomalies are superimposed on the Earth's magnetic field. This is similar to gravity anomalies, however, the magnetic field changes with both the magnitude and direction. Unlike the Earth's gravitational field, the Earth's magnetic field is constantly changing 
and is impossible to accurately predict what the field will be at any point in the very distant future (Kearey et al, 1991).

When a material is set in an external magnetic field it can acquire a magnetization in the direction of the field and is lost when the substance is removed from the field. This is referred to as induced magnetization and is caused by the alignment of dipoles within the material in the direction of the field. The intensity of induced magnetization, $J_{i}$, is defined as

$$
J_{i}=\frac{M}{L A}
$$

where $M$ is the magnetic moment, $L$ is the length of the sample and $A$ is the crosssectional area.

The degree to which a material is magnetized is determined by its magnetic susceptibility. The susceptibility, $k$, of a substance is defined as the ratio of intensity of magnetization to the magnetizing field and is with respect to unit volume:

$$
k=\frac{J_{i}}{H}
$$

Magnetic susceptibility is the most important variable measured in magnetics, and serves the same purposes as density in gravity interpretation. Susceptibility is dimensionless, however in the SI system it is greater by a factor of $4 \pi$ than the c.g.s system. Anomalies in the presence of the Earth's field are entirely caused by the presence of magnetic minerals in the underlying rocks. The magnetic susceptibility of most rocks is proportional primarily to the magnetite content, and to a lesser degree minerals such as ilmenite or pyrrhotite. Magnetite is generally an accessory mineral and can comprise up 
to $10 \%$ of the rock therefore, because of this variability in magnetite content a direct correlation between lithology and susceptibility is difficult. However, it has been shown that sedimentary rocks have the lowest average susceptibility and basic igneous rocks having the highest average (Telford, et al 1976).

The magnetic field $B$, is generated by two different sources. Conduction currents deep from within the Earth's core form the primary source, and the presence of ferromagnetic materials in basement rocks, intrusive rocks, or magnetic ore bodies form the secondary source. Methods based on measuring the secondary source help to understand subsurface geology in this project. The total magnetization of rocks is the vector sum of two fields:

$$
J=J_{i}+J_{r}
$$

where $J_{i}$, the induced magnetization is dependent on an external field, and, $J_{r}$, remanent magnetization, which is present even in the absence of an external field. On an atomic level all substances are magnetic (Heiland, 1968). Each atom acts as a dipole and for different substances the arrangement of these dipoles defines its magnetic behavior. All materials can be classified in one of three groups based on their magnetic properties: diamagnetic, paramagnetic, and ferromagnetic. The ferromagnetic group is subdivided into two divisions: ferrimagnetic and antiferrimagnetic. The coupling of dipoles within ferrimagnetic substances such as magnetite are aligned antiparallel to each other, however, the number of dipoles in each direction is different. As a result, these materials produce a very strong magnetization and a high susceptibility. The strength of magnetization decreases with temperature until the Curie temperature at which point the 
magnetization disappears. Minerals such as magnetite, titanomagnetite, ilmenite, iron, and oxides of iron, titanium, and pyrrhotite are examples of ferromagnetic minerals (Telford, 1976).

Remanent magnetization is a permanent magnetization that was acquired when the rock formed. For the case of igneous rocks, some of the dipoles within the magnetic minerals aligned with the existent Earth's magnetic field when solidified through the Curie temperature. If the field is strong enough then the dipoles would permanently orient themselves across imperfections within the grains of the mineral setting up a permanent magnetization that exists separately from an external field. Any rock containing magnetic minerals may have both remanent and induced magnetizations. The amplitude of magnetic anomalies is based on the magnitude of the $J$ and the shape of the anomaly is affected by the direction of the $J$ vector (Telford et al, 1976). 


\section{MAGNETIC DATA ACQUISITION AND PROCESSING}

\section{$\underline{\text { Instrument and Procedure }}$}

All magnetic data were collected with a truck-mounted magnetometer with the assistance of Mark Bultman of the USGS. Total intensity Earth's magnetic field data was acquired by a Geometrics G-823A cesium-vapor magnetometer. The instrument sample rate is 10 readings per second. The unit operates over a magnetic field range of 20,000 to 90,000 nT. The sensor is compensated to provide a flat response over the center most angular orientation of less than $0.5 \mathrm{nT}$. The magnetometer is mounted on a fiberglass boom suspended 3.1 meters behind the rear bumper of a 4 wheel drive utility vehicle and 3.6 meters above the ground (when the vehicle is level). The utility vehicle contains a computer to record the output from the frequency counter and to simultaneously record Y-code GPS data. The latitude, longitude, and elevations were collected in the truck during the survey. Heading correction is done in the data reduction software.

\section{$\underline{\text { Survey Layout }}$}

Truck-mounted magnetic data were collected along the same roads used for gravity acquisition. The Rex Ranch and Northern Cottonwood Canyon profiles are identical to their corresponding gravity profiles. However, because the road ended the Southern Cottonwood Canyon magnetic profile is approximately half the length of its corresponding gravity profile. See Fig. 10 for the survey layout. Aeromagnetic data were also used to supplement this project and the map view of the profiles is shown in Fig. 11. 


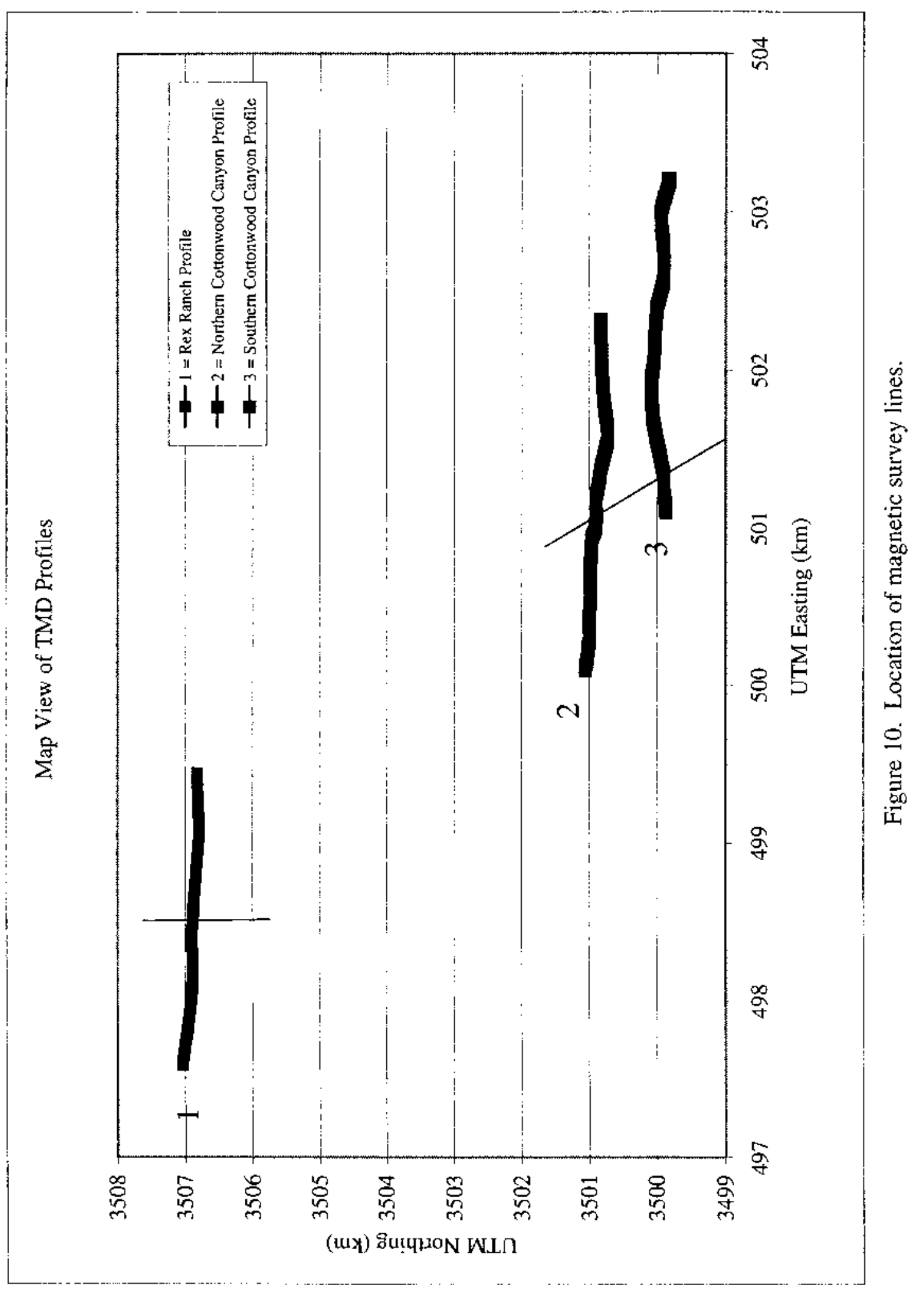




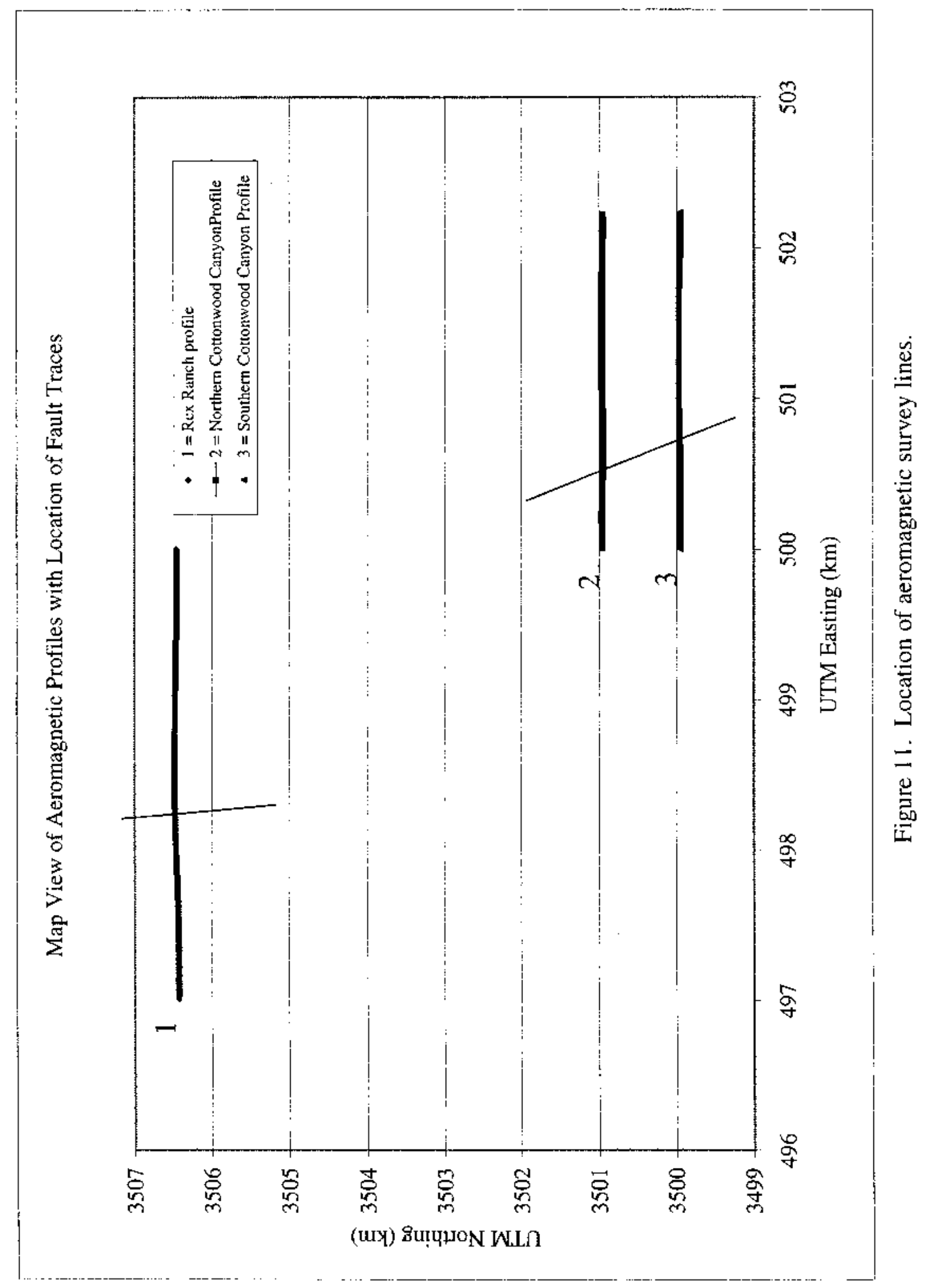




\section{DATA REDUCTION}

The magnetic data were reduced using programs provided by the USGS. The reduction process is much more simple than reduction of gravity data. Generally, a diurnal variation correction is applied to the data. However, it was deemed unnecessary to correct for the diurnal variation because of the short duration of time it took for data acquisition. The average time for the truck to acquire data for the three profiles was less than 10 minutes. Therefore, this eliminated the need for a base station. Later, the oneminute archives were checked from the National Geophysical Data Center to verify that no magnetic storms were present during the survey.

The International Geomagnetic Reference Field, IGRF, defines the theoretical undisturbed magnetic field at any point along the Earth's surface. The IGRF was removed from the magnetic data so that variations from this theoretical field were eliminated. Finally, a heading correction was applied to the data because of the strong magnetic effect of the truck. The corrected and reduced magnetic profiles are shown in Figs. 12, 13, and 14. Also, previously acquired aeromagnetic data are shown in Figs. 15, 16 and 17. A moving average of the data was added to the profiles to smooth out the highly fluctuating nature of the magnetic survey. The surface fault scarps were also noted in the plots, as well as any cultural artifacts such as cattleguards or gates. 


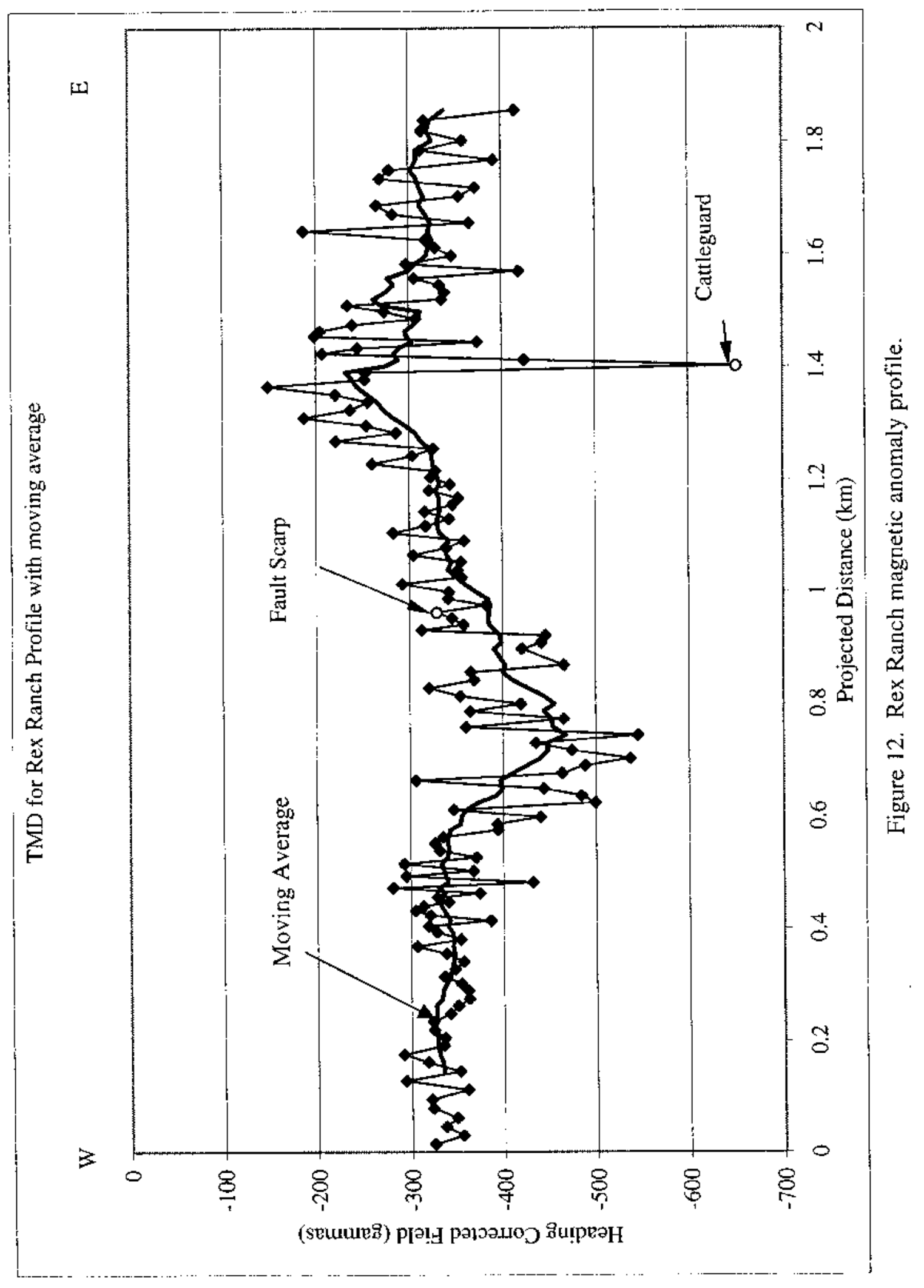




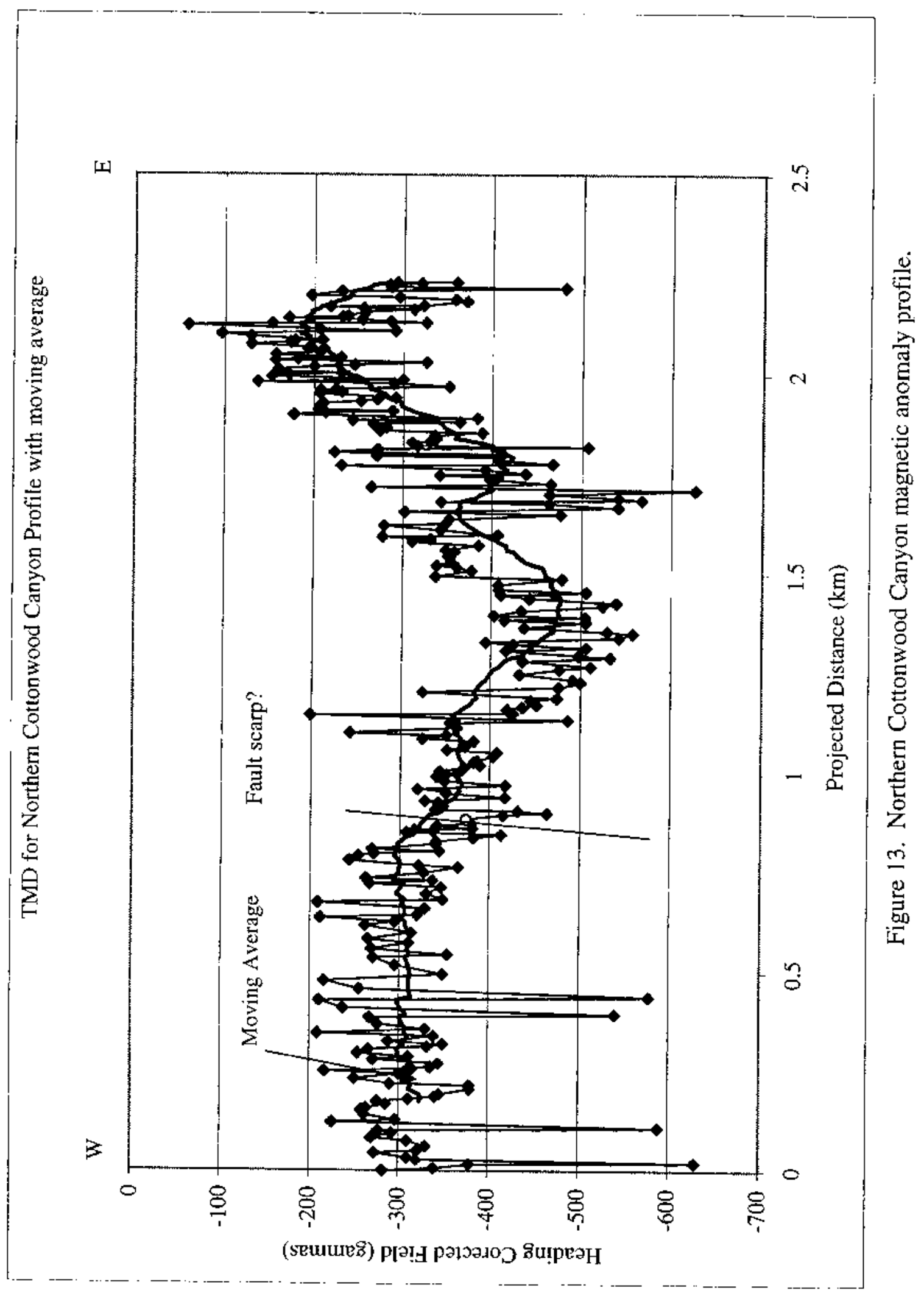




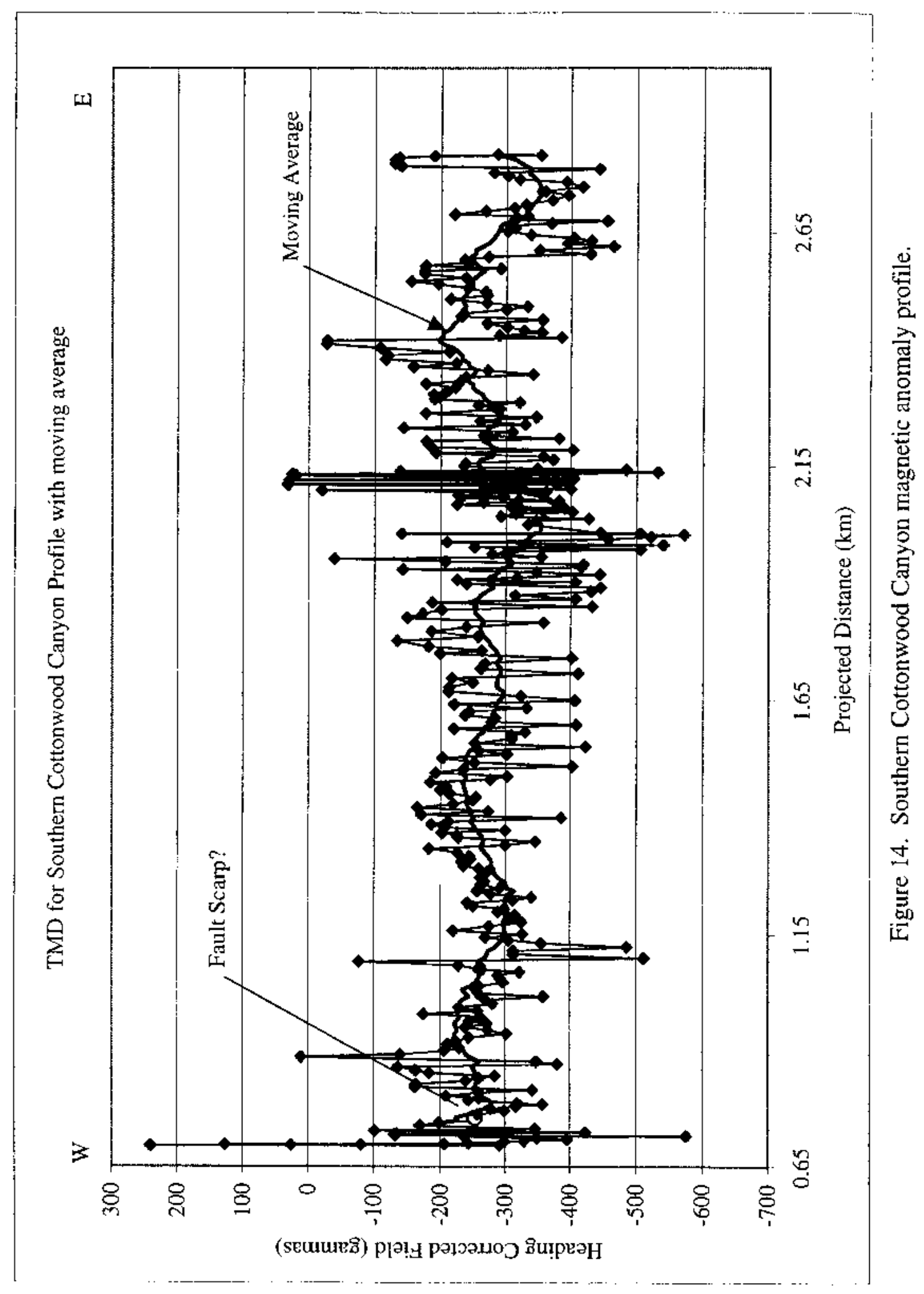




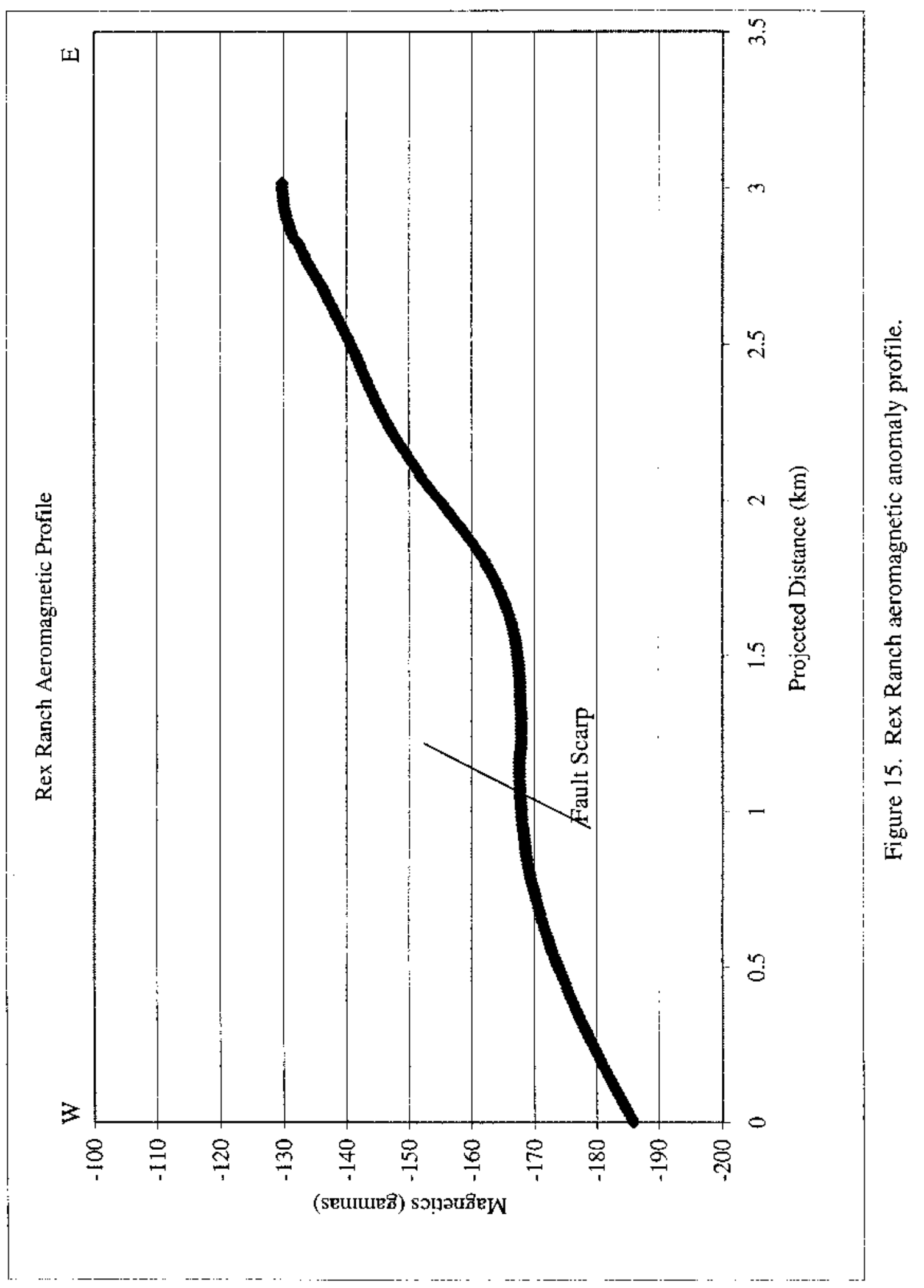


51

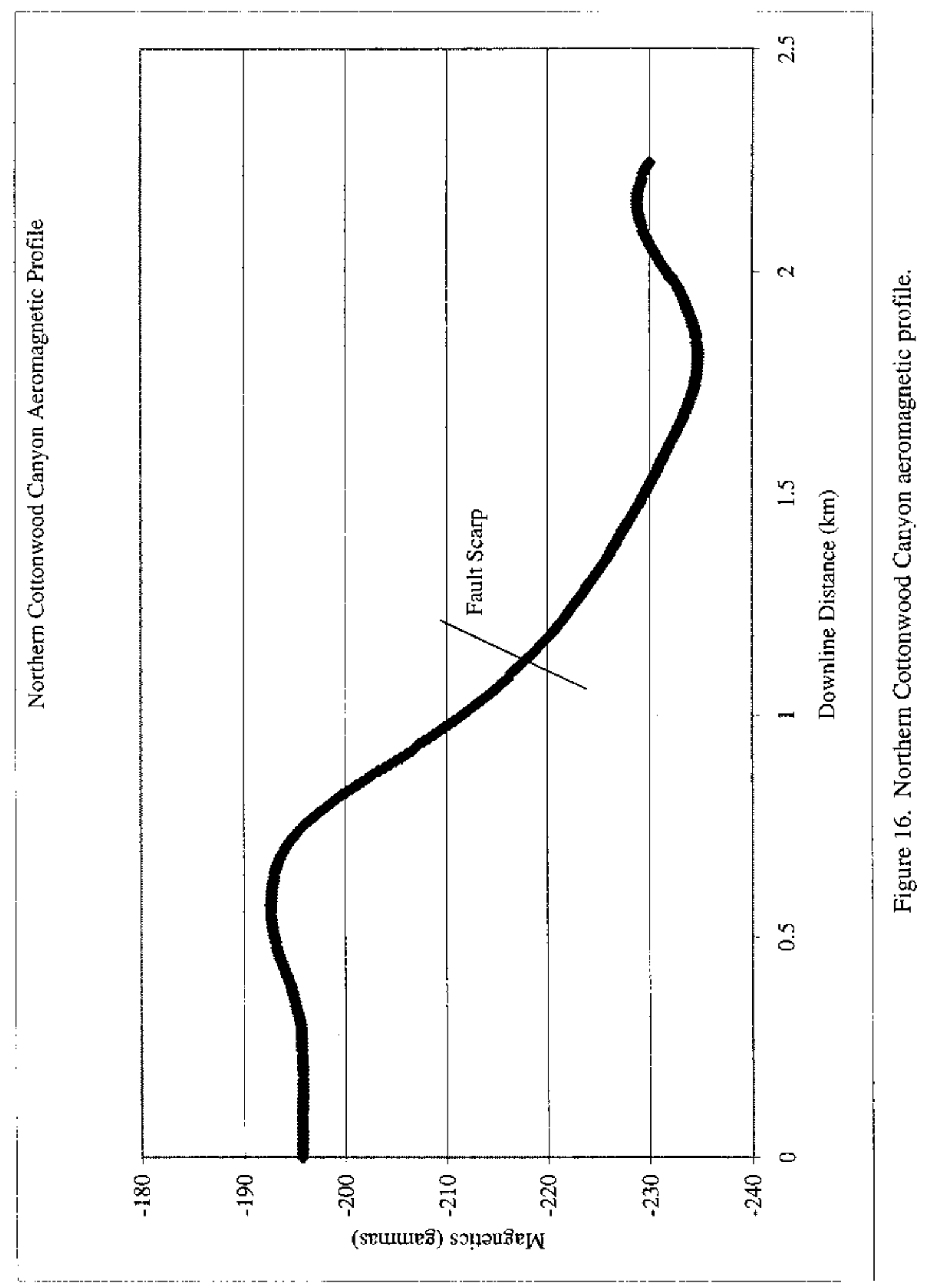




$$
11
$$




\section{MODELING AND INTERPRETATION}

\section{$\underline{\text { Software }}$}

A software program called GM-SYS was used for the majority of the modeling in this project. GM-SYS uses a Marqardt inversion algorithm (Marquardt, 1963) to linearize and invert the calculations. This program executes this algorithm for gravity and magnetics developed by the USGS and is used in their modeling program, SAKI (Webring, 1985). GM-SYS implements a two-dimensional, flat-earth model for the calculations. This means each structural unit extends infinitely in a direction perpendicular to the profile. The model also extends to $30,000 \mathrm{~km}$ along the $\mathrm{x}-\mathrm{x}$ axis, so as to avoid edge effects. Forward modeling is the creation of a geologic model and the subsequent calculation of the magnetic and gravity response to that earth model. The difference between the observed data and the calculated data is minimized by reshaping the model, or by altering the physical properties of the structural units contained within, i.e. density and susceptibility. Inversion algorithms within GM-SYS compute an earth model based on the observed field data and a user-specified starting model. The inversion is used to optimize the earth model, therefore, a poorly-formed starting model will result in unreasonable results. Gravity and magnetic models are inherently nonunique, so several models may fit the data equally well. Measured physical properties such as rock density and rock susceptibility can constrain the models to geologically reasonable ones. The most geologically reasonable model that fit the data was chosen. Initial estimates for rock properties were obtained from textbooks (Carmichael, 1982 and 
Clark, 1966), from physical measurement of rock properties (Gettings and Houser, 1997). Rock lithologies were based on geologic mapping by Drewes (1971a). $\underline{\text { Projection to a straight line }}$

GM-SYS requires the data to be in a straight-line profile. However, due to the nature of fieldwork the data is not often collected in a perfectly straight line, therefore it must be projected onto one. A program provided by M.E. Gettings (pers. comm., 2000) projects the coordinates of the station onto a line that is perpendicular to the azimuth of the fault scarp. The azimuth of the fault scarp was measured as positive degrees clockwise off true north from field maps. The Rex Ranch fault strikes zero degrees, the Northern Cottonwood Canyon fault strikes 355 degrees, and the Southern Cottonwood Canyon fault strikes 347 degrees. The projected distances in all figures and models were measured eastward from the farthest westward station. In all of the profiles the view is north and the cross-section is west to east. The same origin was used for the ground magnetic, aeromagnetic and gravity data in each profile so that simultaneous modeling could be performed. The visual representation of the truck-mounted magnetic data within the software was improved by replacing them with a moving average of the data Figs. (12-14). The convention for the CBGA values used in modeling is oriented so that the positive axis represents and higher density values. For each theoretical model the gravity response, magnetic response, and the aeromagnetic response were interpreted to test the validity of the earth model. Figs. 18 and 19 represent the plan view of the profiles in their original locations, and then their projected locations. The fault traces are shown perpendicular to the projected profiles. 


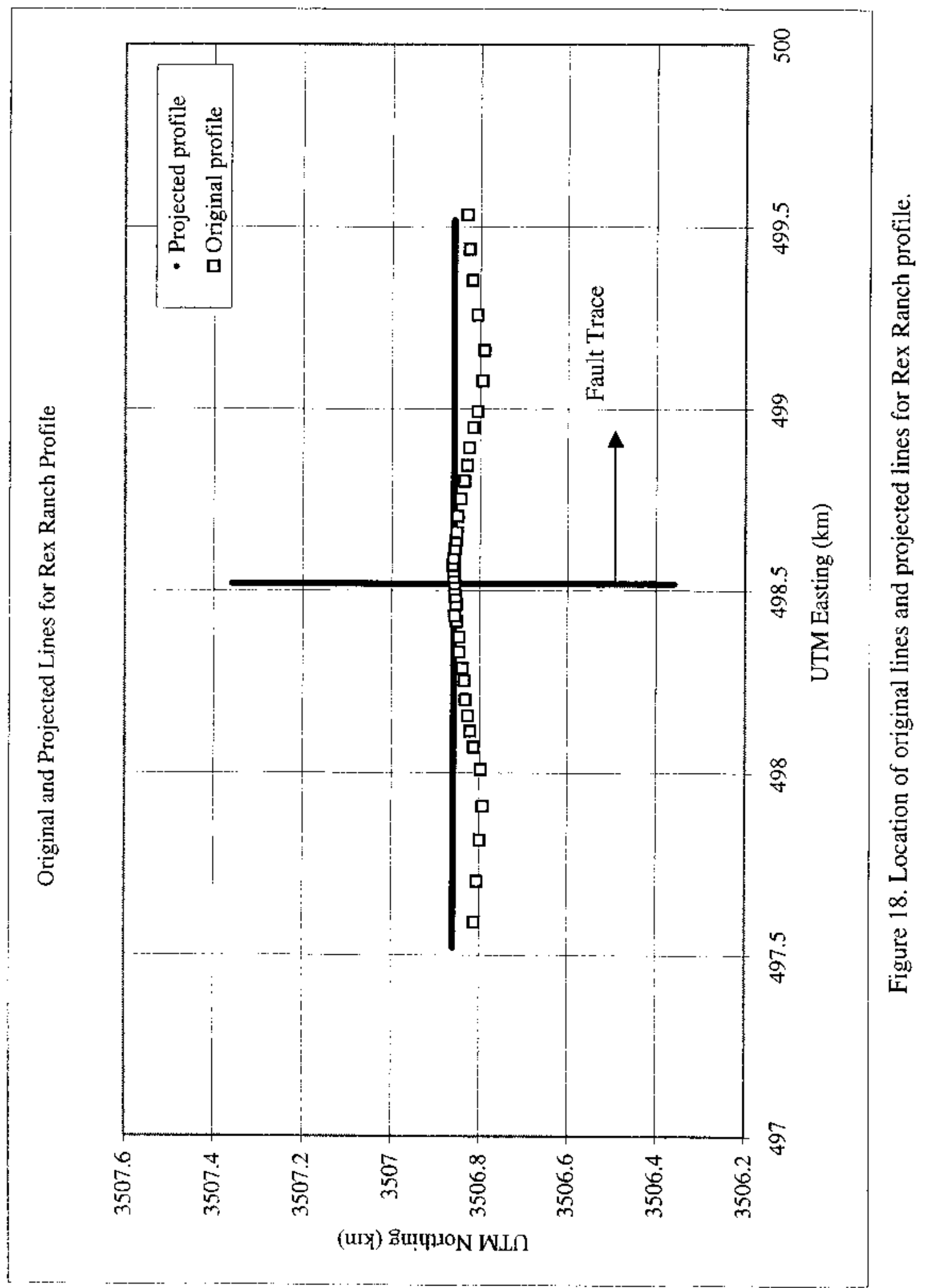




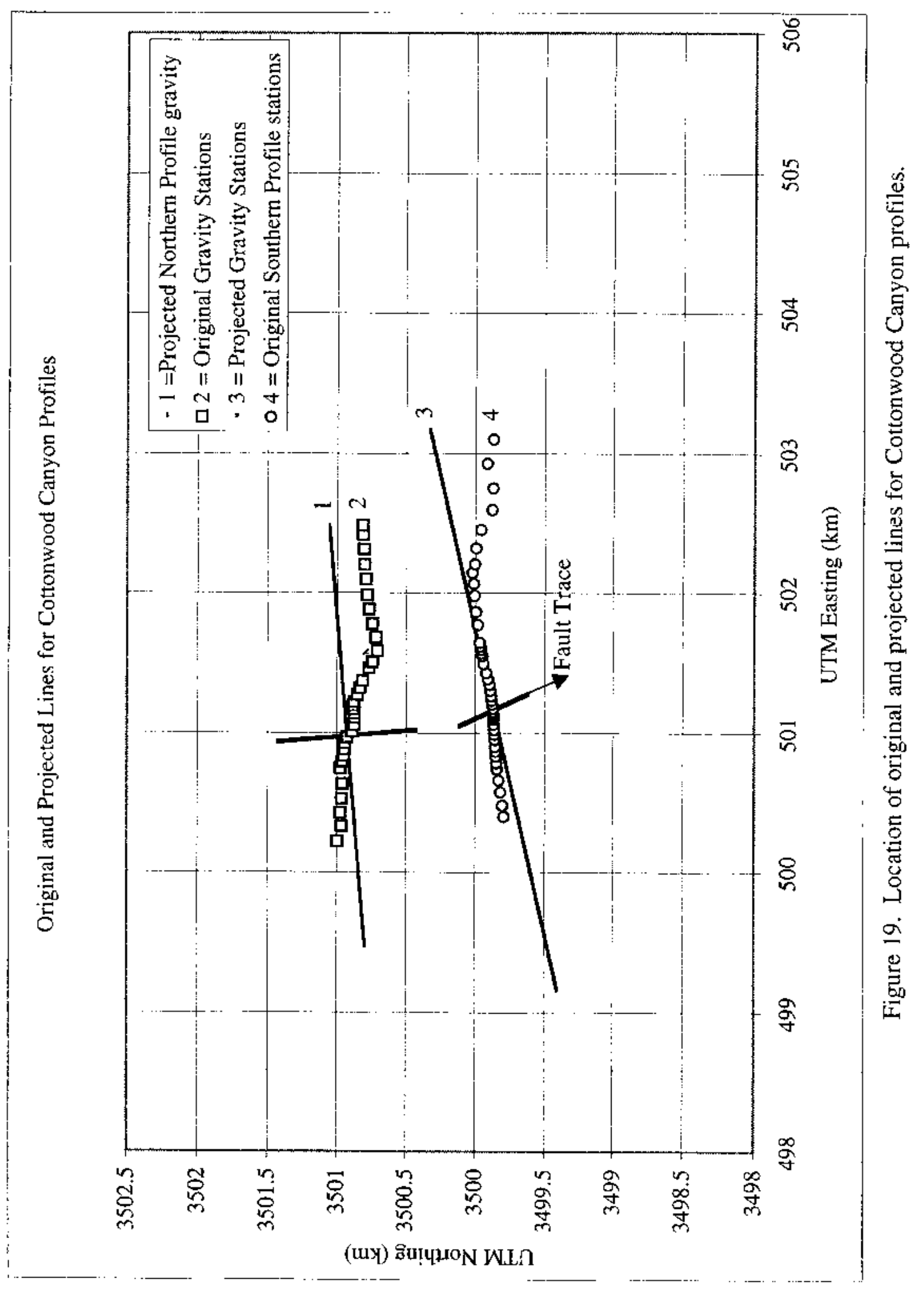




\section{REX RANCH PROFILE}

The Rex Ranch fault scarp is observed (see Fig. 2) in aerial photographs to extend for over $3 \mathrm{~km}$ along the western flank of the Santa Rita Mountains. It shows up on the northern side of Montosa Canyon and continues down to the southern side of Sheehy Canyon. The fault scarp has been eroded away down in the canyons, but, it is still well exposed in the higher terraces. The fault scarp cuts Holocene gravel deposits mapped by Drewes (1971a), which consist mainly of alluvium carried by streams from the neighboring mountains to the west, as well as some colluvium and talus. Unlike the other profiles, the fault scarp is still preserved where the profile crosses over it. It dips 6 degrees to the west with nearly $3 \mathrm{~m}$ of relief between the upthrown and downthrown side of the fault. There is no well $\log$ information available in this area to help constrain lithology and their respective geophysical properties. Bulk density measurements were made for a locality near the profile in upper basin fill, and the observed value was 1.87 g/cc (Gettings and Houser, 1997). The upper basin fill unit is thought to be Miocene to lower Pleistocene in age and is unconsolidated to poorly consolidated (Gettings and Houser, 1997).

The modeled profiles of Rex Ranch are presented in Fig. 22, 23, and 24. The rock descriptions for all units are presented in Table 2 . The gravity data were modeled first because of the available measured constraints on the density of the upper basin fill. The Continental Granodiorite was used as the basement rock with a density of $2.67 \mathrm{~g} / \mathrm{cc}$. Although this unit was used as the primary source of basement rock it is very likely that other stocks have intruded the granodiorite throughout time. These intrusions were 
assumed to have the same density ( $\rho=2.67 \mathrm{~g} / \mathrm{cc}$ ), as the Continental Granodiorite, therefore, subsequent magnetic modeling will require the addition of intrusive bodies with different susceptibilities to the earth model.

The gravity anomaly gradient steepens to the west towards the center of the Santa Cruz Basin (Fig. 23). Initial gravity modeling of depth to bedrock show a basinward thickening of sediments. Although, the gravity anomaly gradient does not flatten out in this profile there is at least $3.5 \mathrm{mGal}$ of relief in the gravity anomaly profile. An infinite horizontal slab model shows that a body with a density of $2.67 \mathrm{~g} / \mathrm{cc}$ and a thickness of 30 $\mathrm{m}$ would have a gravity effect of $3.5 \mathrm{mGal}$. The thickness of this theoretical infinite horizontal slab model approximates the offset in bedrock at depth. The earth model used has $100 \mathrm{~m}$ of relief in the bedrock so this value is acceptable because the infinite horizontal slab model represents the minimum thickness required to produce the same gravity effect.

There are several other minor gradients in the gravity data, which may correspond to smaller faults within the bedrock. Some of these faults have propagated to the surface, while others have not, resulting in only the folding of sedimentary layer above the faults. In the case where faults have propagated to the surface they have become exposed to erosion and may have disappeared. The prominent fault trace that is present today most likely represents a younger fault with enough movement at depth to have caused surface rupture. The fault trace is located $0.93 \mathrm{~km}$ along the $\mathrm{x}$-axis on Fig. 23 and 24 . The top of the headwall of the fault at depth believed to be causing the surface fault scarp is at $0.84 \mathrm{~km}$ along the $\mathrm{x}$-axis and dips about 40 degrees to the west with about $30 \mathrm{~m}$ of relief 
(Figs. 22 and 23). The relationship between the fault at the surface with the fault at depth is bounded by two limiting cases, which depend on the brittle/ductile nature of basin-fill sediments. Figure 20 illustrates the two cases. The movement along the bedrock fault

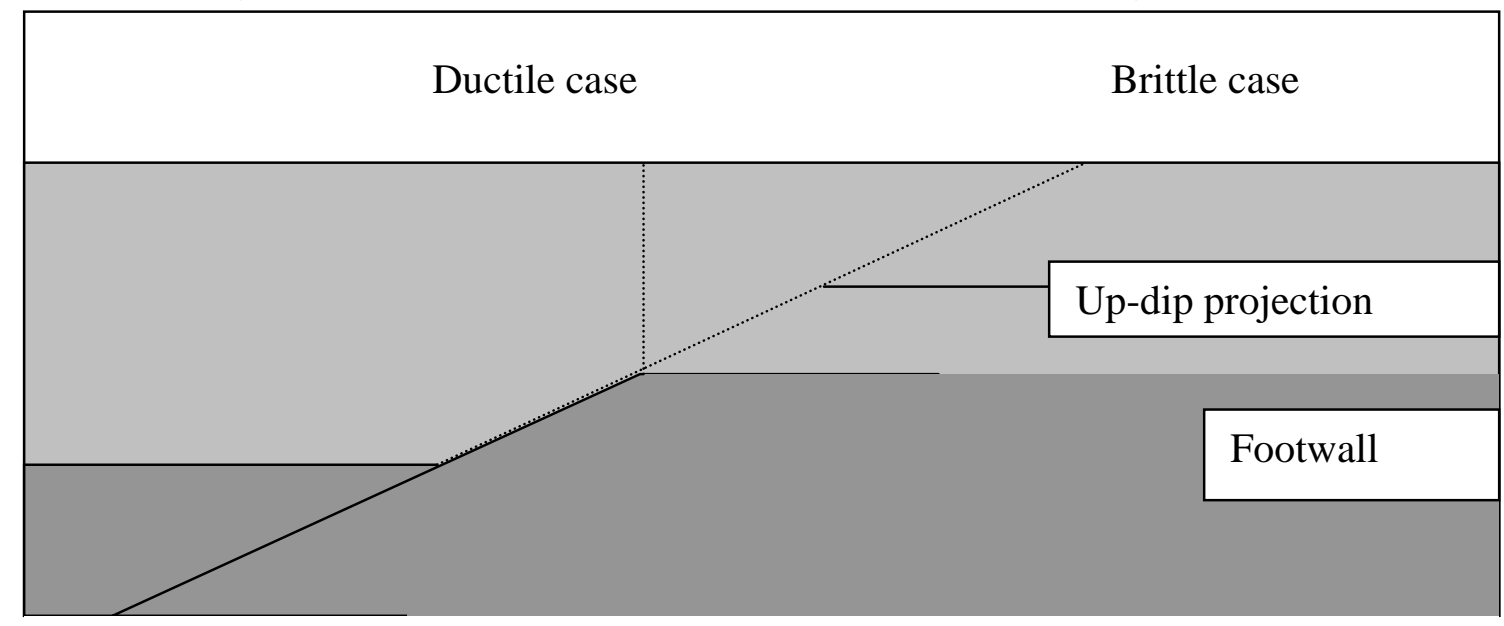

Figure 20. Model of fault propagation through ductile and sediments.

could propagate in such a manner as to cause the surface fault scarps to be directly above the top of the footwall. This case would most likely occur in unconsolidated, hence, ductile sediments. The other limiting case is that the movement of the bedrock fault through the sediments would project along the up-dip angle through to the surface. This case would represent movement through brittle sediments. The most likely scenario would be for the surface fault scarp to be within this range and depends on factors such as the amount of cementation of sediments, the amount of compaction and the presence of a heat source possibly from an intrusion. For the Rex Ranch profile, the up-dip projection is located at $0.95 \mathrm{~km}$ and the top of the footwall is located at $0.84 \mathrm{~km}$ (Figs. 22 and 23). The fault scarp being at $0.93 \mathrm{~km}$ lies closer to the case of up-dip movement. In Fig. 21, the location of the surface rupture is indicated by the bold arrow and the up-dip projection of the fault at depth is represented by the dotted line. 


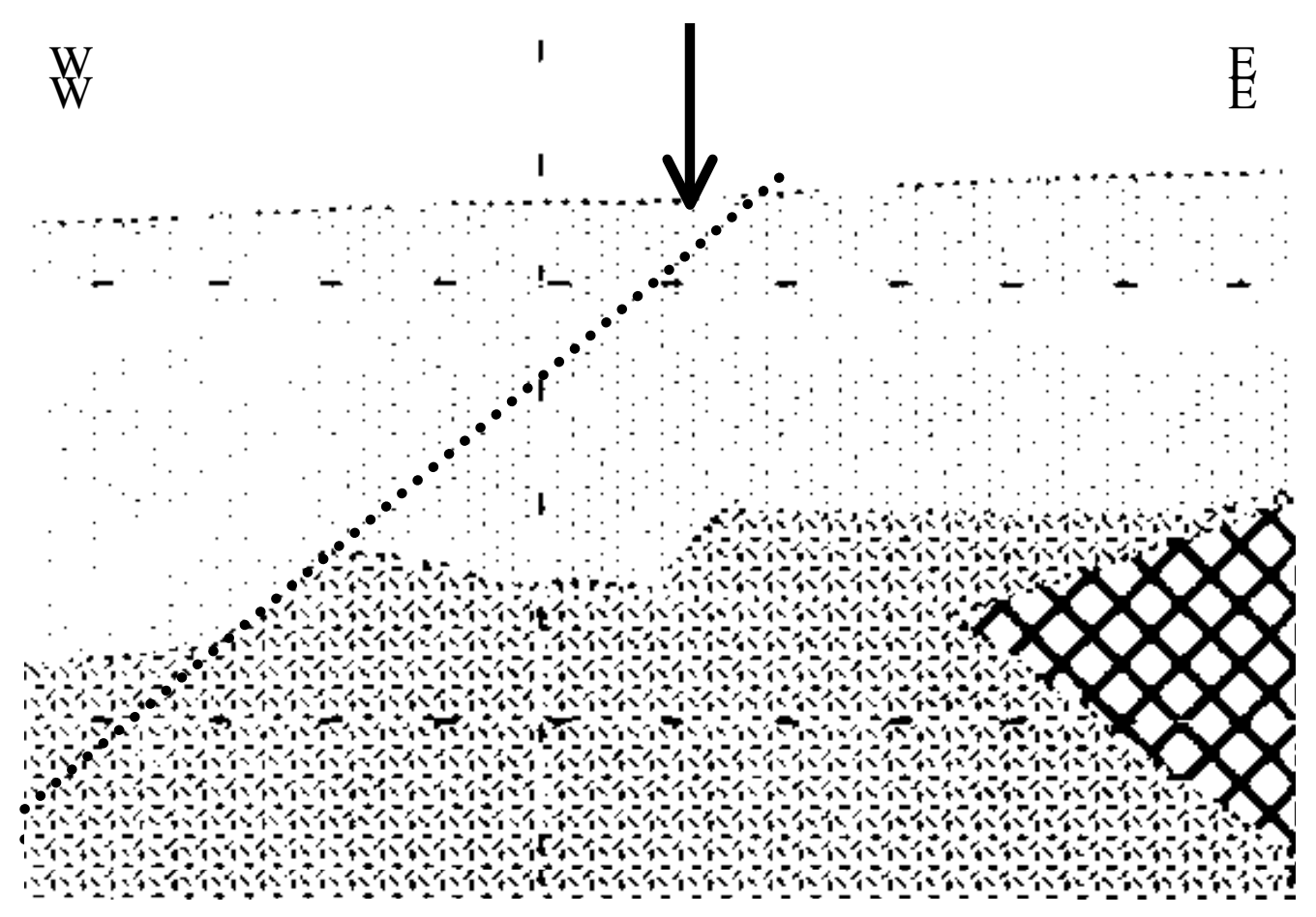

Figure 21. Magnification of Rex Ranch model.

As seen in the model for the Rex Ranch profile (Figs. 21, 22 and 23) there are several step faults within the vicinity of the fault chosen to cause the surface fault scarp. It is possible that one of these faults is responsible for movement on the surface. Since the existence of only one prominent fault on the surface is present however, it is probably caused by the most recent fault. Older faults at the surface may have existed at some point but have since had their escarpments eroded away. If the sequence of faulting between the range of $0.7 \mathrm{~km}$ and $1.4 \mathrm{~km}$ on the $\mathrm{x}$-axis in figs. 22 and 23 were assumed to be from the same extensional period of time then the progression of faulting would advance towards the basin so that the youngest fault would be closest to the center of the 
basin. The possibility exists that a combination of faults have caused the surface fault scarp, however, this could only be supported if the overlying sediments have changed in terms of their brittle-ductile characteristics. Possibly the sediments have been recemented and re-hardened through time to fulfill the criteria for this multi-fault theory. This multi-fault system might also be explained by having slightly different angles of dip for the several faults such that they superimposed each other at the present day surface fault scarp.

The magnetic data were modeled by starting with the previously discussed gravity model and then were refined by using the aeromagnetic data. There is a large 100 gamma anomaly centered at $1.2 \mathrm{~km}$ along the $\mathrm{x}$-axis (Figs. 22 and 23). This significant magnetically low anomaly does not correspond to a large anomaly in the gravity data and so it was modeled as an intrusive body with the same density as the surrounding bedrock. The long wavelength of the anomaly indicates that a deeper cause within the bedrock is the source. The intrusive body known as the Squaw Gulch Granite is exposed extensively to the southeast closer to the Santa Rita Mountains (Fig. 4) and is described by Drewes (1971a) as a pink coarse-grained granite and quartz monzonite. This Squaw Gulch Granite is nearly batholitic in size and was emplaced during the Jurassic coinciding with a period of a magnetic field reversal (Gettings, pers. comms., 1999). The intensity of remanent magnetization of this body used to fit the magnetic data was $9 \times 10^{-4}$ emu/cc. This value is probably too high for the granitic phase of the Squaw Gulch Granite so the quartz monzonite phase is more likely the cause of the magnetic response. 
Farther to the east a magnetic high in the data is located at $1.85 \mathrm{~km}$ (Fig. 22 and 23) coupled with a gravity gradient that dips towards the mountains. An intrusive igneous body slightly dipping to the east was inserted into the model with a higher magnetic susceptibility $\left(6.5 \times 10^{-4} \mathrm{cgs}\right)$ than the surrounding bedrock material $\left(2.0 \times 10^{-4}\right.$ cgs). The contact between the intrusive body and the host rock is nearly vertical. The only intrusive body nearby with a higher percentage of magnetite by volume than the host rock is the Josephine Canyon Diorite, which is exposed $5 \mathrm{~km}$ to the east in Montosa Canyon. Assuming the bedrock is the Continental Granodiorite, Mooney and Bleifuss (1953), showed that the magnetite content by volume ranged from $0.4 \%$ to $3.9 \%$ with a mean value of $2.0 \%$. The Josephine Canyon Diorite which was emplaced during the Late Cretaceous has a mean value of $3.0 \%$, ranging from $0.9 \%$ to $5.3 \%$. The higher magnetite content and near proximity to the field area makes it a reasonable candidate to explain the magnetic anomaly.

The model used to fit the gravity data and the truck-mounted data (TMD) did not originally fit the aeromagnetic data. The magnetic highs in the TMD did not coincide 
with magnetic highs in the aeromagnetic set and were consistently shifted by approximately $0.5 \mathrm{~km}$ as illustrated in Figure 21. The flight line of the aeromagnetic data was north of the TMD profile. So, the apparent shift between the two sets of data was concluded to be a result of a geologic body striking to the northwest and that any offset is due to where the profile crosses that anomaly. The TMD were shifted by $0.5 \mathrm{~km}$ and the peaks and troughs were then aligned with one another.

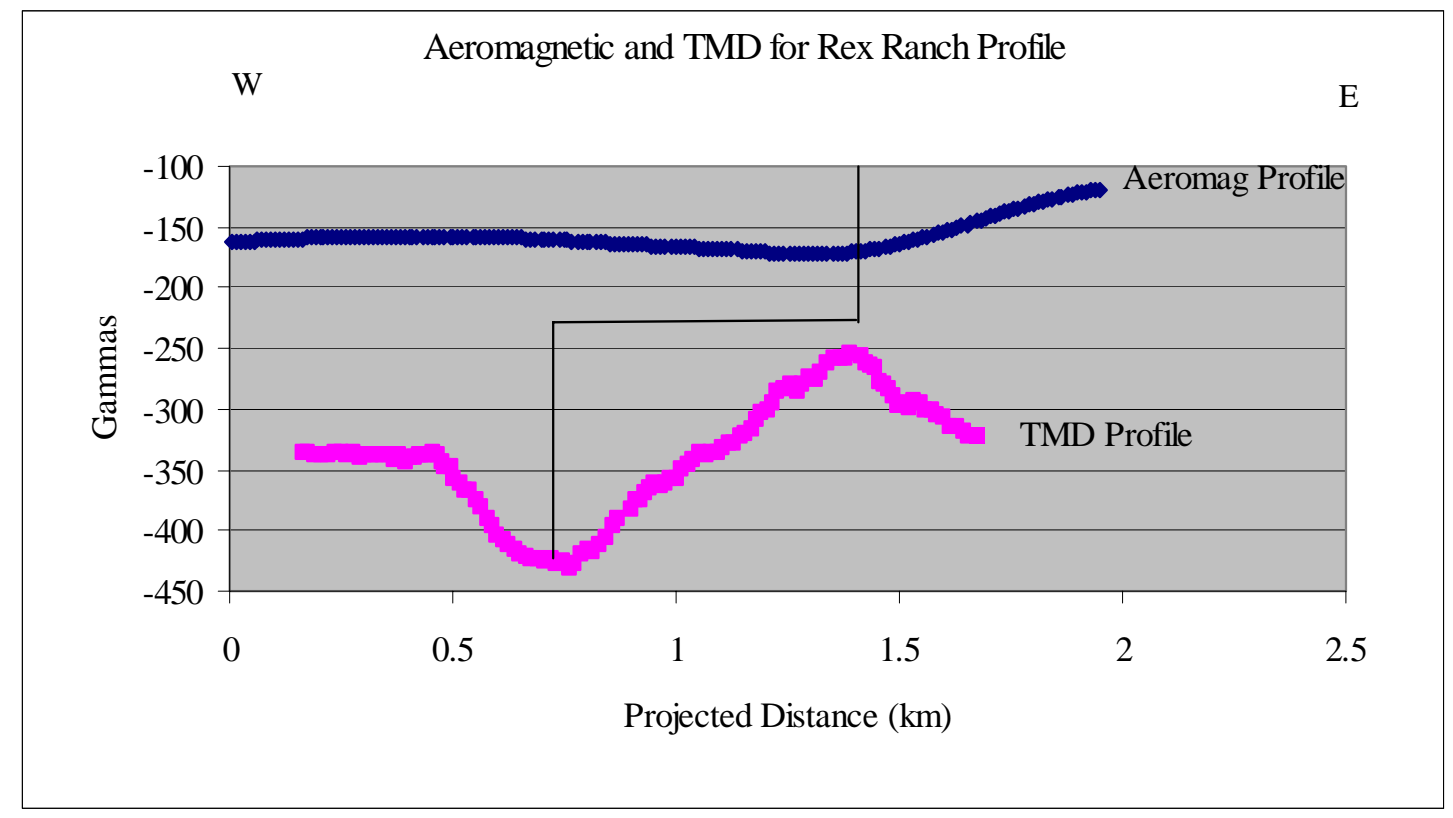

Figure 22. Offset in peaks due to the profiles crossing the trace of the fault at different locations.

The western half of the model up until $1.65 \mathrm{~km}$ (Fig. 23 and 24) shows a very reasonable fit to the three observed data sets and their respective models. Beyond 1.65 $\mathrm{km}$ the two magnetic sets deviate from the observed values. The aeromagnetic data suggest that either the intrusive body is too deep or the susceptibility is too low. The gravity model constrains the depth to bedrock at this point so moving this body up or 
down would then cause a major misfit to the gravity data. The susceptibility of the intrusive body was increased to gain a better fit to the aeromagnetic data however, this caused the fit of the TMD to become worse. This area is difficult to model because the positive gradient in the aeromagnetic data coincides with a negative gradient in the TMD. This discordance between data sets may due to: (1) GM-SYS requires that the polygons in the earth model be perpendicular to the cross section and extend to infinity without change in shape, or change in physical properties, this is rarely achieved in reality; (2) the flight line and TMD lines are along different azimuths to the strike of the causing body; or (3) the absence of data farther to the east means that the model is unconstrained and therefore impossible to model. The redeeming quality of this section in the model is that the same inflection point is present in both sets of the magnetic data and that both data sets have a gradient dipping to the east. 


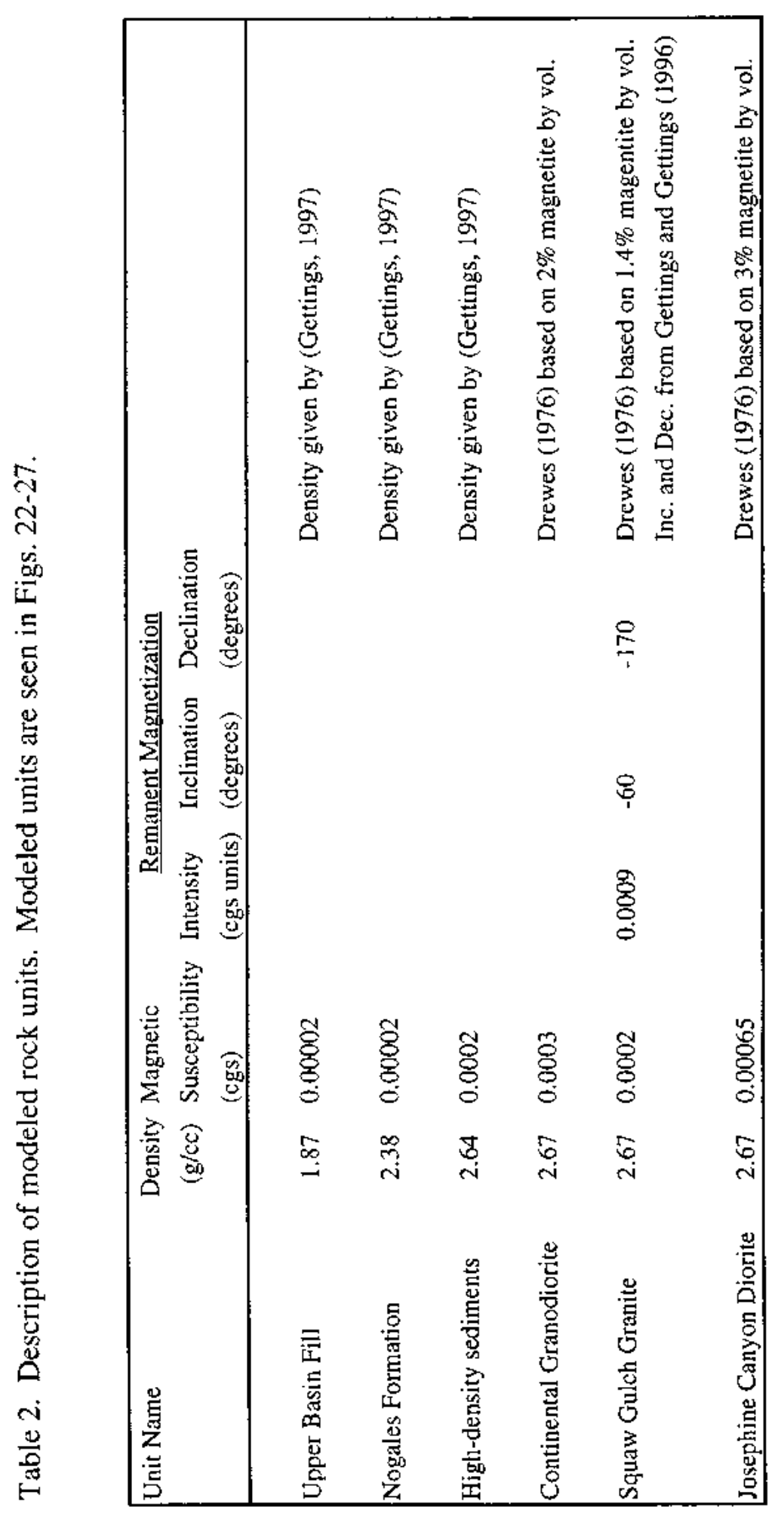



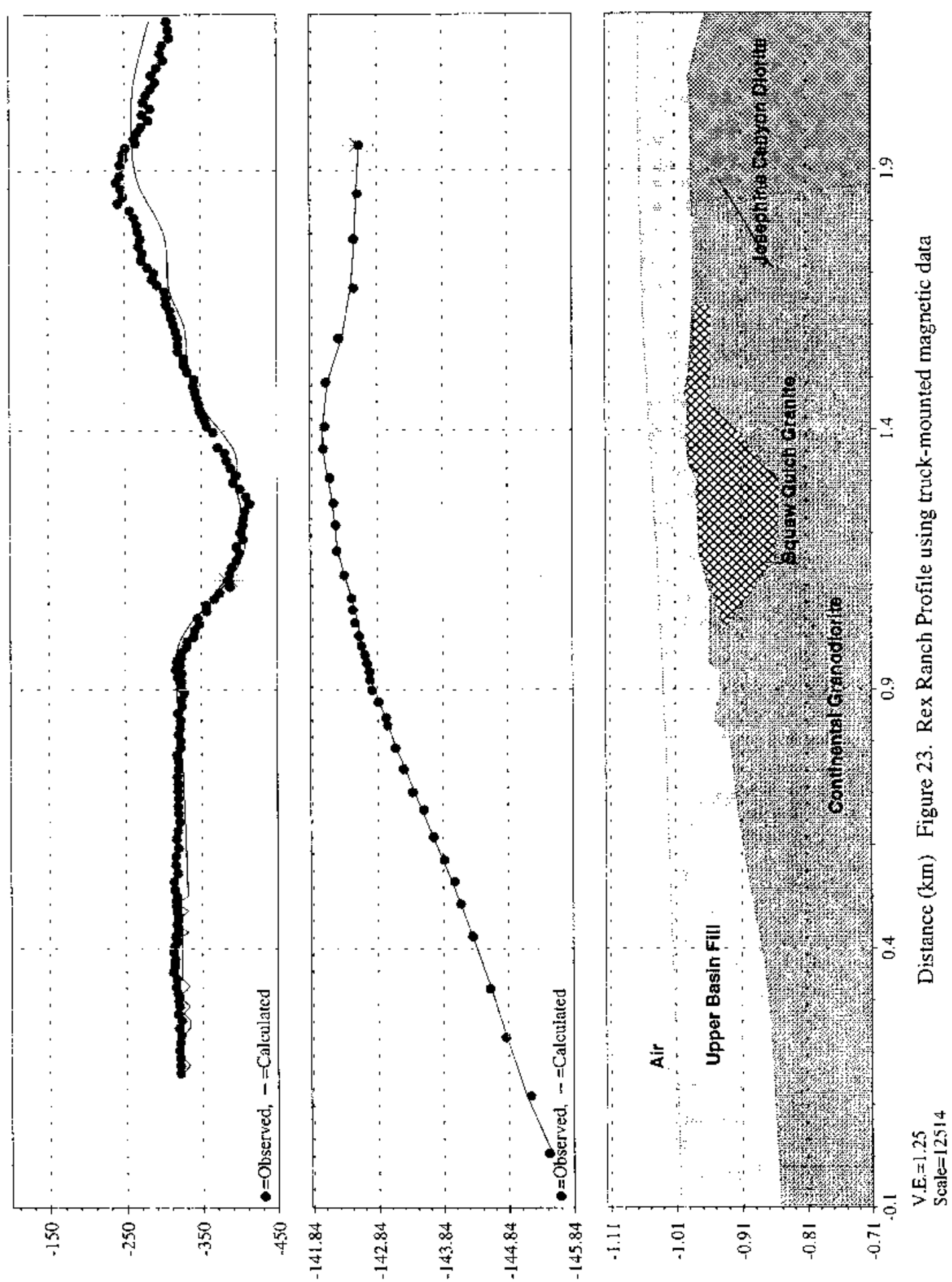

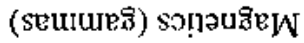

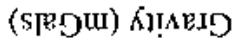

(uश्र) पฺा 


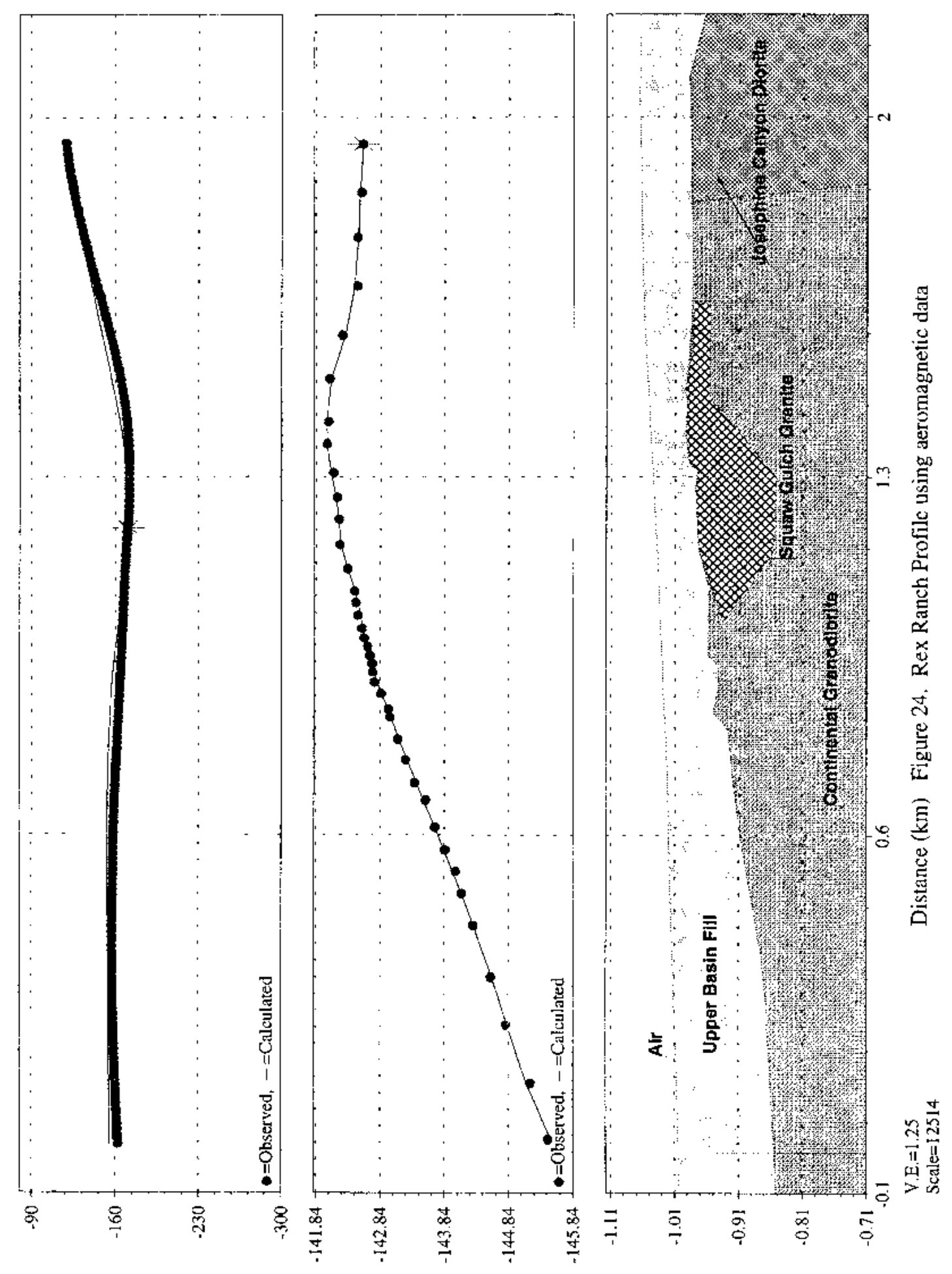

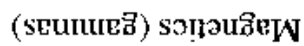

(s[EDU) К!ㅡㅁ

(ux) y1dag 


\section{NORTHERN COTTONWOOD CANYON PROFILE}

The modeled lines for this profile are presented in Figs. 25, 26 and 27. The surficial escarpment that extends across Cottonwood Canyon is eroded away where the northern profile crosses it. The fault trace is evident in the aerial photographs (see Fig. 3) and the location is interpolated from field maps (Houser, pers. comms., 2000). The fault is located at $0.88 \mathrm{~km}$ along the $\mathrm{x}$-axis on Figs. 24 and 25 . The dip and relief of this fault is similar to the fault to the northwest that crosses the Rex Ranch profile.

Unlike the Rex Ranch area, the basement rocks are exposed very close to the Cottonwood Canyon area and help to constrain the earth model for the Cottonwood Canyon profiles. Drewes (1971a) mapped the geology and location of faults near this area. The reversely polarized Squaw Gulch Granite discussed earlier is exposed at the surface, as well as the strongly magnetic Josephine Canyon Diorite, which outcrops closer to the field area. The Nogales Formation, a thick, dense sedimentary sequence containing mostly volcanic material composes the entire terrace where this profile was collected.

The model for this profile was constrained by using the available structural controls mapped by Drewes (1971a) and the bulk density measurements of the Nogales Formation (Gettings and Houser, 1997). Due to the close proximity of the southern profile to the northern profile a model that was geologically reasonable had to be made that simultaneously took into the account the geophysical data collected for both the northern and southern profiles. 
The gravity data were modeled first using the simplest model of the Nogales Formation, where the bulk density, $\rho=2.38 \mathrm{~g} / \mathrm{cc}$ (Gettings and Houser, 1997), overlying the basement rock $\rho=2.67 \mathrm{~g} / \mathrm{cc}$. The inclusion of intrusive bodies into the model was reserved for the magnetic modeling. On the eastern half of the profile there is a $2 \mathrm{mGal}$ anomaly that peaks at $1.7 \mathrm{~km}$ (Fig. 26) and then steepens to the east before reaching the trough at $2.0 \mathrm{~km}$, at this point the gradient changes inflection and increases before the profile ends. This was first modeled with a large fault dipping to the east, however, this did not fit the data at the east end of the profile (Fig. 26). So, a horst and graben structure was adopted to provide the mass excess needed to fit the positive gradient at the end of the gravity profile. The depth to the down dropped graben is approximately $0.19 \mathrm{~km}$ with the eastern wall dipping 55 degrees and the western wall dipping 30 degrees, however, there was variability with these angles. If these angles were steepened then the other half of the profile became misfit to the data and depth to bedrock on that half had to be increased to compensate for the excess mass of the bedrock. Drewes (1971a) mapped other faults that run into Cottonwood Canyon as well as some fault splays off of the major fault. Brenda Houser (pers. comms., 1999) located a fault higher up in the canyon that strikes NE and SW, dips 60 degrees to the NW with Tertiary volcanics and Precambrian igneous and metamorphics on the southeast side and the Nogales formation on the northwest side. The geologic evidence of northwest-southeast faulting supports the possibility of a horst and graben feature.

On the western half of the profile the data were fit very well. The anomaly at $0.78 \mathrm{~km}$ (Fig. 26) associated with the surface fault scarp was modeled as a fault along 
the Squaw Gulch Granite, which was added to model the magnetic data. The contact between the intrusive body and the bedrock fits a fault model. The faults at depth, which cause displacement at the surface, have occurred in the last few thousand years and this sill of Squaw Gulch Granite was emplaced during the Jurassic. The fault may be older than a few thousand years and may have been reactivated during different periods of tectonic activity. The fault continues to have normal movement today. The fault plane dips about 58 degrees down to the west with $0.05 \mathrm{~km}$ of relief (Fig. 25). In Fig. 25, the bold arrow indicates the location of the surface rupture and the up-dip projection of the

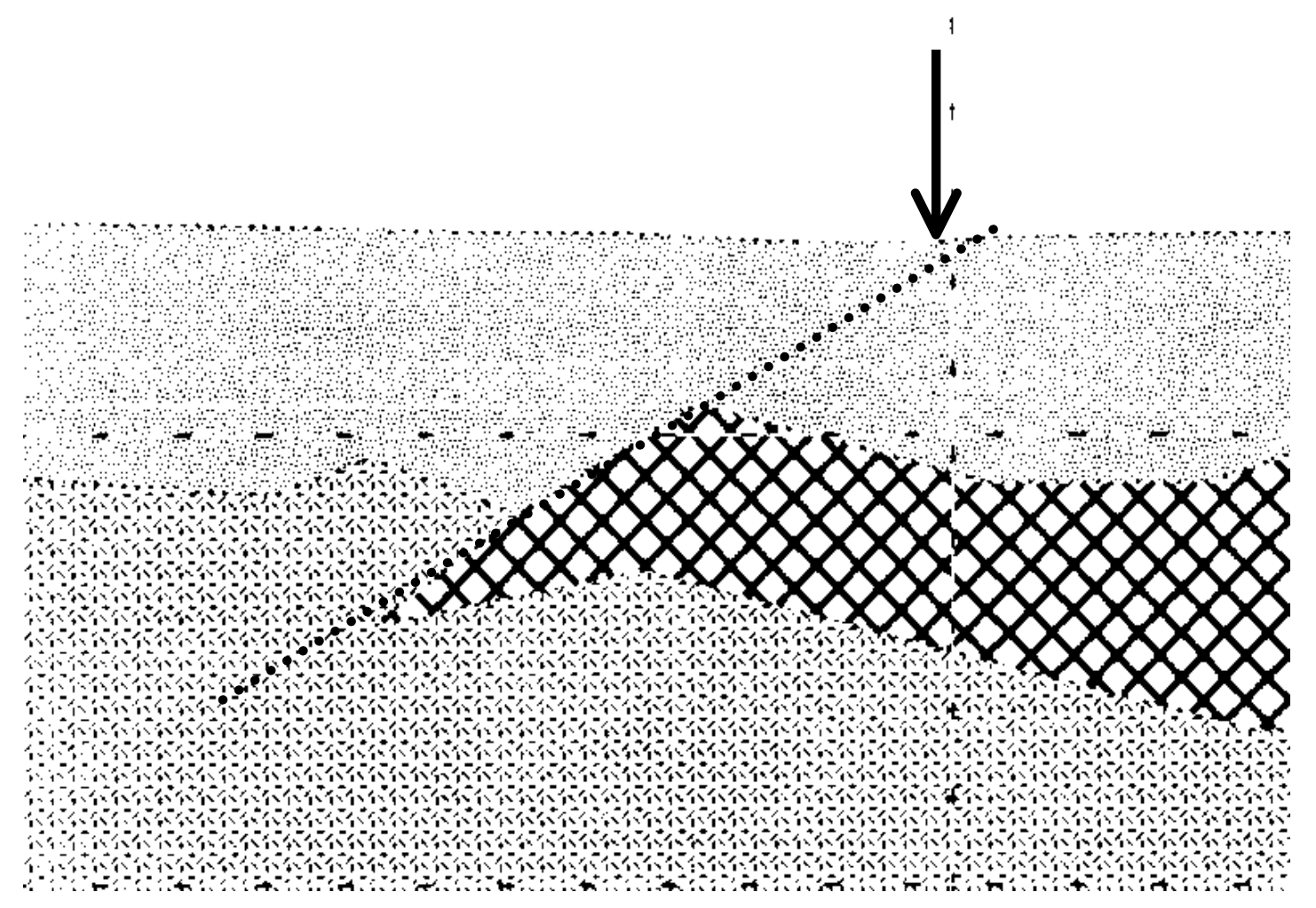

Figure 25. Magnification of Northern Cottonwood Canyon Fault.

fault at depth is represented by the dotted line. The surface fault scarp exists just to the west of the up-dip plane suggesting a brittle deformation within the overlying Nogales 
sediments. This is sensible given that the Nogales is a high-density unit that has been described as well indurated (Drewes, 1971b).

The magnetic model is composed of three different bodies excluding the Nogales Formation. The exposure of the Squaw Gulch Granite very close to the profile justified its insertion into the model. However, it was quickly determined that this body alone could not fit the magnetic data. Since the gravity model was very sensitive to change near the horst and graben area, it was a primary constraint on the magnetic model. The western half of the profile was stable and relatively level at $300 \mathrm{nT}$ until $0.8 \mathrm{~km}$ (Fig. 26) where it begins to dip towards the east and decrease until $1.2 \mathrm{~km}$ where it reached a low of $500 \mathrm{nT}$. This was modeled by inserting a sill of the Squaw Gulch Granite, which extended laterally for $1.3 \mathrm{~km}$. The gravity model defined the top of this body, and the bottom of the body was adjusted to obtain a good fit to the magnetic data without affecting the fit to the gravity data. The magnetic high towards the eastern end at $1.9 \mathrm{~km}$ (Fig. 26) of the profile could not be modeled with reversely polarized Squaw Gulch Granite. Therefore a normally polarized intrusive body with a higher susceptibility than the host rock was inserted into the model. The susceptibility of this body needed to fit the magnetic high was $6.5 \times 10^{-4} \mathrm{cgs}$, which corresponds to $2 \%$ magnetite by volume (Mooney and Bleifuss, 1953). The magnetite content of the Josephine Canyon Diorite ranges from $0.9 \%$ to $5.3 \%$ by volume (Drewes, 1976) and is exposed nearby so it is very likely to be the cause of the magnetic high. Since there is no geologic control on the subsurface shape and extent of this body its shape and size could be freely adjusted to fit the data. At $1.0 \mathrm{~km}$ (Fig. 26) there is a slight anomaly superimposed on the regional 
gradient, which coincides with the surface fault scarp. The fit to this section is not perfect however, the inflection point in the calculated data mimics the inflection point in the TMD. Efforts to better fit this section resulted in a misfit to the gravity data. Taking into account that data set is a moving average of the TMD and that the gravity values have not been modified, the model, which fit the gravity data very well, was chosen. The earth model created for the gravity and magnetic data was then applied to aeromagnetic data. Except for the extreme ends of the profile fit the aeromagnetic data (Fig. 27) very well. However, the deviation from the observed data was very small at about 10 gammas on both ends and was deemed to be a reasonable fit. 


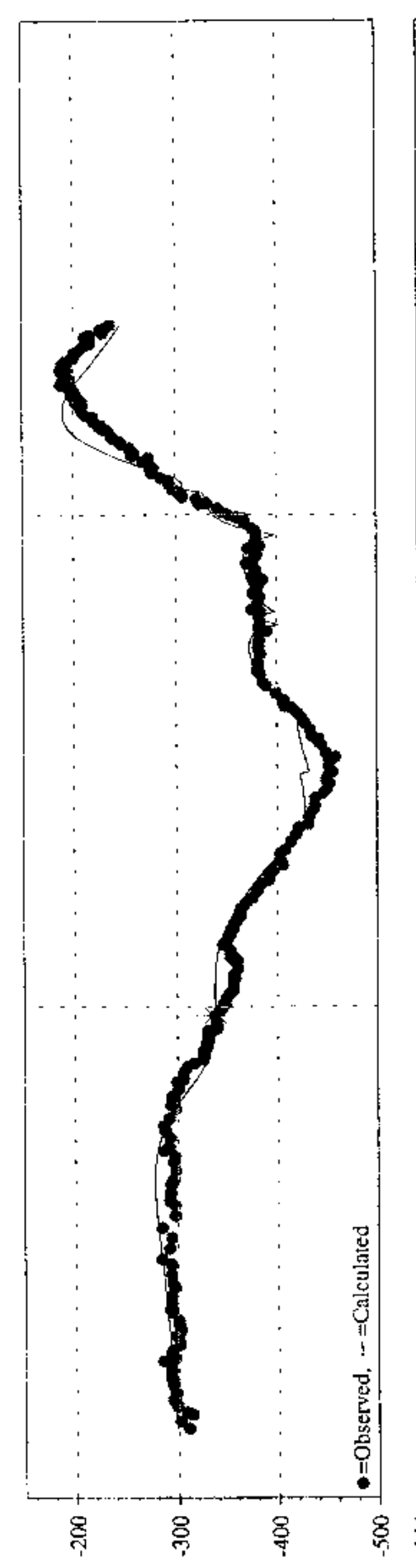

(sedules) sonorkeN

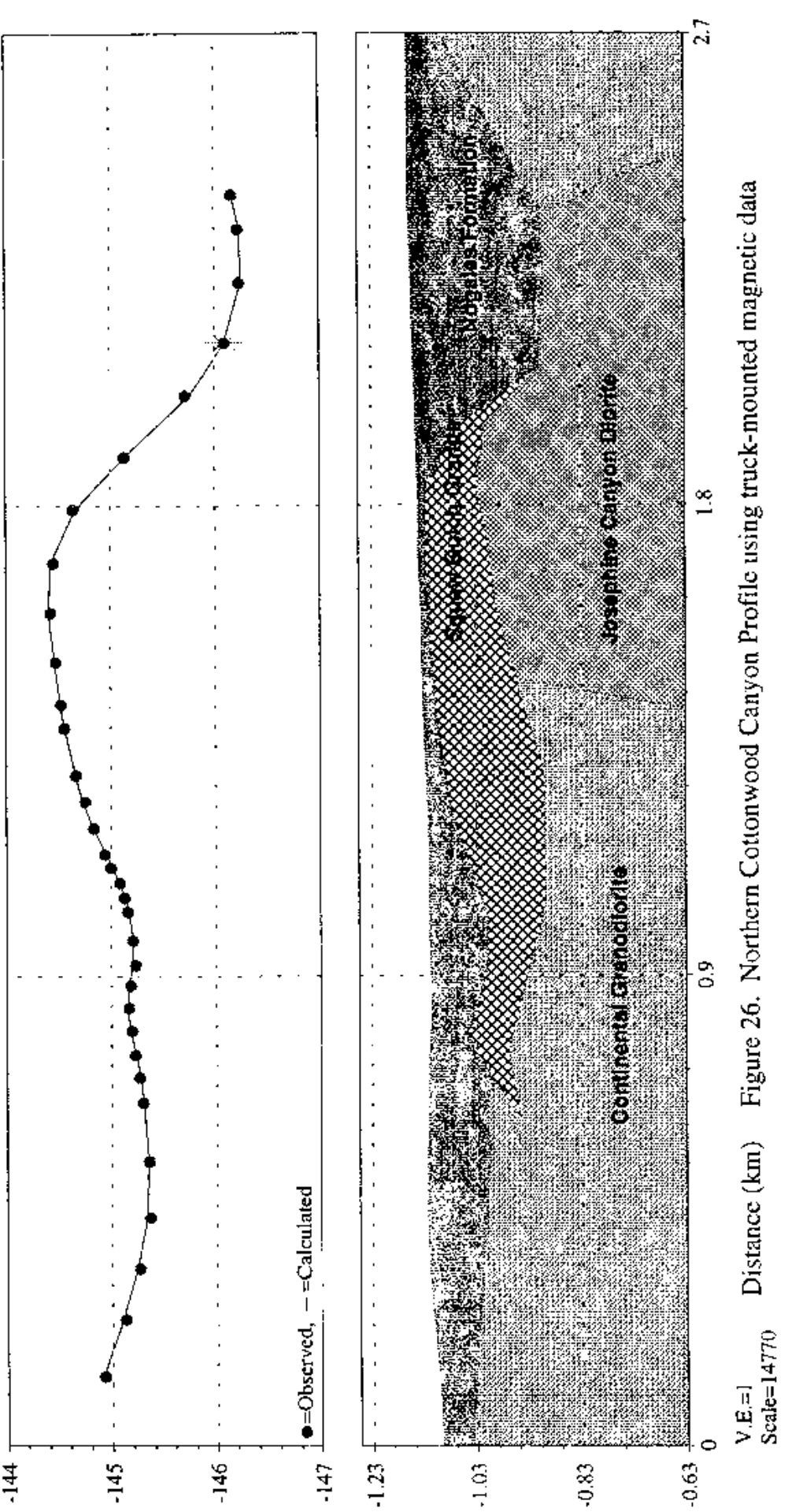

(S|tSU) RIIMEJO (us) पाd (T 

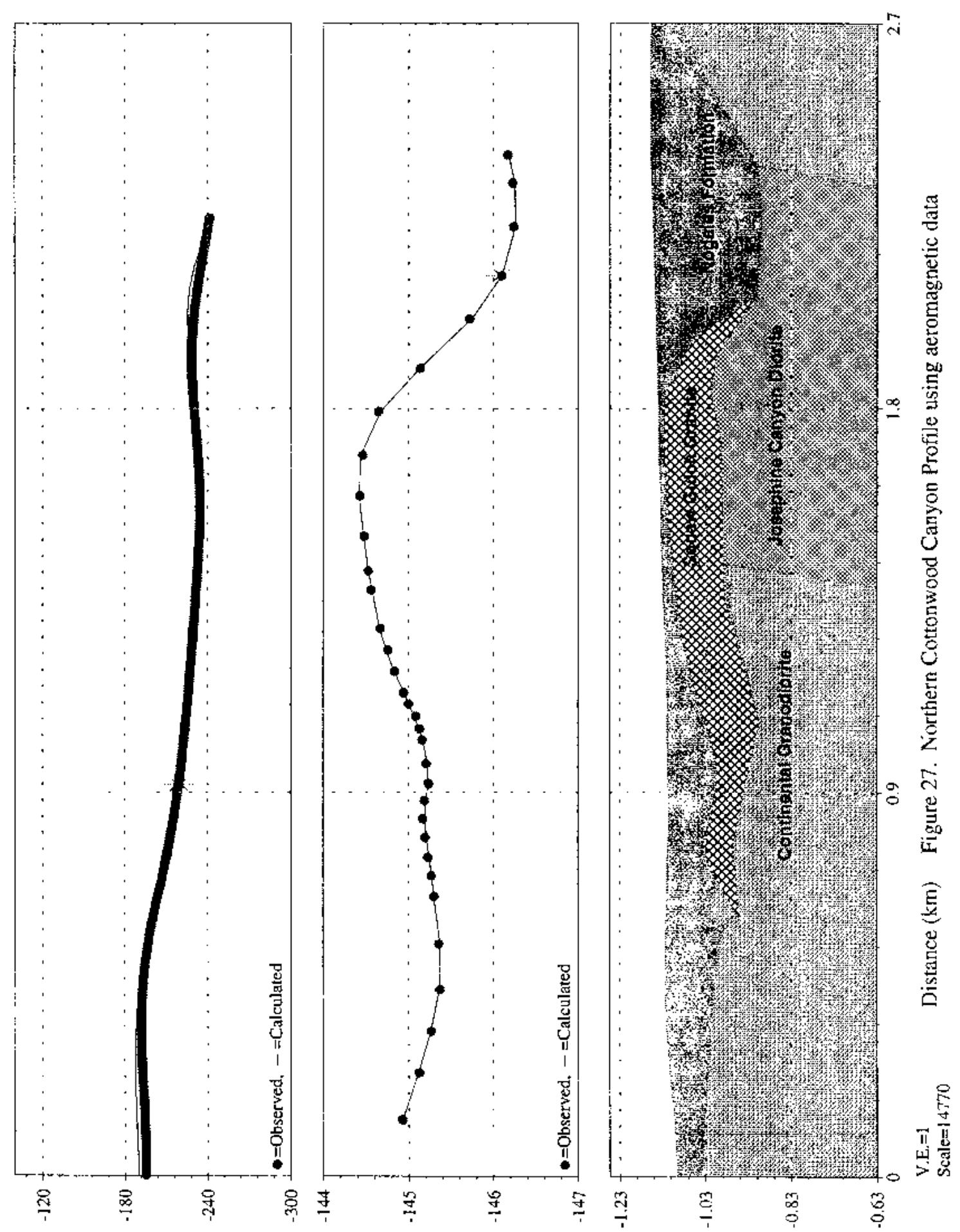

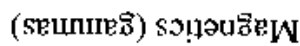

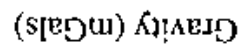

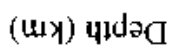




\section{SOUTHERN COTTONWOOD CANYON PROFILE}

The profile along the southern terrace of Cottonwood Canyon was located about $1.2 \mathrm{~km}$ to the south of the northern profile. The fault scarp was visible where the profile crossed it and dips towards the west with 2 meters of relief. The fault is located at 0.75 km on the model shown in Figs. 28, 29 and 30.

The gravity anomaly for the southern profile was again modeled first using the available geological and geophysical constraints. The bedrock units used in modeling the northern profile were used in the southern profile. Unlike the northern profile, the upper basin fill, $\rho=1.87 \mathrm{~g} / \mathrm{cc}$, is present and overlies the Nogales formation (Drewes, 1972). Also, there is a high-density caliche layer, $\rho=2.64 \mathrm{~g} / \mathrm{cc}$ within the upper basin fill that has a variable thickness (Gettings and Houser, 1997). The large range of CBGA values is about 6 mGals within the southern profile. The trace of the fault mapped by Houser farther up Cottonwood Canyon was projected to intersect the profile at $2.1 \mathrm{~km}$ which coincides with the inflection point of the large $5 \mathrm{mGal}$ anomaly as seen in the eastern portion of the profile (Fig. 29). Therefore, a fault dipping to the west with relief approximately $0.3 \mathrm{~km}$ was used to model the data. It appears that the profile begins in the graben and crosses the rising southern flank of the horst feature (Fig. 29). The gravity model indicates the presence of several other smaller faults located within the Squaw Gulch Granite, however, as they are modeled they do not offset the Nogales above. This suggests that faults are not present but rather are variations in the paleotopography of the top of the Squaw Gulch body. The surface fault scarp has an anomaly similar to the one 


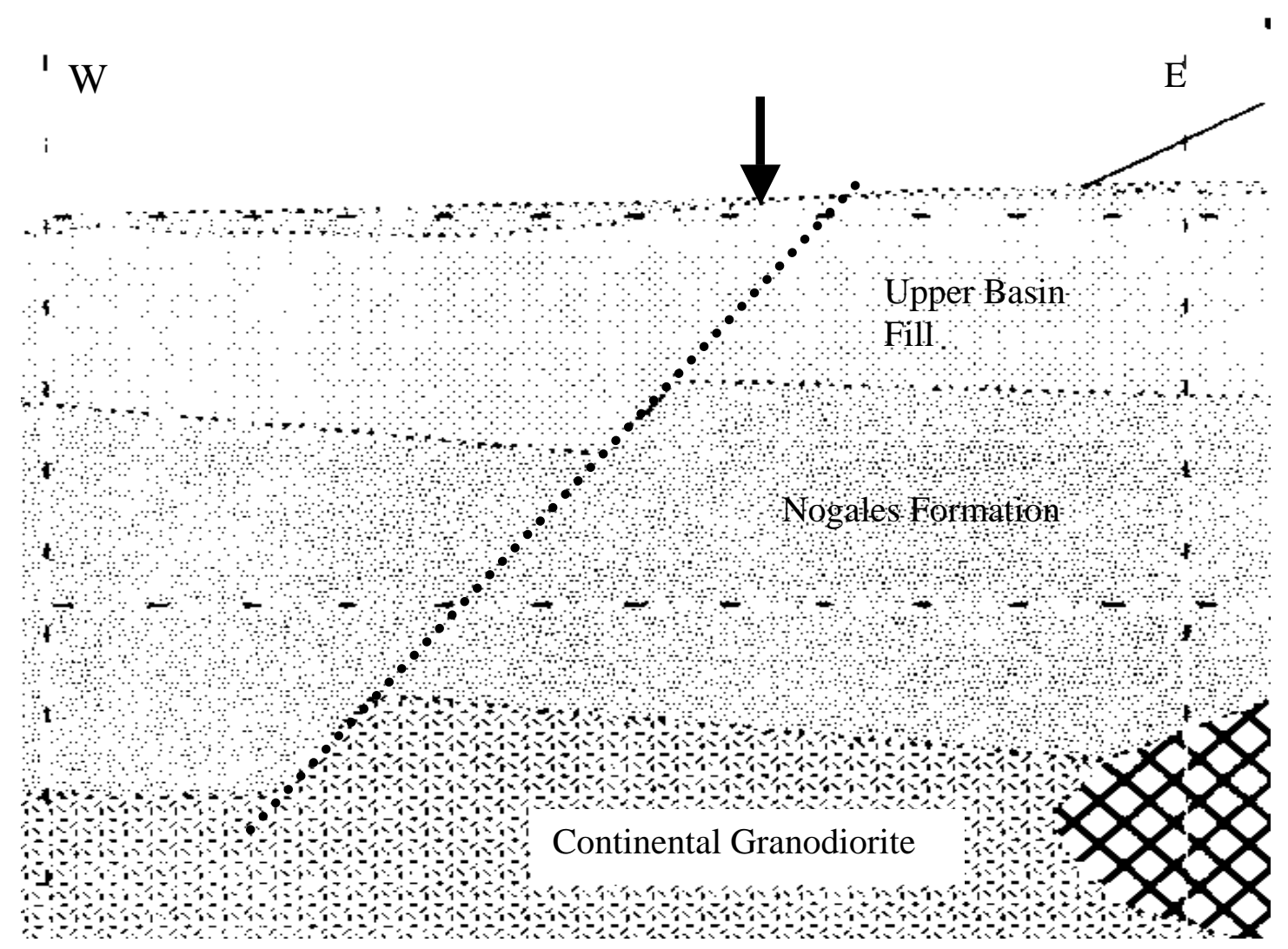

Figure 28. Magnification of Southern Cottonwood Canyon model.

in the northern profile. However, the fault at depth does not coincide with the contact of the Squaw Gulch granite, but exists solely in the bedrock material. The fault within the bedrock dips about 50 degrees to the west with $0.06 \mathrm{~km}$ of relief. The Nogales sediments above are faulted as a result, and Fig. (28) shows that the fault plane is exactly up-dip from the fault within the bedrock. The fault propagated through the upper basin fill unit to the surface in a few meters west of the up-dip projection of the bedrock fault. This would suggest that upper basin fill unit is also a well-indurated layer. The presence of the high-density layer near the surface somewhat masked the subsurface geology. A model was created without the caliche layer and the results were very poor. The fault that modeled the anomaly was an unrealistic feature resembling a spike of significant 
relief. Although the high-density layer was required to help fit the gravity data, its thickness was constrained to less than 10 meters so that it would not dominate the model. Lack of roads prevented the acquisition of magnetic data west of the fault scarp so only half of the profile could be modeled. The magnetic data were modeled using a combination of the reversely polarized Squaw Gulch Granite and highly magnetized Josephine Canyon Profile. There is a magnetic low located at $1.9 \mathrm{~km}$, which coincides with the large fault modeled in the gravity. The sharp anomaly could not be modeled by varying the susceptibility of the Continental granodiorite alone, so, the reversely polarized, Squaw Gulch Granite $\left(\mathrm{k}=1.0 \times 10^{-4} \mathrm{cgs}\right)$ was added as intrusive sill into the bedrock and the anomaly around $1.9 \mathrm{~km}$ was well fit. To the east however, the magnetic response of the Squaw Gulch was systematically lower than observed data. Increasing the thickness of the body made the fit worse. The Josephine Canyon Diorite $\left(\mathrm{k}=6.5 \times 10^{-3}\right)$ was added as an intrusive body into the Squaw Gulch. This provided the positive response in the magnetic data needed to fit the profile in the range of 0.7 to 1.6 $\mathrm{km}$. Also, using the Josephine Canyon Diorite fit the aeromagnetic high located in the western portion of the profile. This model shows that the extent of the diorite to be less than $1 \mathrm{~km}$ where it is in contact with the intrusive granite. If the diorite was increased in horizontal extent then the response was too positive and the fit to the data was worsened, especially, in the region of 1.9 to $2.4 \mathrm{~km}$ (Fig. 30). The magnetic high here was difficult to model because of its intensity of $100 \mathrm{nT}$. Magnetite bearing sediments were considered $\left(\mathrm{k}=2.5 \times 10^{-3}\right)$, however, their response was too weak and could not match the data. The diorite was extended to underlay the location of the magnetic high and the 
response was too positive. Since, the Squaw Gulch granite was somehow related to the large fault in the horst and graben, it seemed plausible that the sill was faulted and that remnants of it remained at the top of the fault. A thin layer of the Squaw Gulch near the surface was used to obtain a good fit to the magnetic data. The geologic map indicates large exposures of the Squaw Gulch granite just to the east of this area (Drewes, 1976) and so erosion could justify the thinness of the Squaw Gulch at the surface versus the thickness of it at depth. 

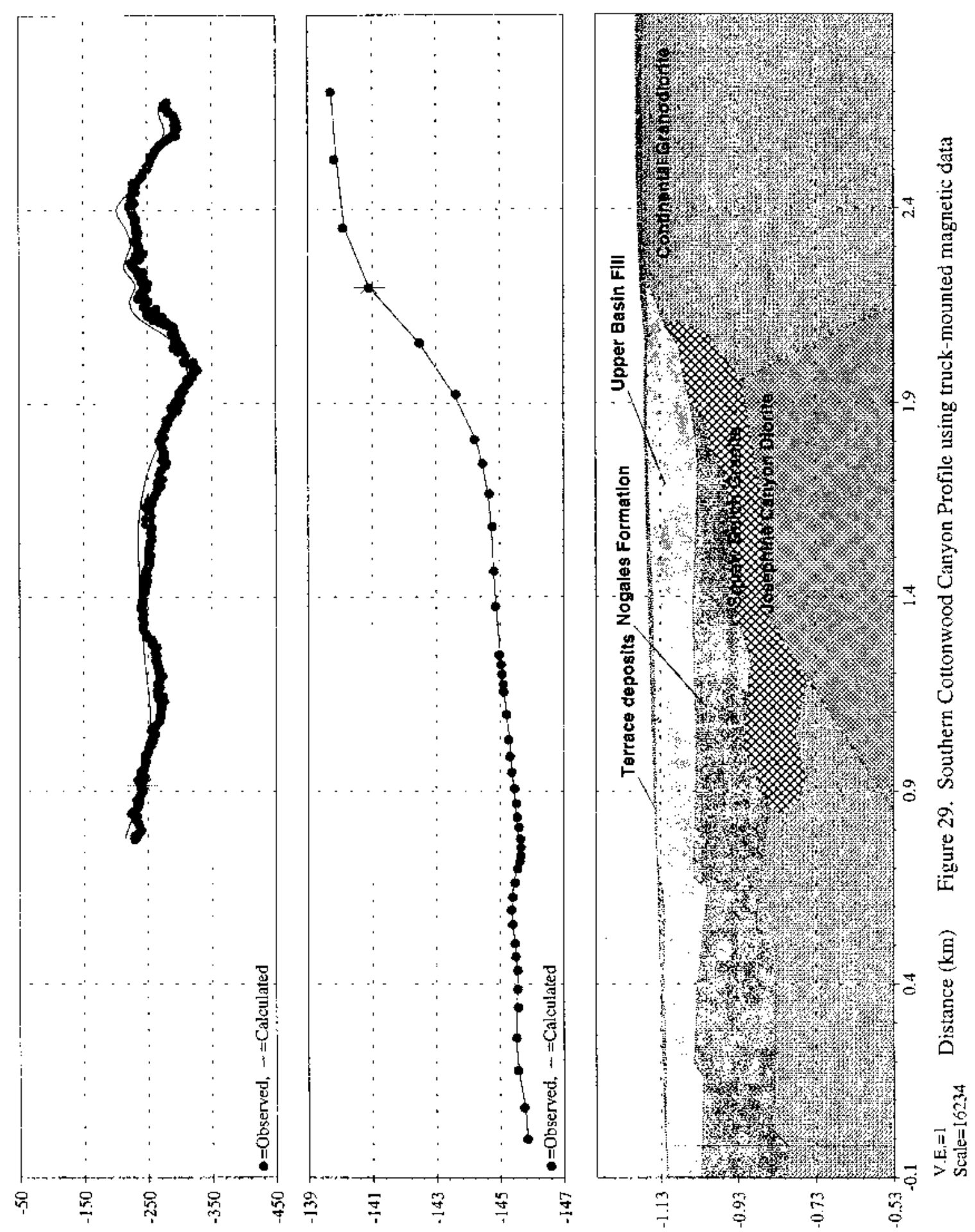

(stนณue8) sonousew

(SIEDUI) KIIAEID

(uiv) y1daCI 

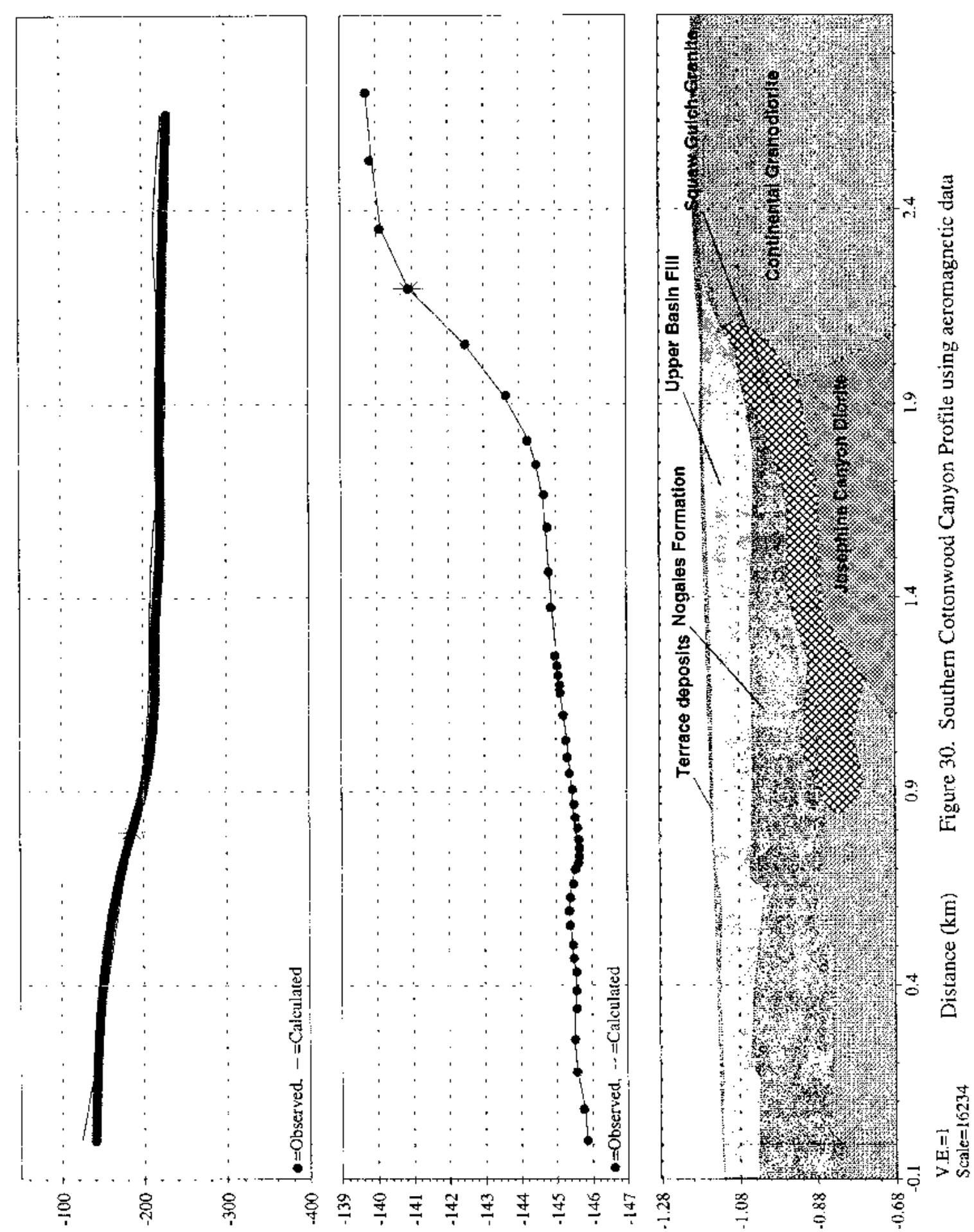

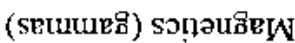

(S[BDUI) AlIARJD

(ux) 4xdoc 


\section{CONCLUSIONS}

Gravity data collected along profiles across late Quaternary basin-bounding faults near the western flank of the Santa Rita Mountains proved to be useful in understanding the relationship of the gravity response of the faults at depth with their resulting surface fault scarps. Truck-mounted magnetic data and airborne magnetic data did not prove as useful for studying these smaller faults but rather helped in modeling the broader geological picture.

Because of the inherent nonuniqueness involved with geophysical modeling it was important to include any independent geologic knowledge. Density measurements of the upper basin fill, the Nogales Formation, and the high-density caliche layer were used to constrain to the models (Gettings and Houser, 1997). Geologic mapping by Drewes (1971a) and Houser (1997) were also used to justify the insertion of strongly magnetic bodies such as the Josephine Canyon Diorite, and reversely polarized bodies such as the Squaw Gulch Granite. Also, faults mapped out by Drewes and Houser helped to form the structural control of the models, especially in the Cottonwood Canyon area where two profiles in close vicinity to one another had to be tied together geologically.

The first profile was modeled along Rex Ranch road on the northern terrace of Montosa Canyon. The gravity data were collected over the course of several days and there was no base station control in the field. Some of the smaller gradients may not actually be due to faults but rather to the uncertainty in gravity values. The general trend of the gravity data shows bedrock dipping towards the center of the basin. The magnetic data show a large magnetic low at $1.2 \mathrm{~km}$ and a large magnetic high at $1.9 \mathrm{~km}$. The low 
was modeled by emplacing a sill of the Squaw Gulch Granite, which had a remanent magnetization of $9 \times 10^{-4} \mathrm{cgs}$. The magnetic high was modeled with an intrusive body with a high susceptibility of $6.5 \times 10^{-4}$. The anomaly of the surface fault scarp was modeled as a fault in the bedrock about $100 \mathrm{~m}$ below. The fault plane in the bedrock was projected to the surface and shown to intersect the surface east of the present day fault. This would suggest that the upper basin fill responded in more of a brittle fashion to movement created by the fault at depth.

The gravity data for the two Cottonwood Canyon profiles suggest the presence of a large horst and graben structure. The northern profile seems to have been collected along the top of the northern footwall before going down the fault plane onto the top of the graben. The east end of the gravity profile increases again as it approaches the southern footwall. The southern profile begins along the graben surface and climbs up the southern footwall as indicated by the increasing gravity values. A thickness of 0.2 $\mathrm{km}$ of Nogales sediments above the graben was found through gravity modeling of the northern profile.

The Squaw Gulch Granite was modeled closer to the surface in the northern profile than in the southern profile. The depth to the sill discrepancy between the two profiles can be resolved by assuming that large scale faulting down dropped the Squaw Gulch Granite. The surface fault scarp that extends through the Cottonwood canyon postdates any of the large-scale faulting primarily because of the lack of relief at the earth's surface that accommodate the movement. The fault planes of the faults at depth as shown in Fig. 24 and 26 were projected to the surface. And similar to the Rex Ranch 
profile, the overlying sediments were faulted in a manner conducive to having brittle characteristics. In each of the three profiles the surface rupture is only 10 to $20 \mathrm{~m}$ west of the up-dip projection of the modeled fault at depth. This might suggest brittle deformation within the consolidated sediments at greater depths followed by ductile deformation closer to the surface which coincides with unconsolidated.

Although the models shown above are the best fit of the gravity, magnetic and aeromagnetic anomaly profiles for the available constraints they are not perfect. Misfits to the data originate from the simple shapes used to model the data and from the data having some error in them. There is always a tradeoff between a perfect fit to the data and the geological soundness of the model. The latter was always opted for because of the inherent ambiguities involved in modeling. The simpler model is generally the more geologically insightful one. Although the usage of very specific rock types was used, there is always the possibility that the geophysical response might be due to something different. The usage of Squaw Gulch as the primary magnetic source for the profiles is not beyond reproach. There are several other reversely magnetized volcanic rock units within the Santa Rita Mountains that could be the source for the anomalies, however, none in as close proximity as the Squaw Gulch Granite and Josephine Canyon Diorite.

The data and conclusions from this thesis will lend insight to current and future large-scale efforts. Arizona's number one source of income is comes from the mining industry, and the next frontier for the discovery of mineral prospects is in the study of shallow basins covered by Quaternary deposits. This project is also part of a larger project to delineate geologic form and subsurface geologic structure of the Santa Cruz 
basin. The location of controlling structures has important implications in many ground water issues and earthquake hazards.

The modeled faults in the three profiles offset the overlying sediments, i.e. the Nogales Formation, from 30 to $60 \mathrm{~m}$ with a mean of $45 \mathrm{~m}$ of relief and the dip of the faults at depth ranged from 40 to 58 degrees with an average of 32 degrees. The surface rupture was observed to have 2 meters of relief. If it is assumed that one seismic event caused the $2 \mathrm{~m}$ of relief at the surface and that the average relief of the fault at depth is 45 m then there have been 22 events. Given the age of the Nogales Formation to be approximately 16 mya then an earthquake that would cause $2 \mathrm{~m}$ of relief at the surface would occur about every $0.7 \mathrm{my}$. This earthquake recurrence period is possibly an overestimate due to surface erosion and the recurrence interval might be more every 1 my.

The ability to do a high precision gravity survey relies heavily on the location control especially the altitude control. The use of differential GPS in this survey made possible a high precision survey, however, careful planning was required to ensure that satellite coverage was sufficient to obtain the required elevation and location accuracy. 


\section{REFERENCES}

Clark, S.P., Handbook of Physical Constants; The Geological Society of America, INC., p. 587.

Carmichael, R.S., 1982, CRC Handbook of Physical Properties of Rocks: CRC Press, Inc., $345 \mathrm{p}$.

Coney, P.J., 1987, The regional tectonic setting and possible causes of Cenozoic extension in the North American Cordillera: Geological Society Special Publication No.28, pp. 177-186.

Dobrin, M.B., 1976, Introduction to Geophysical Prospecting: Mcgraw-Hill, Inc., 630 p.

Drewes, H., 1971a, Geologic map of the Mt. Wrightson quadrangle, southeast of Tucson, Santa Cruz and Pima counties, Arizona: U.S. Geological Survey Miscellaneous Geologic Investigations Map I-614, scale 1:48000.

Drewes, H., 1971b, Mesozoic stratigraphy of the Santa Rita Mountains, southeast of Tucson, Arizona: U.S. Geological Survey Professional. Paper 658-C, 81p.

Drewes, H., 1972, Cenozoic rocks of the Santa Rita Mountains, southeast of Tucson, Arizona: U.S. Geological Survey Professional Paper 746, 66p.

Drewes, H., 1976, Plutonic rocks of the Santa Rita Mountains, southeast of Tucson, Arizona: U.S. Geological Survey Professional Paper 915, 75 p.

Drewes, H., 1972, Structural Geology of the Santa Rita Mountains, Southeast of Tucson, Arizona: U.S. Geological Survey Professional Paper 748, 35 p.

Gettings, P.E., and Gettings, M.E., 1996, Modelling of a magnetic and gravity anomaly profile from the Dragoon Mountains to Sierra Vista, southeastern Arizona: U.S. Geological Survey Open-File Report 96-288, 15 p.

Gettings, M.E., Houser, B.B., 1997, Basin Geology of the Upper Santa Cruz Valley,Pima and Santa Cruz Counties, Southeastern Arizona: U.S. Geological Survey OpenFile Report 97-676, 46 p.

Heiland, C.A., 1968, Geophysical Exploration: Hafner Publishing Co., 1013 p.

Hegman, M., 1998, Gravity and Magnetic Survey: M.S. Thesis, , University of Arizona.

Kearey, P., and Brooks, M., 1991, An Introduction to Geophysical Exploration: Blackwell Scientific Publications, 254 p. 
Marquardt, D.W., 1963, An algorithm for least-squares estimation of non-linear parameters, J. SIAM, v. 11, p. 431-441.

Mooney, H.M., and Bleifuss R., Magnetic Susceptibility Measurements in Minnesota, Part II, Analysis of Field Results: Geophysics, Vol. 18, pp. 383-393, 1953.

Robbins, S.L., and Oliver, H.W., 1970, On making inner-zone terrain corrections to gravity data: U.S. Geological Survey In-House Memorandum.

Tanbal, K.M., 1987, A gravity survey over late quaternary fault scarps west of the Santa Rita Mountains, Arizona: M.S. Thesis, University of Arizona, 55 p.

Telford, W.M., Geldart, L.P., Sheriff, R.E., and Keys, D.A., 1976, Applied Geophysics: Cambridge University Press, 860 p.

Webring, M., 1985, SAKI: A FORTRAN program for generalized linear inversion of gravity and magnetic profiles: U.S. Geological Survey Open-File Report 85-122, 29 p. 
APPENDIX A: GRAVITY DATA

\begin{tabular}{|c|c|c|c|c|c|c|c|c|c|c|}
\hline $\begin{array}{l}\text { Station } \\
\text { ID }\end{array}$ & $\begin{array}{l}\text { Lat. } \\
\text { Deg. }\end{array}$ & $\begin{array}{l}\text { Longitude } \\
\text { Deg. }\end{array}$ & $\begin{array}{l}\text { Elev. } \\
(\mathrm{m})\end{array}$ & $\begin{array}{l}\text { Observed } \\
\text { Gravity } \\
\text { (mGal) }\end{array}$ & $\begin{array}{c}\text { Free Air } \\
\text { Anomaly } \\
\text { (mGal) }\end{array}$ & $\begin{array}{c}\text { Simple } \\
\text { Bouger } \\
\text { Anomaly } \\
(\mathrm{p}=2.67 \mathrm{~g} / \mathrm{cc})\end{array}$ & $\begin{array}{c}\text { Complete } \\
\text { Bouger } \\
\text { Anomaly } \\
(\mathrm{p}=2.67 \mathrm{~g} / \mathrm{cc})\end{array}$ & $\begin{array}{c}\text { Inner Zone } \\
\text { Terrain } \\
\text { Correction } \\
(\mathrm{p}=2.67 \mathrm{~g} / \mathrm{cc})\end{array}$ & $\begin{array}{c}\text { Total } \\
\text { Terrain } \\
\text { Correction }\end{array}$ & $\begin{array}{c}\text { Uncertainty in } \\
\text { CBGA } \\
(\mathrm{p}=2.67 \mathrm{~g} / \mathrm{cc}) \\
(\mathrm{mGal})\end{array}$ \\
\hline $\mathrm{rr}-01$ & 31.69673333 & -111.0042667 & 1067.15 & 979106.49 & -23.13 & -142.55 & -142.57 & 0.09 & 1.14 & 0.23 \\
\hline rr-02 & 31.69668333 & -111.0052667 & 1065.81 & 979106.78 & -23.26 & -142.52 & -142.55 & 0 & 1.13 & 0.23 \\
\hline $\mathrm{rr}-03$ & 31.69661667 & -111.0061667 & 1064.39 & 979107.14 & -23.33 & -142.43 & -142.49 & 0 & 1.1 & 0.22 \\
\hline rr-04 & 31.69651667 & -111.0071667 & 1062.43 & 979107.60 & -23.47 & -142.35 & -142.49 & 0 & 1.02 & 0.21 \\
\hline $\mathrm{rr}-05$ & 31.69636667 & -111.0082 & 1059.52 & 979108.37 & -23.58 & -142.14 & -142.26 & 0.04 & 1.03 & 0.21 \\
\hline $\mathrm{rr}-06$ & 31.69641667 & -111.0090833 & 1054.59 & 979109.53 & -23.94 & -141.95 & -142.06 & 0.07 & 1.04 & 0.21 \\
\hline $\mathrm{rr}-07$ & 31.69651667 & -111.0099833 & 1051.53 & 979110.17 & -24.26 & -141.92 & -142.1 & 0.02 & 0.97 & 0.2 \\
\hline $\mathrm{rr}-08$ & 31.6966 & -111.0104167 & 1049.31 & 979110.63 & -24.49 & -141.91 & -142.02 & 0.11 & 1.03 & 0.21 \\
\hline rr-09 & 31.69668333 & -111.0110333 & 1046.75 & 979111.14 & -24.78 & -141.91 & -142.07 & 0.09 & 0.98 & 0.2 \\
\hline $\mathrm{rr}-10$ & 31.69668333 & -111.0110333 & 1046.73 & 979111.14 & -24.79 & -141.91 & -142.12 & 0.05 & 0.94 & 0.19 \\
\hline $\mathrm{rr}-11$ & 31.69671667 & -111.0115333 & 1044.81 & 979111.48 & -25.04 & -141.95 & -142.18 & 0.04 & 0.92 & 0.19 \\
\hline $\mathrm{rr}-12$ & 31.69678333 & -111.012 & 1042.95 & 979111.82 & -25.28 & -141.98 & -142.21 & 0.04 & 0.91 & 0.19 \\
\hline $\mathrm{rr}-13$ & 31.69685 & -111.0125167 & 1040.01 & 979112.40 & -25.6 & -141.98 & -142.22 & 0.04 & 0.9 & 0.18 \\
\hline $\mathrm{rr}-14$ & 31.6969 & -111.0130167 & 1038.41 & 979112.65 & -25.86 & -142.05 & -142.34 & 0 & 0.85 & 0.17 \\
\hline $\mathrm{rr}-15$ & 31.69695 & -111.0134833 & 1037.24 & 979112.78 & -26.1 & -142.16 & -142.45 & 0 & 0.85 & 0.17 \\
\hline $\mathrm{rr}-16$ & 31.69696667 & -111.0137167 & 1036.69 & 979112.87 & -26.18 & -142.18 & -142.47 & 0 & 0.85 & 0.17 \\
\hline $\mathrm{rr}-17$ & 31.69696667 & -111.0139833 & 1036.1 & 979112.95 & -26.28 & -142.21 & -142.5 & 0 & 0.85 & 0.17 \\
\hline $\mathrm{rr}-18$ & 31.69698333 & -111.01425 & 1035.29 & 979113.05 & -26.42 & -142.27 & -142.56 & 0 & 0.85 & 0.17 \\
\hline rr-19 & 31.697 & -111.01445 & 1034.95 & 979113.08 & -26.5 & -142.31 & -142.6 & 0 & 0.85 & 0.17 \\
\hline $\mathrm{rr}-20$ & 31.697 & -111.0146167 & 1034.51 & 979113.12 & -26.59 & -142.35 & -142.65 & 0 & 0.84 & 0.17 \\
\hline $\mathrm{rr}-21$ & 31.69698333 & -111.0148 & 1034.13 & 979113.14 & -26.69 & -142.41 & -142.69 & 0.01 & 0.86 & 0.18 \\
\hline $\mathrm{rr}-22$ & 31.69696667 & -111.0149667 & 1032.85 & 979113.36 & -26.87 & -142.44 & -142.72 & 0.02 & 0.86 & 0.18 \\
\hline rr-23 & 31.69696667 & -111.0151333 & 1031.38 & 979113.65 & -27.03 & -142.44 & -142.73 & 0 & 0.84 & 0.17 \\
\hline rr-24 & 31.69695 & -111.01535 & 1030.63 & 979113.76 & -27.15 & -142.47 & -142.76 & 0.01 & 0.85 & 0.17 \\
\hline $\mathrm{rr}-25$ & 31.69693333 & -111.0155833 & 1030.2 & 979113.75 & -27.29 & -142.57 & -142.86 & 0 & 0.84 & 0.17 \\
\hline $\mathrm{rr}-26$ & 31.69698333 & -111.0159 & 1029.36 & 979113.78 & -27.52 & -142.71 & -142.98 & 0 & 0.86 & 0.18 \\
\hline $\mathrm{rr}-27$ & 31.69693333 & -111.0160667 & 1028.82 & 979113.88 & -27.59 & -142.71 & -143 & 0 & 0.84 & 0.17 \\
\hline
\end{tabular}




\begin{tabular}{|c|c|c|c|c|c|c|c|c|c|c|}
\hline $\mathrm{rr}-28$ & 31.696866667 & -111.0165167 & 1026.79 & 979114.24 & -27.85 & -142.74 & -143.03 & 0 & 0.84 & 0.17 \\
\hline $\mathrm{rr}-29$ & 31.69688333 & -111.01695 & 1025.69 & 979114.30 & -28.13 & -142.9 & -143.19 & 0 & 0.84 & 0.17 \\
\hline $\mathrm{rr}-30$ & 31.6968 & -111.0174167 & 1024.41 & 979114.34 & -28.47 & -143.1 & -143.38 & 0 & 0.85 & 0.17 \\
\hline $\mathrm{rr}-31$ & 31.69676667 & -111.0177833 & 1023.64 & 979114.32 & -28.73 & -143.28 & -143.55 & 0 & 0.86 & 0.18 \\
\hline $\mathrm{rr}-32$ & 31.69675 & -111.0183333 & 1022.93 & 979114.31 & -28.96 & -143.43 & -143.7 & 0 & 0.85 & 0.17 \\
\hline $\mathrm{rr}-33$ & 31.6967 & -111.0188 & 1022.02 & 979114.34 & -29.21 & -143.57 & -143.86 & 0 & 0.84 & 0.17 \\
\hline rr-34 & 31.69665 & -111.0192333 & 1020.83 & 979114.42 & -29.49 & -143.72 & -144.02 & 0 & 0.83 & 0.17 \\
\hline $\mathrm{rr}-35$ & 31.69658333 & -111.0197 & 1019.67 & 979114.55 & -29.72 & -143.82 & -144.12 & 0 & 0.82 & 0.17 \\
\hline $\mathrm{rr}-36$ & 31.69643333 & -111.02035 & 1017.85 & 979114.71 & -30.1 & -143.99 & -144.3 & 0.02 & 0.82 & 0.17 \\
\hline rr-37 & 31.69638333 & -111.0214167 & 1015.77 & 979114.80 & -30.65 & -144.31 & -144.57 & 0 & 0.86 & 0.18 \\
\hline rr-38 & 31.69645 & -111.0224 & 1012.67 & 979115.18 & -31.23 & -144.55 & -144.81 & 0 & 0.86 & 0.18 \\
\hline rr-39 & 31.6965 & -111.0235333 & 1009.51 & 979115.50 & -31.89 & -144.85 & -145.19 & 0 & 0.78 & 0.16 \\
\hline rr-40 & 31.69655 & -111.0247667 & 1007.07 & 979115.71 & -32.44 & -145.13 & -145.47 & 0 & 0.77 & 0.16 \\
\hline $\mathrm{cw}-01$ & 31.64255 & -110.9738167 & 1154.56 & 979081.32 & -16.97 & -146.16 & -146.17 & 0.08 & 1.21 & 0.24 \\
\hline $\mathrm{cw}-02$ & 31.64255 & -110.9745167 & 1152.17 & 979082.82 & -16.2 & -145.13 & -145.23 & 0 & 1.12 & 0.23 \\
\hline $\mathrm{cw}-03$ & 31.64246667 & -110.9756 & 1149.3 & 979082.33 & -17.58 & -146.18 & -146.29 & 0 & 1.11 & 0.22 \\
\hline $\mathrm{cw}-04$ & 31.64241667 & -110.9768 & 1145.93 & 979083.19 & -17.74 & -145.97 & -146.1 & 0 & 1.09 & 0.22 \\
\hline $\mathrm{cw}-05$ & 31.64235 & -110.9778667 & 1142.15 & 979084.31 & -17.79 & -145.6 & -145.72 & 0 & 1.09 & 0.22 \\
\hline $\mathrm{cw}-06$ & 31.64226667 & -110.9791 & 1139.31 & 979085.44 & -17.52 & -145.01 & -145.14 & 0 & 1.08 & 0.22 \\
\hline $\mathrm{cw}-07$ & 31.64213333 & -110.98015 & 1136.19 & 979086.54 & -17.38 & -144.51 & -144.65 & 0 & 1.07 & 0.22 \\
\hline $\mathrm{cw}-08$ & 31.64191667 & -110.9812333 & 1133.03 & 979087.35 & -17.53 & -144.32 & -144.46 & 0 & 1.06 & 0.21 \\
\hline $\mathrm{cw}-09$ & 31.64166667 & -110.9822333 & 1130.48 & 979087.77 & -17.87 & -144.37 & -144.43 & 0.08 & 1.14 & 0.23 \\
\hline $\mathrm{cw}-10$ & 31.64156667 & -110.9832333 & 1130.14 & 979087.76 & -17.98 & -144.44 & -144.48 & 0.08 & 1.16 & 0.23 \\
\hline $\mathrm{cw}-11$ & 31.6419 & -110.9840833 & 1127.87 & 979088.09 & -18.38 & -144.59 & -144.53 & 0.17 & 1.26 & 0.25 \\
\hline $\mathrm{cw}-12$ & 31.64211667 & -110.9845667 & 1126.45 & 979088.27 & -18.65 & -144.7 & -144.56 & 0.26 & 1.34 & 0.27 \\
\hline $\mathrm{cw}-13$ & 31.64255 & -110.9855167 & 1121.71 & 979089.15 & -19.27 & -144.78 & -144.67 & 0.26 & 1.31 & 0.26 \\
\hline $\mathrm{cw}-14$ & 31.64271667 & -110.98605 & 1119.16 & 979089.60 & -19.62 & -144.85 & -144.76 & 0.26 & 1.29 & 0.26 \\
\hline $\mathrm{cw}-15$ & 31.64288333 & -110.9865833 & 1116.88 & 979090.03 & -19.91 & -144.89 & -144.84 & 0.22 & 1.24 & 0.25 \\
\hline $\mathrm{cw}-16$ & 31.6431 & -110.9871 & 1116.16 & 979090.18 & -20 & -144.89 & -144.92 & 0.15 & 1.17 & 0.24 \\
\hline $\mathrm{cw}-17$ & 31.64316667 & -110.9873833 & 1115.54 & 979090.22 & -20.15 & -144.98 & -145 & 0.15 & 1.18 & 0.24 \\
\hline cw-18 & 31.6431 & -110.9876833 & 1115.77 & 979089.98 & -20.32 & -145.17 & -145.09 & 0.26 & 1.27 & 0.26 \\
\hline cw-19 & 31.64306667 & -110.9879833 & 1116.07 & 979089.94 & -20.26 & -145.15 & -145.13 & 0.19 & 1.21 & 0.24 \\
\hline $\mathrm{cw}-20$ & 31.64306667 & -110.9882667 & 1115.99 & 979089.92 & -20.31 & -145.19 & -145.16 & 0.2 & 1.22 & 0.25 \\
\hline $\mathrm{cw}-21$ & 31.64308333 & -110.98885 & 1115.17 & 979089.98 & -20.51 & -145.29 & -145.21 & 0.26 & 1.28 & 0.26 \\
\hline $\mathrm{cw}-22$ & 31.64325 & -110.98935 & 1114.15 & 979090.14 & -20.67 & -145.34 & -145.26 & 0.24 & 1.27 & 0.26 \\
\hline $\mathrm{cw}-23$ & 31.64355 & -110.9897667 & 1111.3 & 979090.85 & -20.87 & -145.22 & -145.19 & 0.22 & 1.22 & 0.25 \\
\hline $\mathrm{cw}-24$ & 31.64371667 & -110.9902167 & 1111.27 & 979090.94 & -20.79 & -145.14 & -145.17 & 0.17 & 1.16 & 0.23 \\
\hline
\end{tabular}




\begin{tabular}{|c|c|c|c|c|c|c|c|c|c|c|}
\hline $\mathrm{cw}-25$ & 31.64373333 & -110.9906667 & 1113.45 & 979090.53 & -20.53 & -145.12 & -145.22 & 0.1 & 1.1 & 0.22 \\
\hline $\mathrm{cw}-26$ & 31.64376667 & -110.9911667 & 1115.71 & 979089.99 & -20.38 & -145.22 & -145.23 & 0.15 & 1.19 & 0.24 \\
\hline $\mathrm{cw}-27$ & 31.64386667 & -110.9916167 & 1116.78 & 979089.82 & -20.23 & -145.2 & -145.27 & 0.05 & 1.12 & 0.23 \\
\hline $\mathrm{cw}-28$ & 31.64398333 & -110.9921333 & 1117.16 & 979089.72 & -20.22 & -145.23 & -145.3 & 0.05 & 1.12 & 0.23 \\
\hline $\mathrm{cw}-29$ & 31.64385 & -110.9933167 & 1119.65 & 979089.15 & -20.01 & -145.3 & -145.32 & 0.04 & 1.17 & 0.24 \\
\hline $\mathrm{cw}-30$ & 31.6439 & -110.9944333 & 1120.9 & 979088.78 & -20 & -145.43 & -145.37 & 0.1 & 1.26 & 0.25 \\
\hline $\mathrm{cw}-31$ & 31.644 & -110.9954833 & 1116.5 & 979089.79 & -20.36 & -145.29 & -145.27 & 0.1 & 1.22 & 0.25 \\
\hline $\mathrm{cw}-32$ & 31.64393333 & -110.9965 & 1108.84 & 979091.52 & -20.98 & -145.06 & -145.13 & 0.11 & 1.12 & 0.23 \\
\hline $\mathrm{cw}-33$ & 31.6442 & -110.99765 & 1098.32 & 979094.00 & -21.77 & -144.67 & -144.93 & 0 & 0.92 & 0.19 \\
\hline cc-01 & 31.63365 & -110.9666167 & 1194.86 & 979078.43 & -6.7 & -140.41 & -140.08 & 0.08 & 1.57 & 0.32 \\
\hline cc- 02 & 31.63386667 & -110.96845 & 1195.26 & 979078.19 & -6.84 & -140.59 & -140.09 & 0.02 & 1.74 & 0.35 \\
\hline cc- 03 & 31.63366667 & -110.9703167 & 1190.55 & 979078.77 & -7.7 & -140.92 & -140.72 & 0.02 & 1.44 & 0.29 \\
\hline cc-04 & 31.63368333 & -110.97195 & 1185.36 & 979079.16 & -8.91 & -141.55 & -141.41 & 0.02 & 1.38 & 0.28 \\
\hline cc-05 & 31.63408333 & -110.97345 & 1171.65 & 979080.61 & -11.72 & -142.83 & -142.9 & 0.02 & 1.16 & 0.23 \\
\hline cc-06 & 31.63513333 & -110.9754833 & 1173.8 & 979079.02 & -12.74 & -144.08 & -144.12 & 0 & 1.19 & 0.24 \\
\hline cc-07 & 31.63521667 & -110.9767167 & 1173.71 & 979078.68 & -13.1 & -144.44 & -144.46 & 0 & 1.21 & 0.24 \\
\hline cc- 08 & 31.63538333 & -110.9773667 & 1172.53 & 979078.66 & -13.51 & -144.71 & -144.23 & 0.51 & 1.71 & 0.34 \\
\hline cc-09 & 31.63528333 & -110.9781833 & 1170.97 & 979079.03 & -13.61 & -144.64 & -144.69 & 0 & 1.18 & 0.24 \\
\hline cc-10 & 31.63523333 & -110.9790833 & 1168.94 & 979079.35 & -13.91 & -144.71 & -144.78 & 0 & 1.16 & 0.23 \\
\hline cc-11 & 31.63513333 & -110.9803 & 1166.11 & 979079.88 & -14.25 & -144.73 & -144.82 & 0 & 1.14 & 0.23 \\
\hline cc-12 & 31.635 & -110.9812667 & 1163.94 & 979080.23 & -14.55 & -144.8 & -144.87 & 0 & 1.15 & 0.23 \\
\hline cc-13 & 31.63486667 & -110.9826 & 1160.69 & 979080.75 & -15.02 & -144.9 & -144.95 & 0 & 1.18 & 0.24 \\
\hline cc-14 & 31.63473333 & -110.9822167 & 1159.5 & 979080.84 & -15.3 & -145.04 & -145.08 & 0 & 1.19 & 0.24 \\
\hline cc-15 & 31.6347 & -110.9824667 & 1158.81 & 979080.94 & -15.41 & -145.07 & -145.08 & 0 & 1.22 & 0.25 \\
\hline cc-16 & 31.64663333 & -110.9827333 & 1158.1 & 979081.04 & -15.53 & -145.12 & -145.12 & 0 & 1.22 & 0.25 \\
\hline cc-17 & 31.6347 & -110.9835833 & 1157.58 & 979081.07 & -15.65 & -145.19 & -145.18 & 0 & 1.23 & 0.25 \\
\hline cc-18 & 31.63461667 & -110.9842 & 1155.9 & 979081.32 & -15.91 & -145.25 & -145.22 & 0 & 1.25 & 0.25 \\
\hline cc-19 & 31.63445 & -110.9848833 & 1154 & 979081.57 & -16.24 & -145.37 & -145.29 & 0 & 1.3 & 0.26 \\
\hline cc-20 & 31.63433333 & -110.98535 & 1152.71 & 979081.75 & -16.44 & -145.43 & -145.33 & 0 & 1.32 & 0.27 \\
\hline cc-21 & 31.63421667 & -110.9857667 & 1151.45 & 979081.94 & -16.64 & -145.48 & -145.39 & 0 & 1.31 & 0.26 \\
\hline cc-22 & 31.63416667 & -110.9862167 & 1150.11 & 979082.10 & -16.88 & -145.58 & -145.51 & 0 & 1.28 & 0.26 \\
\hline cc-23 & 31.63411667 & -110.9866333 & 1148.82 & 979082.36 & -17.02 & -145.57 & -145.52 & 0 & 1.27 & 0.26 \\
\hline cc-24 & 31.63408333 & -110.9869833 & 1147.62 & 979082.54 & -17.2 & -145.62 & -145.55 & 0 & 1.28 & 0.26 \\
\hline cc-25 & 31.63405 & -110.98725 & 1146.7 & 979082.65 & -17.37 & -145.69 & -145.61 & 0 & 1.29 & 0.26 \\
\hline cc-26 & 31.634 & -110.9875833 & 1145.51 & 979082.86 & -17.53 & -145.71 & -145.61 & 0.04 & 1.31 & 0.26 \\
\hline cc-27 & 31.634 & -110.9878167 & 1143.99 & 979083.14 & -17.72 & -145.73 & -145.58 & 0.09 & 1.36 & 0.27 \\
\hline cc-28 & 31.63396667 & -110.9880333 & 1142.49 & 979083.43 & -17.89 & -145.73 & -145.57 & 0.09 & 1.37 & 0.28 \\
\hline
\end{tabular}




\begin{tabular}{|c|c|c|c|c|c|c|c|c|c|c|}
\hline cc-29 & 31.63395 & -110.9882 & 1141.29 & 979083.67 & -18.01 & -145.72 & -145.64 & 0 & 1.29 & 0.26 \\
\hline cc-30 & 31.63396667 & -110.9884 & 1141.35 & 979083.68 & -17.99 & -145.7 & -145.54 & 0.02 & 1.37 & 0.28 \\
\hline cc-31 & 31.63395 & -110.9887833 & 1140.42 & 979083.86 & -18.09 & -145.7 & -145.49 & 0 & 1.42 & 0.29 \\
\hline cc-32 & 31.63391667 & -110.9891667 & 1139.45 & 979084.07 & -18.18 & -145.68 & -145.41 & 0 & 1.48 & 0.3 \\
\hline cc-33 & 31.6339 & -110.9895333 & 1138.54 & 979084.27 & -18.26 & -145.66 & -145.37 & 0 & 1.5 & 0.3 \\
\hline cc-34 & 31.63388333 & -110.9899333 & 1137.53 & 979084.48 & -18.36 & -145.65 & -145.4 & 0 & 1.46 & 0.29 \\
\hline cc-35 & 31.63385 & -110.99045 & 1136.12 & 979084.77 & -18.5 & -145.63 & -145.48 & 0 & 1.36 & 0.27 \\
\hline cc-36 & 31.63383333 & -110.9908167 & 1135.2 & 979085.00 & -18.55 & -145.58 & -145.5 & 0 & 1.29 & 0.26 \\
\hline cc-37 & 31.6338 & -110.9911833 & 1134.23 & 979085.16 & -18.69 & -145.61 & -145.57 & 0 & 1.24 & 0.25 \\
\hline cc-38 & 31.63378333 & -110.9916833 & 1132.96 & 979085.43 & -18.82 & -145.59 & -145.57 & 0 & 1.23 & 0.25 \\
\hline cc-39 & 31.63373333 & -110.9921833 & 1131.74 & 979085.67 & -18.94 & -145.58 & -145.58 & 0 & 1.21 & 0.24 \\
\hline cc- 40 & 31.63363333 & -110.9930167 & 1129.59 & 979086.08 & -19.2 & -145.59 & -145.53 & 0 & 1.27 & 0.26 \\
\hline cc-41 & 31.6335 & -110.9939 & 1127.35 & 979086.47 & -19.48 & -145.63 & -145.57 & 0 & 1.26 & 0.25 \\
\hline cc-42 & 31.63338333 & -110.9949 & 1124.72 & 979086.92 & -19.83 & -145.68 & -145.76 & 0 & 1.12 & 0.23 \\
\hline cc-43 & 31.63328333 & -110.9957667 & 1122.36 & 979087.35 & -20.13 & -145.72 & -145.86 & 0 & 1.05 & 0.21 \\
\hline
\end{tabular}


APPENDIX B: TRUCK MAGNETIC DATA

\begin{tabular}{|c|c|c|c|c|c|c|}
\hline Station ID & Lat. Deg. & Long. Deg. & $\begin{array}{l}\text { Elev } \\
(\mathrm{m})\end{array}$ & $\begin{array}{c}\text { Observed*100 } \\
\text { (nT) }\end{array}$ & IGRF*100 (nT) & $\begin{array}{l}\text { Heading Corrected } \\
\text { Field*100 (nT) }\end{array}$ \\
\hline rr-mag-01 & 31.69873056 & -111.0254806 & 1007 & 4790837 & -82656 & -33282 \\
\hline rr-mag-02 & 31.69868056 & -111.0253306 & 1007 & 4792418 & -81073 & -32435 \\
\hline rr-mag-03 & 31.69863056 & -111.0251667 & 1008 & 4792836 & -80656 & -35513 \\
\hline rr-mag-04 & 31.69859722 & -111.025 & 1008 & 4791983 & -81510 & -33637 \\
\hline rr-mag-05 & 31.69855 & -111.0248306 & 1009 & 4790502 & -82991 & -34851 \\
\hline rr-mag-06 & 31.69849722 & -111.0246472 & 1009 & 4793206 & -80287 & -32278 \\
\hline rr-mag-07 & 31.69845 & -111.0244806 & 1009 & 4793260 & -80233 & -32093 \\
\hline rr-mag-08 & 31.69839722 & -111.0242972 & 1010 & 4789451 & -84043 & -36034 \\
\hline rr-mag-09 & 31.69835 & -111.0241306 & 1010 & 4795982 & -77511 & -29371 \\
\hline rr-mag-10 & 31.69829722 & -111.0239472 & 1011 & 4790287 & -83205 & -35196 \\
\hline rr-mag-11 & 31.69825 & -111.0237806 & 1011 & 4791929 & -81563 & -31758 \\
\hline rr-mag-12 & 31.69819722 & -111.0236306 & 1011 & 4795709 & -77783 & -29145 \\
\hline rr-mag-13 & 31.69814722 & -111.0234667 & 1012 & 4791147 & -82345 & -33442 \\
\hline rr-mag-14 & 31.6981 & -111.0233167 & 1012 & 4793934 & -79558 & -33555 \\
\hline rr-mag-15 & 31.69806667 & -111.0231667 & 1013 & 4791699 & -81790 & -32416 \\
\hline rr-mag-16 & 31.69801667 & -111.0230167 & 1013 & 4791790 & -81698 & -32324 \\
\hline rr-mag-17 & 31.69796667 & -111.0228667 & 1013 & 4792676 & -80812 & -34149 \\
\hline rr-mag-18 & 31.69793056 & -111.0227167 & 1013 & 4792388 & -81102 & -35016 \\
\hline rr-mag-19 & 31.6979 & -111.0225806 & 1014 & 4791264 & -82225 & -36223 \\
\hline rr-mag-20 & 31.69786667 & -111.0224306 & 1014 & 4789553 & -83937 & -36126 \\
\hline rr-mag-21 & 31.69783056 & -111.0223 & 1015 & 4791857 & -81633 & -35377 \\
\hline rr-mag-22 & 31.6978 & -111.0221667 & 1015 & 4793120 & -80372 & -33567 \\
\hline rr-mag-23 & 31.69776667 & -111.0220306 & 1015 & 4792141 & -81353 & -34690 \\
\hline rr-mag-24 & 31.69773056 & -111.0218806 & 1016 & 4792587 & -80904 & -35613 \\
\hline rr-mag-25 & 31.6977 & -111.0217306 & 1016 & 4792557 & -80935 & -33785 \\
\hline rr-mag-26 & 31.697666667 & -111.0216 & 1017 & 4795209 & -78284 & -30647 \\
\hline rr-mag-27 & 31.69763056 & -111.0214667 & 1017 & 4797938 & -75554 & -35350 \\
\hline rr-mag-28 & 31.69761667 & -111.0213306 & 1017 & 4798070 & -75424 & -32748 \\
\hline rr-mag-29 & 31.6976 & -111.0212167 & 1018 & 4796681 & -76814 & -31898 \\
\hline rr-mag-30 & 31.69758056 & -111.0211167 & 1018 & 4792598 & -80897 & -38611 \\
\hline rr-mag-31 & 31.69756667 & -111.0210167 & 1018 & 4795276 & -78220 & -32086 \\
\hline rr-mag-32 & 31.69754722 & -111.0209306 & 1018 & 4797831 & -75665 & -30523 \\
\hline rr-mag-33 & 31.69753056 & -111.0208472 & 1019 & 4798183 & -75313 & -31361 \\
\hline rr-mag-34 & 31.69751667 & -111.0207667 & 1019 & 4794573 & -78924 & -34046 \\
\hline rr-mag-35 & 31.6975 & -111.0206806 & 1019 & 4793971 & -79526 & -32841 \\
\hline rr-mag-36 & 31.69748056 & -111.0206 & 1019 & 4793968 & -79529 & -37444 \\
\hline rr-mag-37 & 31.69746667 & -111.0204972 & 1019 & 4800498 & -73001 & -28086 \\
\hline rr-mag-38 & 31.69744722 & -111.0203972 & 1020 & 4798427 & -75072 & -43154 \\
\hline rr-mag-39 & 31.69744722 & -111.0202806 & 1020 & 4795326 & -78174 & -29523 \\
\hline rr-mag-40 & 31.69741667 & -111.0201806 & 1021 & 4794111 & -79388 & -36738 \\
\hline rr-mag-41 & 31.69739722 & -111.0200472 & 1021 & 4801738 & -71763 & -29268 \\
\hline rr-mag-42 & 31.69738056 & -111.0199306 & 1021 & 4795967 & -77536 & -37073 \\
\hline rr-mag-43 & 31.69736667 & -111.0198 & 1022 & 4798875 & -74630 & -33099 \\
\hline rr-mag-44 & 31.69735 & -111.0196667 & 1022 & 4797429 & -76077 & -32580 \\
\hline rr-mag-45 & 31.69733056 & -111.0195472 & 1022 & 4799585 & -73922 & -33459 \\
\hline rr-mag-46 & 31.69731667 & -111.0194167 & 1022 & 4802145 & -71364 & -39446 \\
\hline rr-mag-47 & 31.69731667 & -111.0193 & 1023 & 4802202 & -71308 & -39390 \\
\hline rr-mag-48 & 31.69731667 & -111.0191667 & 1023 & 4808369 & -65144 & -43976 \\
\hline rr-mag-49 & 31.69733056 & -111.0190306 & 1023 & 4806933 & -66584 & -34666 \\
\hline rr-mag-50 & 31.69733056 & -111.0189 & 1024 & 4806775 & -66743 & -49958 \\
\hline rr-mag-51 & 31.69735 & -111.0187667 & 1024 & 4806125 & -67397 & -48443 \\
\hline
\end{tabular}




\begin{tabular}{|c|c|c|c|c|c|c|}
\hline rr-mag-52 & 31.69736667 & -111.0186306 & 1025 & 4806999 & -66525 & -44342 \\
\hline rr-mag-53 & 31.69738056 & -111.0184806 & 1025 & 4811001 & -62527 & -30609 \\
\hline rr-mag-54 & 31.69738056 & -111.0183472 & 1025 & 4807004 & -66526 & -46339 \\
\hline rr-mag-55 & 31.69739722 & -111.0181972 & 1025 & 4808184 & -65351 & -48836 \\
\hline rr-mag-56 & 31.69741667 & -111.0180667 & 1026 & 4807760 & -65778 & -53694 \\
\hline rr-mag-57 & 31.69744722 & -111.0179167 & 1026 & 4809052 & -64490 & -47443 \\
\hline rr-mag-58 & 31.69746667 & -111.0177806 & 1026 & 4807835 & -65710 & -43528 \\
\hline rr-mag-59 & 31.69748056 & -111.0176306 & 1027 & 4809249 & -64301 & -54508 \\
\hline rr-mag-60 & 31.69751667 & -111.0174806 & 1027 & 4805640 & -67914 & -35996 \\
\hline rr-mag-61 & 31.69751667 & -111.0173306 & 1028 & 4804832 & -68723 & -46541 \\
\hline rr-mag-62 & 31.69753056 & -111.0171806 & 1028 & 4805144 & -68415 & -36497 \\
\hline rr-mag-63 & 31.69753056 & -111.0170472 & 1029 & 4799694 & -73868 & -41950 \\
\hline rr-mag-64 & 31.69753056 & -111.0169 & 1029 & 4798496 & -75069 & -35440 \\
\hline rr-mag-65 & 31.69751667 & -111.01675 & 1029 & 4795038 & -78528 & -32017 \\
\hline rr-mag-66 & 31.69748056 & -111.0165972 & 1030 & 4796894 & -76674 & -36938 \\
\hline rr-mag-67 & 31.69746667 & -111.01645 & 1030 & 4794386 & -79184 & -36534 \\
\hline rr-mag-68 & 31.69744722 & -111.0163167 & 1030 & 4783328 & -90242 & -46560 \\
\hline rr-mag-69 & 31.69739722 & -111.0160167 & 1031 & 4788979 & -84593 & -42098 \\
\hline rr-mag-70 & 31.69738056 & -111.0159 & 1032 & 4789105 & -84467 & -44136 \\
\hline rr-mag-71 & 31.69736667 & -111.0157667 & 1033 & 4785298 & -88276 & -44594 \\
\hline rr-mag-72 & 31.69735 & -111.0156667 & 1033 & 4797379 & -76196 & -31281 \\
\hline rr-mag-73 & 31.69733056 & -111.0155667 & 1034 & 4796603 & -76971 & -35774 \\
\hline rr-mag-74 & 31.69731667 & -111.01545 & 1034 & 4795532 & -78044 & -34547 \\
\hline rr-mag-75 & 31.69729722 & -111.0153306 & 1035 & 4799131 & -74446 & -32915 \\
\hline rr-mag-76 & 31.69728056 & -111.0151972 & 1035 & 4794198 & -79381 & -38184 \\
\hline rr-mag-77 & 31.69726667 & -111.0150806 & 1035 & 4797921 & -75658 & -34127 \\
\hline rr-mag-78 & 31.69725 & -111.0149472 & 1036 & 4797565 & -76014 & -34228 \\
\hline rr-mag-79 & 31.69723056 & -111.0147972 & 1036 & 4797217 & -76365 & -29216 \\
\hline rr-mag-80 & 31.69719722 & -111.0146667 & 1036 & 4796602 & -76980 & -35591 \\
\hline rr-mag-81 & 31.69718056 & -111.0145306 & 1037 & 4798829 & -74753 & -35125 \\
\hline rr-mag-82 & 31.69716667 & -111.0143806 & 1037 & 4796432 & -77153 & -35475 \\
\hline rr-mag-83 & 31.69715 & -111.01425 & 1037 & 4796207 & -77378 & -30403 \\
\hline rr-mag-84 & 31.69711667 & -111.0141167 & 1038 & 4797160 & -76424 & -33929 \\
\hline rr-mag- 85 & 31.69709722 & -111.0139806 & 1038 & 4797002 & -76582 & -35842 \\
\hline rr-mag-86 & 31.69708056 & -111.0138306 & 1039 & 4798936 & -74651 & -28222 \\
\hline rr-mag-87 & 31.69705 & -111.0137 & 1039 & 4799215 & -74371 & -31721 \\
\hline rr-mag-88 & 31.69703056 & -111.0135667 & 1040 & 4799150 & -74439 & -34235 \\
\hline rr-mag-89 & 31.69701667 & -111.0134306 & 1040 & 4799120 & -74470 & -31661 \\
\hline rr-mag-90 & 31.69699722 & -111.0133 & 1041 & 4792723 & -80870 & -34614 \\
\hline rr-mag-91 & 31.69696667 & -111.0131667 & 1041 & 4796943 & -76649 & -35261 \\
\hline rr-mag-92 & 31.69695 & -111.0130306 & 1042 & 4797581 & -76012 & -32139 \\
\hline rr-mag-93 & 31.69693056 & -111.0129167 & 1042 & 4799003 & -74592 & -34388 \\
\hline rr-mag-94 & 31.69691667 & -111.0127806 & 1043 & 4797416 & -76179 & -32306 \\
\hline rr-mag-95 & 31.69689722 & -111.0126667 & 1044 & 4799434 & -74160 & -32772 \\
\hline rr-mag-96 & 31.69688056 & -111.0125306 & 1044 & 4802292 & -71303 & -26012 \\
\hline rr-mag-97 & 31.69685 & -111.0123806 & 1045 & 4800608 & -72988 & -30338 \\
\hline rr-mag-98 & 31.69683056 & -111.0122472 & 1045 & 4801305 & -72296 & -32560 \\
\hline rr-mag-99 & 31.69681667 & -111.0121 & 1046 & 4804986 & -68617 & -22106 \\
\hline rr-mag-100 & 31.69678056 & -111.0119472 & 1046 & 4804551 & -69051 & -28589 \\
\hline rr-mag-101 & 31.69676667 & -111.0118167 & 1047 & 4807473 & -66129 & -25389 \\
\hline rr-mag-102 & 31.69675 & -111.0116667 & 1048 & 4808877 & -64726 & -18724 \\
\hline rr-mag-103 & 31.69671667 & -111.0115167 & 1048 & 4808160 & -65444 & -23658 \\
\hline rr-mag-104 & 31.69669722 & -111.0113667 & 1049 & 4806686 & -66920 & -25532 \\
\hline rr-mag-105 & 31.69668056 & -111.0112306 & 1050 & 4811923 & -61683 & -22055 \\
\hline rr-mag-106 & 31.696666667 & -111.0110806 & 1050 & 4811105 & -62502 & -14865 \\
\hline rr-mag-107 & 31.69663056 & -111.0109472 & 1051 & 4807950 & -65657 & -25195 \\
\hline rr-mag-108 & 31.69661667 & -111.0108167 & 1052 & 4805982 & -67627 & -25307 \\
\hline
\end{tabular}




\begin{tabular}{|c|c|c|c|c|c|c|}
\hline rr-mag-109 & 31.6966 & -111.0106972 & 1052 & 4764818 & -108792 & -65110 \\
\hline rr-mag-110 & 31.69658056 & -111.0105806 & 1053 & 4789811 & -83798 & -42438 \\
\hline rr-mag-111 & 31.69656667 & -111.0104667 & 1053 & 4808018 & -65592 & -20677 \\
\hline rr-mag-112 & 31.69654722 & -111.0103667 & 1054 & 4806844 & -66767 & -24447 \\
\hline rr-mag-113 & 31.69653056 & -111.0102472 & 1054 & 4804352 & -69262 & -37344 \\
\hline rr-mag-114 & 31.69653056 & -111.0101472 & 1055 & 4804850 & -68765 & -19877 \\
\hline rr-mag-115 & 31.6965 & -111.01005 & 1055 & 4809666 & -63947 & -20451 \\
\hline rr-mag-116 & 31.69648056 & -111.0099306 & 1056 & 4808338 & -65278 & -23918 \\
\hline rr-mag-117 & 31.69646667 & -111.0098167 & 1056 & 4810979 & -62639 & -30721 \\
\hline rr-mag-118 & 31.69646667 & -111.0096806 & 1057 & 4814389 & -59230 & -27312 \\
\hline rr-mag-119 & 31.69646667 & -111.0095667 & 1057 & 4818316 & -55306 & -23388 \\
\hline rr-mag-120 & 31.69646667 & -111.00945 & 1058 & 4819185 & -54439 & -33500 \\
\hline rr-mag-121 & 31.69648056 & -111.0093167 & 1058 & 4822776 & -50851 & -33803 \\
\hline rr-mag-122 & 31.6965 & -111.0091806 & 1059 & 4821917 & -51712 & -33268 \\
\hline rr-mag-123 & 31.69651667 & -111.00905 & 1060 & 4822069 & -51564 & -30625 \\
\hline rr-mag-124 & 31.69653056 & -111.0089167 & 1060 & 4823272 & -50364 & -41828 \\
\hline rr-mag-125 & 31.696566667 & -111.0087806 & 1060 & 4821755 & -51885 & -29702 \\
\hline rr-mag-126 & 31.69658056 & -111.0086306 & 1061 & 4820797 & -52846 & -34588 \\
\hline rr-mag-127 & 31.6966 & -111.0084806 & 1061 & 4820638 & -53009 & -32822 \\
\hline rr-mag-128 & 31.69661667 & -111.0083306 & 1062 & 4818810 & -54840 & -31823 \\
\hline rr-mag-129 & 31.69663056 & -111.0081667 & 1062 & 4823066 & -50589 & -18671 \\
\hline rr-mag-130 & 31.69663056 & -111.0080167 & 1062 & 4817546 & -56112 & -36529 \\
\hline rr-mag-131 & 31.69665 & -111.00785 & 1063 & 4823819 & -49839 & -28275 \\
\hline rr-mag-132 & 31.696666667 & -111.0076806 & 1063 & 4815194 & -58469 & -26551 \\
\hline rr-mag-133 & 31.69666667 & -111.0075167 & 1064 & 4815085 & -58581 & -35414 \\
\hline rr-mag-134 & 31.69668056 & -111.00735 & 1064 & 4814952 & -58719 & -37155 \\
\hline rr-mag-135 & 31.69669722 & -111.0071806 & 1064 & 4814834 & -58841 & -26923 \\
\hline rr-mag-136 & 31.69669722 & -111.0070167 & 1065 & 4813840 & -59837 & -27919 \\
\hline rr-mag-137 & 31.69669722 & -111.0068306 & 1065 & 4813806 & -59875 & -39141 \\
\hline rr-mag-138 & 31.69671667 & -111.0066472 & 1065 & 4810505 & -63179 & -31261 \\
\hline rr-mag-139 & 31.69671667 & -111.0064667 & 1066 & 4813806 & -59883 & -35824 \\
\hline rr-mag-140 & 31.69673056 & -111.0062806 & 1066 & 4810367 & -63326 & -31408 \\
\hline rr-mag-141 & 31.69673056 & -111.0060806 & 1066 & 4810066 & -63631 & -31713 \\
\hline rr-mag-142 & 31.69673056 & -111.0058972 & 1067 & 4811677 & -62022 & -41464 \\
\hline cw-mag-01 & 31.64266667 & -110.9755472 & 1154 & 4787165 & -85750 & -28180 \\
\hline cw-mag-02 & 31.64264722 & -110.9755472 & 1154 & 4787221 & -85692 & -33956 \\
\hline cw-mag-03 & 31.64264722 & -110.9755667 & 1154 & 4783299 & -89615 & -37879 \\
\hline cw-mag-04 & 31.64264722 & -110.9756167 & 1154 & 4786730 & -86183 & -62962 \\
\hline cw-mag-05 & 31.64266667 & -110.9756667 & 1153 & 4789235 & -83679 & -31943 \\
\hline cw-mag-06 & 31.64266667 & -110.9757 & 1153 & 4790253 & -82660 & -30924 \\
\hline cw-mag-07 & 31.64266667 & -110.9757806 & 1153 & 4788557 & -84355 & -27297 \\
\hline cw-mag-08 & 31.64264722 & -110.9758972 & 1153 & 4789114 & -83793 & -32057 \\
\hline cw-mag-09 & 31.64264722 & -110.9759472 & 1153 & 4788172 & -84734 & -32998 \\
\hline cw-mag-10 & 31.64264722 & -110.9759972 & 1153 & 4790231 & -82675 & -30939 \\
\hline cw-mag-11 & 31.64264722 & -110.97605 & 1153 & 4789369 & -83537 & -26934 \\
\hline cw-mag-12 & 31.64263056 & -110.9761667 & 1152 & 4791996 & -80906 & -29170 \\
\hline cw-mag-13 & 31.64263056 & -110.9762 & 1152 & 4793488 & -79413 & -27677 \\
\hline cw-mag-14 & 31.64263056 & -110.9762306 & 1152 & 4793912 & -78989 & -58841 \\
\hline cw-mag-15 & 31.64264722 & -110.9762667 & 1152 & 4792143 & -80758 & -22530 \\
\hline cw-mag-16 & 31.64263056 & -110.9763306 & 1152 & 4786740 & -86158 & -29639 \\
\hline cw-mag-17 & 31.64261667 & -110.9764306 & 1152 & 4795015 & -77879 & -26143 \\
\hline cw-mag-18 & 31.64261667 & -110.9764667 & 1151 & 4795380 & -77515 & -25779 \\
\hline cw-mag-19 & 31.64261667 & -110.9765 & 1151 & 4794854 & -78040 & -26304 \\
\hline cw-mag-20 & 31.64261667 & -110.9765306 & 1151 & 4792615 & -80278 & -28542 \\
\hline cw-mag-21 & 31.64261667 & -110.9765806 & 1151 & 4793602 & -79290 & -27554 \\
\hline cw-mag-22 & 31.64261667 & -110.9766167 & 1151 & 4790101 & -82791 & -31055 \\
\hline cw-mag-23 & 31.64261667 & -110.97665 & 1151 & 4787100 & -85792 & -34056 \\
\hline
\end{tabular}




\begin{tabular}{|c|c|c|c|c|c|c|}
\hline cw-mag-24 & 31.64261667 & -110.9766972 & 1151 & 4786671 & -86220 & -34484 \\
\hline cw-mag-25 & 31.64261667 & -110.9767806 & 1150 & 4783232 & -89658 & -37922 \\
\hline cw-mag-26 & 31.64261667 & -110.9768306 & 1150 & 4777542 & -95348 & -37858 \\
\hline cw-mag-27 & 31.6426 & -110.9769167 & 1150 & 4792139 & -80748 & -29012 \\
\hline cw-mag-28 & 31.6426 & -110.9769806 & 1150 & 4796142 & -76745 & -25009 \\
\hline cw-mag-29 & 31.6426 & -110.9770667 & 1150 & 4791117 & -81767 & -30031 \\
\hline cw-mag-30 & 31.6426 & -110.9770972 & 1149 & 4792240 & -80644 & -21687 \\
\hline cw-mag-31 & 31.64258056 & -110.9771306 & 1149 & 4789679 & -83203 & -31467 \\
\hline cw-mag-32 & 31.64258056 & -110.9771806 & 1149 & 4787641 & -85240 & -33504 \\
\hline cw-mag-33 & 31.64258056 & -110.9772667 & 1149 & 4786717 & -86163 & -34427 \\
\hline cw-mag-34 & 31.64258056 & -110.9772972 & 1149 & 4788720 & -84159 & -27101 \\
\hline cw-mag-35 & 31.64256667 & -110.9773806 & 1148 & 4790086 & -82793 & -31057 \\
\hline cw-mag-36 & 31.64256667 & -110.97745 & 1148 & 4789438 & -83439 & -25378 \\
\hline cw-mag-37 & 31.64254722 & -110.9775306 & 1148 & 4794544 & -78330 & -26594 \\
\hline cw-mag-38 & 31.64254722 & -110.9775667 & 1148 & 4787985 & -84889 & -33153 \\
\hline cw-mag-39 & 31.64254722 & -110.9775972 & 1147 & 4786262 & -86611 & -34875 \\
\hline cw-mag-40 & 31.64254722 & -110.9776472 & 1147 & 4786034 & -86839 & -28791 \\
\hline cw-mag-41 & 31.64253056 & -110.9777167 & 1147 & 4787277 & -85593 & -33857 \\
\hline cw-mag-42 & 31.64253056 & -110.9777667 & 1147 & 4794209 & -78660 & -20850 \\
\hline cw-mag-43 & 31.64251667 & -110.9778306 & 1147 & 4788239 & -84627 & -32891 \\
\hline cw-mag-44 & 31.64251667 & -110.9779 & 1147 & 4793555 & -79309 & -27573 \\
\hline cw-mag-45 & 31.64251667 & -110.9779306 & 1146 & 4794458 & -78406 & -26670 \\
\hline cw-mag-46 & 31.64251667 & -110.9779806 & 1146 & 4795449 & -77414 & -53975 \\
\hline cw-mag-47 & 31.64253056 & -110.9780167 & 1146 & 4797420 & -75443 & -23707 \\
\hline cw-mag-48 & 31.64253056 & -110.9780972 & 1146 & 4800082 & -72781 & -21045 \\
\hline cw-mag-49 & 31.64253056 & -110.9781667 & 1145 & 4796266 & -76595 & -57778 \\
\hline cw-mag-50 & 31.64254722 & -110.9782 & 1145 & 4795605 & -77257 & -25521 \\
\hline cw-mag-51 & 31.64254722 & -110.9782806 & 1145 & 4793247 & -79614 & -21566 \\
\hline cw-mag-52 & 31.64253056 & -110.97835 & 1145 & 4786275 & -86581 & -34845 \\
\hline cw-mag-53 & 31.64253056 & -110.9783806 & 1145 & 4791597 & -81259 & -29523 \\
\hline cw-mag-54 & 31.64253056 & -110.9784306 & 1145 & 4787031 & -85824 & -27024 \\
\hline cw-mag-55 & 31.64251667 & -110.9784667 & 1145 & 4785749 & -87105 & -35369 \\
\hline cw-mag-56 & 31.64251667 & -110.9785667 & 1144 & 4787213 & -85640 & -26831 \\
\hline cw-mag-57 & 31.64249722 & -110.9786167 & 1144 & 4790066 & -82785 & -31049 \\
\hline cw-mag-58 & 31.64249722 & -110.9786667 & 1144 & 4794644 & -78207 & -26471 \\
\hline cw-mag-59 & 31.64249722 & -110.9787167 & 1144 & 4789796 & -83055 & -31319 \\
\hline cw-mag-60 & 31.64249722 & -110.9788 & 1144 & 4789532 & -83316 & -26175 \\
\hline cw-mag-61 & 31.64248056 & -110.9788972 & 1144 & 4791682 & -81162 & -29426 \\
\hline cw-mag-62 & 31.64248056 & -110.9789306 & 1144 & 4793365 & -79479 & -21128 \\
\hline cw-mag-63 & 31.64246667 & -110.9789806 & 1144 & 4789133 & -83710 & -31974 \\
\hline cw-mag-64 & 31.64246667 & -110.9790306 & 1144 & 4788273 & -84568 & -32832 \\
\hline cw-mag-65 & 31.64246667 & -110.9791167 & 1143 & 4793366 & -79473 & -20831 \\
\hline cw-mag-66 & 31.64245 & -110.9791667 & 1143 & 4786322 & -86515 & -34779 \\
\hline cw-mag-67 & 31.64245 & -110.9792167 & 1143 & 4788144 & -84692 & -32956 \\
\hline cw-mag-68 & 31.64245 & -110.9792667 & 1143 & 4786489 & -86347 & -34611 \\
\hline cw-mag-69 & 31.64245 & -110.9793667 & 1142 & 4788159 & -84674 & -26613 \\
\hline cw-mag-70 & 31.64243056 & -110.9794472 & 1142 & 4787433 & -85398 & -33662 \\
\hline cw-mag-71 & 31.64243056 & -110.9795 & 1142 & 4789503 & -83326 & -26168 \\
\hline cw-mag-72 & 31.64241667 & -110.9795806 & 1142 & 4788429 & -84399 & -32663 \\
\hline cw-mag-73 & 31.64241667 & -110.97965 & 1142 & 4784577 & -88249 & -36513 \\
\hline cw-mag-74 & 31.64241667 & -110.9796972 & 1142 & 4781749 & -91077 & -32120 \\
\hline cw-mag-75 & 31.64239722 & -110.9797306 & 1142 & 4796788 & -76037 & -24301 \\
\hline cw-mag-76 & 31.64239722 & -110.9797667 & 1142 & 4789850 & -82975 & -25299 \\
\hline cw-mag-77 & 31.64238056 & -110.9798472 & 1141 & 4786883 & -85938 & -27076 \\
\hline cw-mag-78 & 31.64236667 & -110.9798806 & 1141 & 4786727 & -86094 & -34358 \\
\hline cw-mag-79 & 31.64236667 & -110.97995 & 1141 & 4788306 & -84514 & -26838 \\
\hline cw-mag- 80 & 31.64235 & -110.9800306 & 1141 & 4787121 & -85697 & -33961 \\
\hline
\end{tabular}




\begin{tabular}{|c|c|c|c|c|c|c|}
\hline cw-mag-81 & 31.64235 & -110.9800667 & 1140 & 4787057 & -85761 & -34025 \\
\hline cw-mag-82 & 31.64235 & -110.9801167 & 1140 & 4782884 & -89933 & -38197 \\
\hline cw-mag-83 & 31.64235 & -110.9801472 & 1140 & 4773503 & -99313 & -41330 \\
\hline cw-mag-84 & 31.64233056 & -110.9802306 & 1140 & 4790376 & -82437 & -30701 \\
\hline cw-mag-85 & 31.64233056 & -110.9803306 & 1140 & 4780799 & -92012 & -33661 \\
\hline cw-mag-86 & 31.64231667 & -110.9803806 & 1139 & 4783707 & -89103 & -31600 \\
\hline cw-mag-87 & 31.64229722 & -110.9804806 & 1139 & 4782977 & -89829 & -38093 \\
\hline cw-mag-88 & 31.64229722 & -110.9805806 & 1139 & 4780032 & -92774 & -34132 \\
\hline cw-mag-89 & 31.64228056 & -110.9806306 & 1139 & 4783122 & -89682 & -37946 \\
\hline cw-mag-90 & 31.64228056 & -110.9806806 & 1139 & 4783663 & -89139 & -37403 \\
\hline cw-mag-91 & 31.64228056 & -110.9807306 & 1138 & 4775299 & -97502 & -41485 \\
\hline cw-mag-92 & 31.64226667 & -110.98085 & 1138 & 4767672 & -105126 & -46389 \\
\hline cw-mag-93 & 31.64223056 & -110.98095 & 1137 & 4771951 & -100845 & -43151 \\
\hline cw-mag-94 & 31.64221667 & -110.9810167 & 1137 & 4780331 & -92461 & -33889 \\
\hline cw-mag-95 & 31.64218056 & -110.9811306 & 1137 & 4781491 & -91297 & -34778 \\
\hline cw-mag-96 & 31.64216667 & -110.9812306 & 1136 & 4779908 & -92878 & -34237 \\
\hline cw-mag-97 & 31.64215 & -110.9812806 & 1136 & 4781234 & -91549 & -32740 \\
\hline cw-mag-98 & 31.64213056 & -110.9813306 & 1136 & 4779283 & -93498 & -41762 \\
\hline cw-mag-99 & 31.64213056 & -110.9813806 & 1136 & 4779027 & -93754 & -35113 \\
\hline cw-mag-100 & 31.64209722 & -110.9814806 & 1136 & 4781171 & -91605 & -35072 \\
\hline cw-mag-101 & 31.64208056 & -110.9816 & 1135 & 4783152 & -89621 & -31927 \\
\hline cw-mag-102 & 31.64206667 & -110.9816667 & 1135 & 4774820 & -97952 & -41742 \\
\hline cw-mag-103 & 31.64205 & -110.9818 & 1135 & 4779447 & -93320 & -34918 \\
\hline cw-mag-104 & 31.64201667 & -110.9819167 & 1135 & 4779298 & -93465 & -34656 \\
\hline cw-mag-105 & 31.64199722 & -110.9819667 & 1134 & 4780462 & -92301 & -34017 \\
\hline cw-mag-106 & 31.64196667 & -110.9820806 & 1134 & 4779356 & -93402 & -35140 \\
\hline cw-mag-107 & 31.64193056 & -110.9822167 & 1134 & 4778027 & -94727 & -36376 \\
\hline cw-mag-108 & 31.64191667 & -110.9822667 & 1134 & 4779820 & -92932 & -34423 \\
\hline cw-mag-109 & 31.64189722 & -110.9823306 & 1134 & 4777457 & -95292 & -37153 \\
\hline cw-mag-110 & 31.64188056 & -110.9823972 & 1134 & 4777377 & -95372 & -38934 \\
\hline cw-mag-111 & 31.64186667 & -110.9825 & 1133 & 4776024 & -96722 & -38186 \\
\hline cw-mag-112 & 31.64183056 & -110.9826167 & 1133 & 4775864 & -96878 & -38527 \\
\hline cw-mag-113 & 31.64181667 & -110.9826667 & 1133 & 4773793 & -98947 & -40375 \\
\hline cw-mag-114 & 31.64178056 & -110.9827806 & 1133 & 4776509 & -96226 & -40810 \\
\hline cw-mag-115 & 31.64176667 & -110.9829306 & 1133 & 4785777 & -86955 & -35219 \\
\hline cw-mag-116 & 31.64176667 & -110.9830167 & 1133 & 4783759 & -88972 & -37236 \\
\hline cw-mag-117 & 31.64176667 & -110.9830806 & 1133 & 4782793 & -89937 & -38201 \\
\hline cw-mag-118 & 31.64176667 & -110.9831667 & 1133 & 4783984 & -88745 & -32429 \\
\hline cw-mag-119 & 31.64174722 & -110.9833167 & 1133 & 4785883 & -86843 & -35107 \\
\hline cw-mag-120 & 31.64174722 & -110.9833806 & 1133 & 4796694 & -76030 & -24294 \\
\hline cw-mag-121 & 31.64174722 & -110.9835306 & 1133 & 4803556 & -69165 & -36306 \\
\hline cw-mag-122 & 31.64178056 & -110.9836667 & 1133 & 4805544 & -67176 & -35529 \\
\hline cw-mag-123 & 31.64179722 & -110.9837306 & 1132 & 4813026 & -59694 & -48592 \\
\hline cw-mag-124 & 31.64183056 & -110.9837667 & 1132 & 4801129 & -71593 & -19857 \\
\hline cw-mag-125 & 31.64183056 & -110.9838 & 1132 & 4811355 & -61366 & -42549 \\
\hline cw-mag-126 & 31.64188056 & -110.9839 & 1132 & 4809213 & -63509 & -42077 \\
\hline cw-mag-127 & 31.64193056 & -110.9840167 & 1131 & 4810180 & -62545 & -41898 \\
\hline cw-mag-128 & 31.64196667 & -110.9840972 & 1130 & 4809635 & -63090 & -43568 \\
\hline cw-mag-129 & 31.64203056 & -110.9842306 & 1130 & 4810501 & -62227 & -45131 \\
\hline cw-mag-130 & 31.64209722 & -110.98435 & 1130 & 4806133 & -66596 & -44450 \\
\hline cw-mag-131 & 31.64211667 & -110.9843972 & 1129 & 4805844 & -66884 & -47392 \\
\hline cw-mag-132 & 31.64215 & -110.9844667 & 1129 & 4808697 & -64033 & -32387 \\
\hline cw-mag-133 & 31.64216667 & -110.9845306 & 1129 & 4805280 & -67451 & -47586 \\
\hline cw-mag-134 & 31.64223056 & -110.9846667 & 1129 & 4803936 & -68795 & -49979 \\
\hline cw-mag-135 & 31.64228056 & -110.9847667 & 1128 & 4809963 & -62771 & -49123 \\
\hline cw-mag-136 & 31.64231667 & -110.9848167 & 1128 & 4808472 & -64261 & -43253 \\
\hline cw-mag-137 & 31.64236667 & -110.9849306 & 1128 & 4807363 & -65372 & -47629 \\
\hline
\end{tabular}




\begin{tabular}{|c|c|c|c|c|c|c|}
\hline cw-mag-138 & 31.64243056 & -110.98505 & 1127 & 4808013 & -64724 & -51076 \\
\hline cw-mag-139 & 31.64246667 & -110.9851 & 1127 & 4800798 & -71939 & -43581 \\
\hline cw-mag-140 & 31.64249722 & -110.9852 & 1127 & 4803875 & -68863 & -53281 \\
\hline cw-mag-141 & 31.64254722 & -110.9852806 & 1126 & 4802500 & -70240 & -49750 \\
\hline cw-mag-142 & 31.6426 & -110.9853972 & 1126 & 4803354 & -69388 & -41726 \\
\hline cw-mag-143 & 31.64261667 & -110.98545 & 1125 & 4803360 & -69383 & -50567 \\
\hline cw-mag-144 & 31.64266667 & -110.98555 & 1125 & 4804153 & -68590 & -42511 \\
\hline cw-mag-145 & 31.64271667 & -110.9856972 & 1124 & 4796857 & -75888 & -39415 \\
\hline cw-mag-146 & 31.64273056 & -110.9857667 & 1123 & 4794581 & -78164 & -54211 \\
\hline cw-mag-147 & 31.64278056 & -110.9859 & 1123 & 4790506 & -82238 & -55737 \\
\hline cw-mag-148 & 31.64283056 & -110.98605 & 1122 & 4787371 & -85374 & -52906 \\
\hline cw-mag-149 & 31.64284722 & -110.9861167 & 1122 & 4796972 & -75775 & -43711 \\
\hline cw-mag-150 & 31.64288056 & -110.9862472 & 1121 & 4798234 & -74513 & -50561 \\
\hline cw-mag-151 & 31.64293056 & -110.9863806 & 1120 & 4798020 & -74727 & -41549 \\
\hline cw-mag-152 & 31.64296667 & -110.9865306 & 1119 & 4803503 & -69243 & -50427 \\
\hline cw-mag-153 & 31.643 & -110.9865972 & 1119 & 4800389 & -72360 & -40334 \\
\hline cw-mag-154 & 31.64303056 & -110.9867167 & 1119 & 4797716 & -75033 & -43387 \\
\hline cw-mag-155 & 31.64304722 & -110.9867806 & 1118 & 4797149 & -75600 & -52381 \\
\hline cw-mag-156 & 31.64306667 & -110.9868306 & 1118 & 4799349 & -73401 & -53909 \\
\hline cw-mag-157 & 31.6431 & -110.9869 & 1118 & 4803264 & -69487 & -44255 \\
\hline cw-mag-158 & 31.64311667 & -110.9869472 & 1118 & 4801315 & -71435 & -41078 \\
\hline cw-mag-159 & 31.64313056 & -110.9869972 & 1118 & 4803977 & -68774 & -46926 \\
\hline cw-mag-160 & 31.64318056 & -110.9871167 & 1118 & 4800993 & -71758 & -50522 \\
\hline cw-mag-161 & 31.64321667 & -110.9872 & 1118 & 4808330 & -64422 & -40897 \\
\hline cw-mag-162 & 31.64326667 & -110.9873306 & 1118 & 4812062 & -60691 & -40827 \\
\hline cw-mag-163 & 31.64333056 & -110.9874667 & 1117 & 4796480 & -76274 & -47833 \\
\hline cw-mag-164 & 31.64335 & -110.9875306 & 1117 & 4787267 & -85487 & -33751 \\
\hline cw-mag-165 & 31.64335 & -110.9876167 & 1117 & 4783230 & -89523 & -37787 \\
\hline cw-mag-166 & 31.64335 & -110.9876806 & 1117 & 4780022 & -92729 & -36126 \\
\hline cw-mag-167 & 31.64333056 & -110.9878167 & 1117 & 4780287 & -92461 & -33819 \\
\hline cw-mag-168 & 31.64329722 & -110.9879167 & 1118 & 4779030 & -93715 & -35487 \\
\hline cw-mag-169 & 31.64328056 & -110.9879806 & 1118 & 4781151 & -91593 & -35074 \\
\hline cw-mag-170 & 31.64326667 & -110.9880806 & 1118 & 4785190 & -87550 & -35814 \\
\hline cw-mag-171 & 31.64326667 & -110.9882 & 1118 & 4786136 & -86602 & -34866 \\
\hline cw-mag-172 & 31.64326667 & -110.9882472 & 1118 & 4782455 & -90282 & -38546 \\
\hline cw-mag-173 & 31.64326667 & -110.9883167 & 1118 & 4789915 & -82821 & -31085 \\
\hline cw-mag-174 & 31.64326667 & -110.9883806 & 1118 & 4787866 & -84868 & -33132 \\
\hline cw-mag-175 & 31.64326667 & -110.9884806 & 1118 & 4786602 & -86131 & -27765 \\
\hline cw-mag-176 & 31.64324722 & -110.98855 & 1118 & 4780314 & -92417 & -40681 \\
\hline cw-mag-177 & 31.64324722 & -110.9885667 & 1118 & 4786756 & -85974 & -34238 \\
\hline cw-mag-178 & 31.64324722 & -110.9886167 & 1118 & 4793081 & -79647 & -27911 \\
\hline cw-mag-179 & 31.64324722 & -110.9886806 & 1117 & 4786171 & -86556 & -34820 \\
\hline cw-mag-180 & 31.64324722 & -110.9887306 & 1117 & 4785785 & -86941 & -35205 \\
\hline cw-mag-181 & 31.64324722 & -110.9888472 & 1117 & 4787689 & -85036 & -47613 \\
\hline cw-mag-182 & 31.64326667 & -110.98895 & 1117 & 4790783 & -81943 & -30207 \\
\hline cw-mag-183 & 31.64326667 & -110.9890167 & 1117 & 4788341 & -84381 & -54023 \\
\hline cw-mag-184 & 31.64328056 & -110.9890667 & 1117 & 4786870 & -85851 & -46375 \\
\hline cw-mag-185 & 31.64329722 & -110.9891667 & 1117 & 4786673 & -86050 & -34314 \\
\hline cw-mag-186 & 31.64329722 & -110.9892667 & 1117 & 4792851 & -79870 & -56650 \\
\hline cw-mag-187 & 31.64331667 & -110.9893167 & 1117 & 4795969 & -76751 & -54080 \\
\hline cw-mag-188 & 31.64335 & -110.9894 & 1117 & 4797974 & -74746 & -46390 \\
\hline cw-mag-189 & 31.64338056 & -110.9895 & 1116 & 4800977 & -71744 & -62585 \\
\hline cw-mag-190 & 31.64341667 & -110.9895306 & 1117 & 4810523 & -62201 & -26442 \\
\hline cw-mag-191 & 31.64343056 & -110.9895972 & 1116 & 4812566 & -60155 & -46508 \\
\hline cw-mag-192 & 31.64346667 & -110.9896472 & 1116 & 4817391 & -55333 & -39772 \\
\hline cw-mag-193 & 31.64353056 & -110.98975 & 1115 & 4818685 & -54041 & -40648 \\
\hline cw-mag-194 & 31.64361667 & -110.9898667 & 1115 & 4823944 & -48787 & -34152 \\
\hline
\end{tabular}




\begin{tabular}{|c|c|c|c|c|c|c|}
\hline cw-mag-195 & 31.64365 & -110.9899167 & 1114 & 4816820 & -55912 & -43763 \\
\hline cw-mag-196 & 31.64371667 & -110.9899972 & 1114 & 4825783 & -46952 & -39240 \\
\hline cw-mag-197 & 31.64376667 & -110.9900306 & 1114 & 4826226 & -46511 & -23073 \\
\hline cw-mag-198 & 31.64378056 & -110.9900667 & 1113 & 4816824 & -55914 & -46755 \\
\hline cw-mag-199 & 31.64381667 & -110.9900972 & 1113 & 4818364 & -54376 & -40692 \\
\hline cw-mag-200 & 31.64386667 & -110.9901667 & 1112 & 4807437 & -65307 & -40890 \\
\hline cw-mag-201 & 31.64389722 & -110.99025 & 1112 & 4793960 & -78783 & -27047 \\
\hline cw-mag-202 & 31.64389722 & -110.99035 & 1113 & 4779829 & -92912 & -41176 \\
\hline cw-mag-203 & 31.64389722 & -110.9904167 & 1113 & 4798743 & -73998 & -22262 \\
\hline cw-mag-204 & 31.64389722 & -110.9905472 & 1114 & 4793854 & -78883 & -27147 \\
\hline cw-mag-205 & 31.64389722 & -110.9906 & 1114 & 4792758 & -79980 & -50644 \\
\hline cw-mag-206 & 31.64391667 & -110.9906667 & 1114 & 4789384 & -83352 & -31616 \\
\hline cw-mag-207 & 31.64391667 & -110.9907306 & 1114 & 4790049 & -82686 & -30950 \\
\hline cw-mag-208 & 31.64391667 & -110.9908472 & 1115 & 4788001 & -84732 & -32996 \\
\hline cw-mag-209 & 31.64391667 & -110.9909806 & 1116 & 4787877 & -84852 & -33116 \\
\hline cw-mag-210 & 31.64391667 & -110.9910306 & 1116 & 4793014 & -79715 & -33753 \\
\hline cw-mag-211 & 31.64393056 & -110.9911806 & 1116 & 4787420 & -85306 & -33570 \\
\hline cw-mag-212 & 31.64393056 & -110.9913167 & 1118 & 4805371 & -67354 & -38914 \\
\hline cw-mag-213 & 31.64395 & -110.9913806 & 1118 & 4808338 & -64387 & -27352 \\
\hline cw-mag-214 & 31.64396667 & -110.9914667 & 1118 & 4805118 & -67606 & -28130 \\
\hline cw-mag-215 & 31.64398056 & -110.99155 & 1118 & 4809648 & -63076 & -26605 \\
\hline cw-mag-216 & 31.64401667 & -110.9917306 & 1118 & 4809857 & -62865 & -36365 \\
\hline cw-mag-217 & 31.64406667 & -110.9918806 & 1118 & 4808465 & -64257 & -24293 \\
\hline cw-mag-218 & 31.64408056 & -110.9919667 & 1118 & 4801208 & -71514 & -38337 \\
\hline cw-mag-219 & 31.64411667 & -110.9921167 & 1119 & 4799328 & -73392 & -17729 \\
\hline cw-mag-220 & 31.6441 & -110.9922806 & 1119 & 4799689 & -73028 & -21292 \\
\hline cw-mag-221 & 31.6441 & -110.9923667 & 1119 & 4792197 & -80518 & -28782 \\
\hline cw-mag-222 & 31.6441 & -110.9924667 & 1119 & 4794696 & -78017 & -20514 \\
\hline cw-mag-223 & 31.64408056 & -110.9925667 & 1119 & 4797167 & -75543 & -20634 \\
\hline cw-mag-224 & 31.64406667 & -110.99275 & 1120 & 4796049 & -76658 & -21040 \\
\hline cw-mag-225 & 31.64405 & -110.9929167 & 1120 & 4795733 & -76970 & -25234 \\
\hline cw-mag-226 & 31.64405 & -110.9930167 & 1120 & 4793888 & -78813 & -27077 \\
\hline cw-mag-227 & 31.64405 & -110.9931806 & 1120 & 4791853 & -80846 & -29110 \\
\hline cw-mag-228 & 31.64405 & -110.9933306 & 1121 & 4800315 & -72381 & -20645 \\
\hline cw-mag-229 & 31.64405 & -110.9934167 & 1121 & 4794077 & -78617 & -23073 \\
\hline cw-mag-230 & 31.64403056 & -110.9936167 & 1122 & 4795350 & -77339 & -20701 \\
\hline cw-mag-231 & 31.64399722 & -110.9938472 & 1122 & 4794899 & -77784 & -22415 \\
\hline cw-mag-232 & 31.64398056 & -110.9940306 & 1122 & 4803617 & -69062 & -35113 \\
\hline cw-mag-233 & 31.64403056 & -110.9942472 & 1123 & 4805367 & -67310 & -28884 \\
\hline cw-mag-234 & 31.64406667 & -110.99445 & 1123 & 4807229 & -65447 & -13711 \\
\hline cw-mag-235 & 31.64406667 & -110.99455 & 1123 & 4803494 & -69180 & -29917 \\
\hline cw-mag-236 & 31.6441 & -110.9947472 & 1122 & 4811880 & -60793 & -15285 \\
\hline cw-mag-237 & 31.64411667 & -110.9949167 & 1121 & 4803748 & -68922 & -17186 \\
\hline cw-mag-238 & 31.64411667 & -110.995 & 1121 & 4803907 & -68762 & -23025 \\
\hline cw-mag-239 & 31.64413056 & -110.9951667 & 1120 & 4813208 & -59461 & -16187 \\
\hline cw-mag-240 & 31.64414722 & -110.9953 & 1120 & 4804981 & -67684 & -15948 \\
\hline cw-mag-241 & 31.64414722 & -110.9954167 & 1119 & 4800960 & -71704 & -19968 \\
\hline cw-mag-242 & 31.64414722 & -110.9954806 & 1119 & 4813564 & -59099 & -24483 \\
\hline cw-mag-243 & 31.64418056 & -110.9956306 & 1118 & 4810767 & -61896 & -32560 \\
\hline cw-mag-244 & 31.6442 & -110.9956972 & 1118 & 4805250 & -67413 & -15677 \\
\hline cw-mag-245 & 31.6442 & -110.9957667 & 1117 & 4802801 & -69861 & -18125 \\
\hline cw-mag-246 & 31.6442 & -110.9958306 & 1117 & 4798011 & -74649 & -22913 \\
\hline cw-mag-247 & 31.6442 & -110.9959306 & 1117 & 4799386 & -73273 & -15770 \\
\hline cw-mag-248 & 31.64418056 & -110.9960306 & 1116 & 4800315 & -72341 & -20605 \\
\hline cw-mag-249 & 31.64418056 & -110.9960972 & 1116 & 4795040 & -77615 & -19255 \\
\hline cw-mag-250 & 31.64414722 & -110.9962167 & 1115 & 4795514 & -77137 & -19555 \\
\hline cw-mag-251 & 31.64413056 & -110.9963 & 1115 & 4801326 & -71324 & -12973 \\
\hline
\end{tabular}




\begin{tabular}{|c|c|c|c|c|c|c|}
\hline cw-mag-252 & 31.64411667 & -110.99635 & 1114 & 4803604 & -69043 & -17307 \\
\hline cw-mag-253 & 31.64411667 & -110.9964167 & 1113 & 4803109 & -69538 & -17802 \\
\hline cw-mag-254 & 31.64411667 & -110.9964806 & 1112 & 4800056 & -72590 & -20854 \\
\hline cw-mag-255 & 31.64411667 & -110.9966167 & 1112 & 4808007 & -64636 & -12900 \\
\hline cw-mag-256 & 31.64411667 & -110.99675 & 1110 & 4811268 & -61373 & -9637 \\
\hline cw-mag-257 & 31.64411667 & -110.9967972 & 1110 & 4801580 & -71061 & -29050 \\
\hline cw-mag-258 & 31.64413056 & -110.9968972 & 1109 & 4800406 & -72234 & -20498 \\
\hline cw-mag-259 & 31.64413056 & -110.9970306 & 1108 & 4814958 & -57681 & -5945 \\
\hline cw-mag-260 & 31.64413056 & -110.9971 & 1107 & 4824919 & -47719 & -15252 \\
\hline cw-mag-261 & 31.64414722 & -110.9971667 & 1107 & 4825486 & -47152 & -32517 \\
\hline cw-mag-262 & 31.64418056 & -110.9972167 & 1106 & 4828554 & -44087 & -28506 \\
\hline cw-mag-263 & 31.64423056 & -110.9972972 & 1105 & 4828534 & -44108 & -25294 \\
\hline cw-mag-264 & 31.64428056 & -110.9973972 & 1104 & 4803763 & -68879 & -17143 \\
\hline cw-mag-265 & 31.64428056 & -110.99745 & 1103 & 4808489 & -64153 & -23063 \\
\hline cw-mag-266 & 31.6443 & -110.9975806 & 1102 & 4814470 & -58171 & -23733 \\
\hline cw-mag-267 & 31.64433056 & -110.9977167 & 1101 & 4815308 & -57332 & -25688 \\
\hline cw-mag-268 & 31.64434722 & -110.9977806 & 1100 & 4816211 & -56428 & -31132 \\
\hline cw-mag-269 & 31.6444 & -110.9979306 & 1100 & 4813955 & -58685 & -25451 \\
\hline cw-mag-270 & 31.64441667 & -110.998 & 1099 & 4815137 & -57503 & -21747 \\
\hline cw-mag-271 & 31.64443056 & -110.9980667 & 1099 & 4816947 & -55694 & -32169 \\
\hline cw-mag-272 & 31.64448056 & -110.9981972 & 1098 & 4805376 & -67266 & -37076 \\
\hline cw-mag-273 & 31.6445 & -110.9982667 & 1097 & 4809137 & -63504 & -35780 \\
\hline cw-mag-274 & 31.64454722 & -110.9984167 & 1096 & 4823097 & -49545 & -29466 \\
\hline cw-mag-275 & 31.6446 & -110.9985306 & 1096 & 4820560 & -52086 & -19621 \\
\hline cw-mag-276 & 31.64461667 & -110.9985972 & 1096 & 4827795 & -44851 & -23004 \\
\hline cw-mag-277 & 31.64466667 & -110.9987167 & 1095 & 4806486 & -66160 & -48030 \\
\hline cw-mag-278 & 31.6447 & -110.9987806 & 1095 & 4810843 & -61803 & -28570 \\
\hline cw-mag-279 & 31.64471667 & -110.99885 & 1094 & 4813911 & -58736 & -28380 \\
\hline cw-mag-280 & 31.64473056 & -110.9989 & 1094 & 4788949 & -83698 & -31962 \\
\hline cw-mag-281 & 31.64473056 & -110.9989972 & 1094 & 4784521 & -88125 & -29230 \\
\hline cw-mag-282 & 31.6447 & -110.9990667 & 1094 & 4777971 & -94670 & -35938 \\
\hline cw-mag-283 & 31.64468056 & -110.9990806 & 1093 & 4777511 & -95130 & -95023 \\
\hline cc-mag-01 & 31.63396667 & -110.98845 & 1150 & 4845615 & -24428 & -21604 \\
\hline cc-mag-02 & 31.63396667 & -110.9884306 & 1150 & 4842411 & -27631 & 24105 \\
\hline cc-mag-03 & 31.63394722 & -110.9884167 & 1151 & 4832846 & -37196 & -29100 \\
\hline cc-mag-04 & 31.63396667 & -110.9884306 & 1150 & 4826881 & -43161 & 12739 \\
\hline cc-mag-05 & 31.63396667 & -110.9884167 & 1150 & 4820963 & -49081 & 2655 \\
\hline cc-mag-06 & 31.63396667 & -110.9883972 & 1150 & 4810333 & -59711 & -7975 \\
\hline cc-mag-07 & 31.63396667 & -110.9883806 & 1150 & 4797728 & -72316 & -20580 \\
\hline cc-mag-08 & 31.63398056 & -110.9883472 & 1150 & 4786920 & -83124 & -24262 \\
\hline cc-mag-09 & 31.634 & -110.9883306 & 1150 & 4781386 & -88661 & -29835 \\
\hline cc-mag-10 & 31.63401667 & -110.9882972 & 1150 & 4778246 & -91803 & -32859 \\
\hline cc-mag-11 & 31.63403056 & -110.9882667 & 1151 & 4771624 & -98425 & -39514 \\
\hline cc-mag-12 & 31.63404722 & -110.9882306 & 1151 & 4776199 & -93852 & -34934 \\
\hline cc-mag-13 & 31.63404722 & -110.9882167 & 1151 & 4794651 & -75401 & -23665 \\
\hline cc-mag-14 & 31.63403056 & -110.9882 & 1151 & 4802162 & -67889 & -57469 \\
\hline cc-mag-15 & 31.63403056 & -110.9881806 & 1151 & 4805155 & -64896 & -13160 \\
\hline cc-mag-16 & 31.63403056 & -110.9881667 & 1151 & 4805297 & -64754 & -13018 \\
\hline cc-mag-17 & 31.63403056 & -110.9881306 & 1151 & 4804956 & -65096 & -13360 \\
\hline cc-mag-18 & 31.63401667 & -110.9881 & 1151 & 4807329 & -62722 & -42306 \\
\hline cc-mag-19 & 31.63401667 & -110.98805 & 1151 & 4808231 & -61821 & -10085 \\
\hline cc-mag-20 & 31.634 & -110.9879806 & 1152 & 4802251 & -67800 & -34557 \\
\hline cc-mag-21 & 31.63401667 & -110.9879167 & 1153 & 4794967 & -75087 & -16860 \\
\hline cc-mag-22 & 31.63403056 & -110.9878667 & 1153 & 4791914 & -78144 & -19794 \\
\hline cc-mag-23 & 31.63404722 & -110.9877972 & 1153 & 4786474 & -83587 & -25540 \\
\hline cc-mag-24 & 31.63408056 & -110.9877306 & 1153 & 4785779 & -84285 & -25341 \\
\hline cc-mag-25 & 31.6341 & -110.98765 & 1153 & 4786305 & -83762 & -25702 \\
\hline
\end{tabular}




\begin{tabular}{|c|c|c|c|c|c|c|}
\hline cc-mag-26 & 31.63411667 & -110.9876 & 1154 & 4781615 & -88453 & -29812 \\
\hline cc-mag-27 & 31.63413056 & -110.9875472 & 1154 & 4784101 & -85968 & -27723 \\
\hline cc-mag-28 & 31.63415 & -110.9874972 & 1154 & 4779706 & -90365 & -31556 \\
\hline cc-mag-29 & 31.63416667 & -110.9874667 & 1155 & 4775444 & -94628 & -35671 \\
\hline cc-mag-30 & 31.63418056 & -110.9873972 & 1155 & 4780652 & -89424 & -31843 \\
\hline cc-mag-31 & 31.63419722 & -110.98735 & 1155 & 4787051 & -83025 & -24314 \\
\hline cc-mag-32 & 31.63419722 & -110.9873 & 1155 & 4792398 & -77678 & -25942 \\
\hline cc-mag-33 & 31.63421667 & -110.9872306 & 1155 & 4790852 & -79226 & -20861 \\
\hline cc-mag-34 & 31.63421667 & -110.9871667 & 1156 & 4792451 & -77628 & -25892 \\
\hline cc-mag-35 & 31.63421667 & -110.9870972 & 1156 & 4784226 & -85854 & -34118 \\
\hline cc-mag-36 & 31.63421667 & -110.9870306 & 1156 & 4802203 & -67878 & -16142 \\
\hline cc-mag-37 & 31.63423056 & -110.9869667 & 1156 & 4796021 & -74063 & -16255 \\
\hline cc-mag-38 & 31.63425 & -110.9869 & 1157 & 4787799 & -82288 & -23850 \\
\hline cc-mag-39 & 31.63426667 & -110.98685 & 1157 & 4785510 & -84579 & -25938 \\
\hline cc-mag-40 & 31.63428056 & -110.9867806 & 1157 & 4784144 & -85947 & -28366 \\
\hline cc-mag-41 & 31.63429722 & -110.9867167 & 1157 & 4793605 & -76487 & -18260 \\
\hline cc-mag-42 & 31.63429722 & -110.9866472 & 1157 & 4802178 & -67916 & -16180 \\
\hline cc-mag-43 & 31.63429722 & -110.9865806 & 1157 & 4804784 & -65311 & -13575 \\
\hline cc-mag-44 & 31.63428056 & -110.9865167 & 1158 & 4800441 & -69654 & -38001 \\
\hline cc-mag-45 & 31.63426667 & -110.9864306 & 1159 & 4795361 & -74734 & -34763 \\
\hline cc-mag-46 & 31.63426667 & -110.9863667 & 1159 & 4819397 & -50700 & 1036 \\
\hline cc-mag-47 & 31.63426667 & -110.9862806 & 1159 & 4804525 & -65574 & -13838 \\
\hline cc-mag-48 & 31.63426667 & -110.9862167 & 1159 & 4797842 & -72258 & -20522 \\
\hline cc-mag-49 & 31.63428056 & -110.9861306 & 1159 & 4790287 & -79817 & -22857 \\
\hline cc-mag-50 & 31.63429722 & -110.9860667 & 1159 & 4790785 & -79319 & -21092 \\
\hline cc-mag-51 & 31.63433056 & -110.9859806 & 1159 & 4788982 & -81127 & -22322 \\
\hline cc-mag-52 & 31.63435 & -110.9859 & 1160 & 4787706 & -82405 & -24345 \\
\hline cc-mag-53 & 31.63438056 & -110.9858167 & 1160 & 4781244 & -88871 & -30118 \\
\hline cc-mag-54 & 31.63439722 & -110.9857472 & 1160 & 4784783 & -85334 & -27287 \\
\hline cc-mag-55 & 31.63443056 & -110.9856667 & 1161 & 4787483 & -82638 & -23781 \\
\hline cc-mag-56 & 31.63445 & -110.9856 & 1161 & 4784571 & -85552 & -27114 \\
\hline cc-mag-57 & 31.63448056 & -110.9855167 & 1161 & 4786911 & -83216 & -24463 \\
\hline cc-mag-58 & 31.63451667 & -110.98545 & 1161 & 4785093 & -85036 & -26080 \\
\hline cc-mag-59 & 31.63453056 & -110.9853667 & 1162 & 4795705 & -74427 & -17370 \\
\hline cc-mag-60 & 31.63456667 & -110.9852972 & 1162 & 4785478 & -84657 & -25705 \\
\hline cc-mag-61 & 31.63459722 & -110.9852167 & 1162 & 4788546 & -81592 & -22806 \\
\hline cc-mag-62 & 31.63461667 & -110.9851306 & 1162 & 4784242 & -85898 & -27994 \\
\hline cc-mag-63 & 31.63465 & -110.98505 & 1163 & 4784354 & -85791 & -26934 \\
\hline cc-mag-64 & 31.63468056 & -110.9849806 & 1163 & 4775459 & -94688 & -35793 \\
\hline cc-mag-65 & 31.63469722 & -110.9848972 & 1163 & 4786740 & -83407 & -25826 \\
\hline cc-mag-66 & 31.63473056 & -110.9848167 & 1164 & 4785829 & -84322 & -25465 \\
\hline cc-mag-67 & 31.63476667 & -110.9847306 & 1164 & 4785339 & -84816 & -25950 \\
\hline cc-mag-68 & 31.63479722 & -110.98465 & 1164 & 4781721 & -88435 & -29649 \\
\hline cc-mag-69 & 31.63481667 & -110.9845667 & 1165 & 4782996 & -87165 & -29183 \\
\hline cc-mag-70 & 31.63485 & -110.9844972 & 1165 & 4782399 & -87766 & -28834 \\
\hline cc-mag-71 & 31.63488056 & -110.9844306 & 1165 & 4779109 & -91058 & -32143 \\
\hline cc-mag-72 & 31.63489722 & -110.98435 & 1165 & 4786684 & -83485 & -25810 \\
\hline cc-mag-73 & 31.63494722 & -110.9842667 & 1165 & 4788484 & -81689 & -22734 \\
\hline cc-mag-74 & 31.63498056 & -110.9841806 & 1165 & 4803645 & -66531 & -7726 \\
\hline cc-mag-75 & 31.63501667 & -110.9840972 & 1165 & 4760156 & -110024 & -51137 \\
\hline cc-mag-76 & 31.63504722 & -110.9840167 & 1165 & 4780186 & -89999 & -31213 \\
\hline cc-mag-77 & 31.63508056 & -110.9839306 & 1166 & 4780198 & -89990 & -31185 \\
\hline cc-mag-78 & 31.63511667 & -110.98385 & 1166 & 4762703 & -107488 & -48583 \\
\hline cc-mag-79 & 31.63513056 & -110.9837806 & 1166 & 4777107 & -93087 & -35506 \\
\hline cc-mag-80 & 31.63516667 & -110.9837167 & 1166 & 4780773 & -89422 & -30464 \\
\hline cc-mag-81 & 31.6352 & -110.9836472 & 1166 & 4784367 & -85832 & -26900 \\
\hline cc-mag- 82 & 31.63523056 & -110.9835667 & 1167 & 4778832 & -91370 & -32584 \\
\hline
\end{tabular}




\begin{tabular}{|c|c|c|c|c|c|c|}
\hline cc-mag- 83 & 31.63526667 & -110.9834667 & 1167 & 4789594 & -80612 & -21875 \\
\hline cc-mag-84 & 31.6353 & -110.9833806 & 1167 & 4783936 & -86274 & -27469 \\
\hline cc-mag- 85 & 31.63531667 & -110.9832972 & 1168 & 4780136 & -90078 & -32499 \\
\hline cc-mag-86 & 31.63534722 & -110.9832167 & 1168 & 4780749 & -89468 & -30682 \\
\hline cc-mag-87 & 31.63538056 & -110.9831472 & 1168 & 4779889 & -90331 & -31399 \\
\hline cc-mag- 88 & 31.6354 & -110.9830806 & 1168 & 4782949 & -87274 & -28836 \\
\hline cc-mag-89 & 31.63543056 & -110.9830167 & 1168 & 4781561 & -88666 & -29735 \\
\hline cc-mag-90 & 31.63546667 & -110.98295 & 1168 & 4786227 & -84003 & -25047 \\
\hline cc-mag-91 & 31.63548056 & -110.9828806 & 1168 & 4788555 & -81676 & -24095 \\
\hline cc-mag-92 & 31.63551667 & -110.9828167 & 1168 & 4780264 & -89969 & -31011 \\
\hline cc-mag-93 & 31.63553056 & -110.9827472 & 1168 & 4778672 & -91563 & -33982 \\
\hline cc-mag-94 & 31.63556667 & -110.9826806 & 1169 & 4783670 & -86570 & -27614 \\
\hline cc-mag-95 & 31.63558056 & -110.9826167 & 1169 & 4786849 & -83393 & -25584 \\
\hline cc-mag-96 & 31.6356 & -110.9825306 & 1169 & 4783285 & -86959 & -29055 \\
\hline cc-mag-97 & 31.63563056 & -110.9824667 & 1169 & 4785121 & -85127 & -26196 \\
\hline cc-mag-98 & 31.63566667 & -110.9823806 & 1169 & 4784696 & -85555 & -26689 \\
\hline cc-mag-99 & 31.63568056 & -110.9823167 & 1169 & 4786340 & -83912 & -26103 \\
\hline cc-mag-100 & 31.63571667 & -110.9822472 & 1169 & 4784586 & -85671 & -26719 \\
\hline cc-mag-101 & 31.63573056 & -110.9821806 & 1170 & 4785385 & -84874 & -27180 \\
\hline cc-mag-102 & 31.63575 & -110.9821167 & 1170 & 4785853 & -84407 & -25898 \\
\hline cc-mag-103 & 31.63576667 & -110.9820306 & 1170 & 4789270 & -80992 & -23503 \\
\hline cc-mag-104 & 31.63576667 & -110.9819667 & 1170 & 4795354 & -74909 & -23173 \\
\hline cc-mag-105 & 31.63576667 & -110.9818972 & 1170 & 4794016 & -76249 & -24513 \\
\hline cc-mag-106 & 31.63576667 & -110.9818167 & 1170 & 4794159 & -76107 & -24371 \\
\hline cc-mag-107 & 31.63576667 & -110.9817306 & 1170 & 4796039 & -74229 & -22493 \\
\hline cc-mag-108 & 31.63576667 & -110.98165 & 1170 & 4800384 & -69885 & -18149 \\
\hline cc-mag-109 & 31.63578056 & -110.9815667 & 1170 & 4783369 & -86903 & -29846 \\
\hline cc-mag-110 & 31.63578056 & -110.9814806 & 1171 & 4783990 & -86285 & -34549 \\
\hline cc-mag-111 & 31.63579722 & -110.9814306 & 1171 & 4789005 & -81271 & -22630 \\
\hline cc-mag-112 & 31.63581667 & -110.9813667 & 1172 & 4789343 & -80935 & -22426 \\
\hline cc-mag-113 & 31.63583056 & -110.9813167 & 1172 & 4791753 & -78527 & -20176 \\
\hline cc-mag-114 & 31.63585 & -110.98125 & 1172 & 4781899 & -88384 & -29946 \\
\hline cc-mag-115 & 31.63586667 & -110.9811806 & 1173 & 4791647 & -78636 & -20589 \\
\hline cc-mag-116 & 31.63586667 & -110.9811167 & 1173 & 4799986 & -70300 & -18564 \\
\hline cc-mag-117 & 31.63586667 & -110.9810306 & 1173 & 4797474 & -72813 & -21077 \\
\hline cc-mag-118 & 31.63585 & -110.9809667 & 1173 & 4800101 & -70186 & -38534 \\
\hline cc-mag-119 & 31.63585 & -110.9808806 & 1173 & 4801564 & -68724 & -16988 \\
\hline cc-mag-120 & 31.63585 & -110.9808 & 1173 & 4791318 & -78972 & -27236 \\
\hline cc-mag-121 & 31.63586667 & -110.9807167 & 1174 & 4796279 & -74011 & -16430 \\
\hline cc-mag-122 & 31.63586667 & -110.9806306 & 1174 & 4796662 & -73630 & -21894 \\
\hline cc-mag-123 & 31.63588056 & -110.9805667 & 1174 & 4787581 & -82714 & -24906 \\
\hline cc-mag-124 & 31.63588056 & -110.9804806 & 1174 & 4793221 & -77076 & -25340 \\
\hline cc-mag-125 & 31.63588056 & -110.9804 & 1174 & 4797245 & -73054 & -21318 \\
\hline cc-mag-126 & 31.63589722 & -110.9803167 & 1174 & 4792786 & -77516 & -19935 \\
\hline cc-mag-127 & 31.63589722 & -110.9802306 & 1175 & 4797821 & -72483 & -20747 \\
\hline cc-mag-128 & 31.63591667 & -110.9801667 & 1175 & 4793455 & -76850 & -18341 \\
\hline cc-mag-129 & 31.63591667 & -110.9800972 & 1175 & 4790997 & -79309 & -27573 \\
\hline cc-mag-130 & 31.63591667 & -110.9800167 & 1175 & 4788338 & -81970 & -30234 \\
\hline cc-mag-131 & 31.63591667 & -110.9799306 & 1175 & 4799391 & -70918 & -19182 \\
\hline cc-mag-132 & 31.63593056 & -110.9798667 & 1175 & 4788971 & -81340 & -23531 \\
\hline cc-mag-133 & 31.63593056 & -110.9797806 & 1176 & 4778351 & -91962 & -40226 \\
\hline cc-mag-134 & 31.63593056 & -110.9796806 & 1176 & 4793408 & -76905 & -25169 \\
\hline cc-mag-135 & 31.63593056 & -110.9796 & 1176 & 4798343 & -71972 & -20236 \\
\hline cc-mag-136 & 31.63591667 & -110.9795167 & 1176 & 4800686 & -69630 & -30148 \\
\hline cc-mag-137 & 31.63589722 & -110.9794306 & 1176 & 4810170 & -60146 & -25804 \\
\hline cc-mag-138 & 31.63586667 & -110.9793472 & 1177 & 4803667 & -66647 & -42220 \\
\hline cc-mag-139 & 31.63585 & -110.9792472 & 1177 & 4805594 & -64722 & -25240 \\
\hline
\end{tabular}




\begin{tabular}{|c|c|c|c|c|c|c|}
\hline cc-mag-140 & 31.63581667 & -110.9791667 & 1177 & 4817300 & -53014 & -30951 \\
\hline cc-mag-141 & 31.63579722 & -110.9791 & 1177 & 4810089 & -60226 & -30881 \\
\hline cc-mag-142 & 31.63576667 & -110.9790167 & 1177 & 4812946 & -57369 & -32943 \\
\hline cc-mag-143 & 31.63575 & -110.9789306 & 1178 & 4811298 & -59018 & -21975 \\
\hline cc-mag-144 & 31.63571667 & -110.9788667 & 1178 & 4811319 & -58996 & -40859 \\
\hline cc-mag-145 & 31.63569722 & -110.9787806 & 1178 & 4808206 & -62109 & -27766 \\
\hline cc-mag-146 & 31.63568056 & -110.9787167 & 1178 & 4810296 & -60020 & -28368 \\
\hline cc-mag-147 & 31.63566667 & -110.9786306 & 1178 & 4806612 & -63705 & -23735 \\
\hline cc-mag-148 & 31.63564722 & -110.9785472 & 1179 & 4812135 & -58182 & -24425 \\
\hline cc-mag-149 & 31.63561667 & -110.9784667 & 1179 & 4813369 & -56948 & -33220 \\
\hline cc-mag-150 & 31.6356 & -110.9783806 & 1179 & 4811273 & -59044 & -22001 \\
\hline cc-mag-151 & 31.63556667 & -110.9782806 & 1180 & 4803145 & -67172 & -40662 \\
\hline cc-mag-152 & 31.63554722 & -110.9781806 & 1180 & 4801025 & -69294 & -32330 \\
\hline cc-mag-153 & 31.63553056 & -110.9780806 & 1180 & 4809648 & -60670 & -21188 \\
\hline cc-mag-154 & 31.63553056 & -110.9779806 & 1180 & 4797338 & -72982 & -21246 \\
\hline cc-mag-155 & 31.63551667 & -110.9778806 & 1180 & 4803402 & -66918 & -24901 \\
\hline cc-mag-156 & 31.63551667 & -110.9777806 & 1180 & 4796911 & -73409 & -21673 \\
\hline cc-mag-157 & 31.6355 & -110.9776667 & 1180 & 4787892 & -82429 & -41095 \\
\hline cc-mag-158 & 31.63548056 & -110.9775472 & 1181 & 4804343 & -65980 & -26146 \\
\hline cc-mag-159 & 31.63546667 & -110.9774306 & 1181 & 4799754 & -70569 & -26774 \\
\hline cc-mag-160 & 31.63544722 & -110.9773306 & 1181 & 4793232 & -77092 & -40128 \\
\hline cc-mag-161 & 31.63544722 & -110.9772667 & 1181 & 4798702 & -71624 & -19888 \\
\hline cc-mag-162 & 31.63543056 & -110.9771667 & 1181 & 4804648 & -65677 & -26195 \\
\hline cc-mag-163 & 31.63543056 & -110.97705 & 1182 & 4800532 & -69793 & -18057 \\
\hline cc-mag-164 & 31.63543056 & -110.97695 & 1182 & 4805198 & -65128 & -13392 \\
\hline cc-mag-165 & 31.63543056 & -110.9768306 & 1182 & 4792894 & -77436 & -25700 \\
\hline cc-mag-166 & 31.63544722 & -110.9767306 & 1182 & 4794694 & -75640 & -18583 \\
\hline cc-mag-167 & 31.63544722 & -110.9766306 & 1182 & 4794687 & -75648 & -23912 \\
\hline cc-mag-168 & 31.63543056 & -110.9765306 & 1182 & 4795064 & -75272 & -35790 \\
\hline cc-mag-169 & 31.63543056 & -110.9764306 & 1182 & 4803721 & -66617 & -14881 \\
\hline cc-mag-170 & 31.63541667 & -110.9763472 & 1182 & 4813673 & -56665 & -17183 \\
\hline cc-mag-171 & 31.63541667 & -110.9762667 & 1182 & 4798576 & -71763 & -20027 \\
\hline cc-mag-172 & 31.6354 & -110.9761806 & 1181 & 4790056 & -80286 & -43243 \\
\hline cc-mag-173 & 31.6354 & -110.9761 & 1181 & 4799975 & -70368 & -18632 \\
\hline cc-mag-174 & 31.63538056 & -110.9760167 & 1181 & 4795911 & -74432 & -40675 \\
\hline cc-mag-175 & 31.63536667 & -110.9759306 & 1181 & 4798971 & -71373 & -31402 \\
\hline cc-mag-176 & 31.63534722 & -110.9758472 & 1181 & 4793568 & -76776 & -43018 \\
\hline cc-mag-177 & 31.63533056 & -110.9757667 & 1181 & 4789904 & -80441 & -44553 \\
\hline cc-mag-178 & 31.63533056 & -110.9757167 & 1181 & 4794737 & -75608 & -23872 \\
\hline cc-mag-179 & 31.63531667 & -110.9756667 & 1181 & 4799336 & -71010 & -40643 \\
\hline cc-mag-180 & 31.63531667 & -110.9756167 & 1181 & 4796197 & -74149 & -22413 \\
\hline cc-mag-181 & 31.6353 & -110.9755472 & 1180 & 4805430 & -64917 & -31675 \\
\hline cc-mag-182 & 31.63528056 & -110.9754972 & 1180 & 4802682 & -67667 & -44439 \\
\hline cc-mag-183 & 31.63526667 & -110.9754306 & 1180 & 4799812 & -70534 & -34768 \\
\hline cc-mag-184 & 31.63526667 & -110.9753806 & 1180 & 4804446 & -65902 & -14166 \\
\hline cc-mag-185 & 31.63524722 & -110.9753167 & 1180 & 4800420 & -69928 & -41479 \\
\hline cc-mag-186 & 31.63523056 & -110.97525 & 1179 & 4796071 & -74277 & -41801 \\
\hline cc-mag-187 & 31.63523056 & -110.9752 & 1179 & 4797979 & -72370 & -20634 \\
\hline cc-mag-188 & 31.63523056 & -110.9751472 & 1179 & 4814666 & -55683 & -3947 \\
\hline cc-mag-189 & 31.63521667 & -110.9750806 & 1179 & 4799135 & -71214 & -35448 \\
\hline cc-mag-190 & 31.63521667 & -110.9750306 & 1179 & 4790807 & -79544 & -27808 \\
\hline cc-mag-191 & 31.63521667 & -110.9749806 & 1179 & 4788380 & -81972 & -30236 \\
\hline cc-mag-192 & 31.6352 & -110.9749306 & 1179 & 4793295 & -77054 & -50544 \\
\hline cc-mag-193 & 31.6352 & -110.9748806 & 1179 & 4793501 & -76849 & -25113 \\
\hline cc-mag-194 & 31.63518056 & -110.9748167 & 1179 & 4787925 & -82425 & -53976 \\
\hline cc-mag-195 & 31.63518056 & -110.97475 & 1179 & 4797732 & -72620 & -20884 \\
\hline cc-mag-196 & 31.63516667 & -110.9746972 & 1179 & 4793204 & -77147 & -45666 \\
\hline
\end{tabular}




\begin{tabular}{|c|c|c|c|c|c|c|}
\hline cc-mag-197 & 31.63514722 & -110.9746472 & 1179 & 4795053 & -75298 & -52070 \\
\hline cc-mag-198 & 31.63513056 & -110.9746306 & 1179 & 4802888 & -67463 & -57044 \\
\hline cc-mag-199 & 31.63513056 & -110.9746167 & 1178 & 4804595 & -65757 & -14021 \\
\hline cc-mag-200 & 31.63511667 & -110.9745972 & 1178 & 4806091 & -64261 & -50477 \\
\hline cc-mag-201 & 31.63503056 & -110.9744167 & 1179 & 4806283 & -64066 & -44461 \\
\hline cc-mag-202 & 31.635 & -110.9743306 & 1179 & 4811823 & -58522 & -33398 \\
\hline cc-mag-203 & 31.63498056 & -110.9742806 & 1179 & 4812469 & -57877 & -34649 \\
\hline cc-mag-204 & 31.63494722 & -110.9742306 & 1179 & 4813030 & -57315 & -42674 \\
\hline cc-mag-205 & 31.63493056 & -110.9741667 & 1180 & 4809469 & -60876 & -29223 \\
\hline cc-mag-206 & 31.63491667 & -110.9741306 & 1180 & 4815497 & -54848 & -31400 \\
\hline cc-mag-207 & 31.63488056 & -110.9740806 & 1181 & 4816499 & -53845 & -40192 \\
\hline cc-mag-208 & 31.63486667 & -110.97405 & 1181 & 4817568 & -52776 & -32361 \\
\hline cc-mag-209 & 31.63483056 & -110.974 & 1181 & 4817690 & -52653 & -39000 \\
\hline cc-mag-210 & 31.63481667 & -110.9739667 & 1182 & 4817673 & -52668 & -30729 \\
\hline cc-mag-211 & 31.63479722 & -110.9739167 & 1183 & 4824668 & -45673 & -22444 \\
\hline cc-mag-212 & 31.63478056 & -110.9738806 & 1183 & 4823686 & -46654 & -26498 \\
\hline cc-mag-213 & 31.63475 & -110.9738472 & 1183 & 4821031 & -49308 & -38140 \\
\hline cc-mag-214 & 31.63473056 & -110.9738167 & 1184 & 4823189 & -47149 & -31896 \\
\hline cc-mag-215 & 31.63471667 & -110.9737806 & 1184 & 4823902 & -46437 & -22988 \\
\hline cc-mag-216 & 31.63469722 & -110.9737472 & 1185 & 4824308 & -46031 & -29576 \\
\hline cc-mag-217 & 31.63468056 & -110.9737167 & 1185 & 4830313 & -40024 & -22575 \\
\hline cc-mag-218 & 31.63466667 & -110.9736806 & 1186 & 4820941 & -49396 & -25948 \\
\hline cc-mag-219 & 31.63465 & -110.97365 & 1186 & 4816735 & -53601 & -36152 \\
\hline cc-mag-220 & 31.63465 & -110.9736167 & 1187 & 4816628 & -53708 & -1972 \\
\hline cc-mag-221 & 31.63463056 & -110.9736 & 1187 & 4821098 & -49238 & -39986 \\
\hline cc-mag-222 & 31.63461667 & -110.9735806 & 1187 & 4824114 & -46220 & -32436 \\
\hline cc-mag-223 & 31.63459722 & -110.97355 & 1187 & 4828336 & -41999 & -26746 \\
\hline cc-mag-224 & 31.63458056 & -110.9735306 & 1187 & 4827522 & -42813 & -31011 \\
\hline cc-mag-225 & 31.63458056 & -110.9735167 & 1188 & 4821797 & -48538 & 3198 \\
\hline cc-mag-226 & 31.63456667 & -110.9735 & 1188 & 4820422 & -49913 & -37829 \\
\hline cc-mag-227 & 31.63456667 & -110.9734806 & 1188 & 4821733 & -48602 & 3134 \\
\hline cc-mag-228 & 31.63455 & -110.9734667 & 1188 & 4821770 & -48563 & -39505 \\
\hline cc-mag-229 & 31.63453056 & -110.9734306 & 1188 & 4821777 & -48556 & -30910 \\
\hline cc-mag-230 & 31.63451667 & -110.9734167 & 1188 & 4821009 & -49324 & -38904 \\
\hline cc-mag-231 & 31.63451667 & -110.9733806 & 1189 & 4821594 & -48740 & 2996 \\
\hline cc-mag-232 & 31.63449722 & -110.9733667 & 1189 & 4821801 & -48530 & -40434 \\
\hline cc-mag-233 & 31.63448056 & -110.9733472 & 1189 & 4822632 & -47699 & -35896 \\
\hline cc-mag-234 & 31.63446667 & -110.9733167 & 1189 & 4825986 & -44345 & -23929 \\
\hline cc-mag-235 & 31.63446667 & -110.9732972 & 1189 & 4820557 & -49774 & 1962 \\
\hline cc-mag-236 & 31.63445 & -110.9732806 & 1190 & 4819787 & -50544 & -40124 \\
\hline cc-mag-237 & 31.63445 & -110.9732667 & 1190 & 4821157 & -49173 & 2563 \\
\hline cc-mag-238 & 31.63443056 & -110.9732306 & 1190 & 4815091 & -55239 & -37593 \\
\hline cc-mag-239 & 31.63441667 & -110.9732167 & 1190 & 4806796 & -63533 & -53113 \\
\hline cc-mag-240 & 31.63441667 & -110.9731806 & 1191 & 4804782 & -65548 & -13812 \\
\hline cc-mag-241 & 31.63439722 & -110.97315 & 1191 & 4806715 & -63614 & -48361 \\
\hline cc-mag-242 & 31.63438056 & -110.9731 & 1191 & 4809015 & -61314 & -34803 \\
\hline cc-mag-243 & 31.63436667 & -110.9730306 & 1191 & 4810366 & -59963 & -23482 \\
\hline cc-mag-244 & 31.63435 & -110.9729472 & 1191 & 4810069 & -60261 & -23781 \\
\hline cc-mag-245 & 31.63431667 & -110.9728806 & 1192 & 4814293 & -56035 & -37212 \\
\hline cc-mag-246 & 31.63428056 & -110.9728 & 1192 & 4813911 & -56416 & -35762 \\
\hline cc-mag-247 & 31.63426667 & -110.9727306 & 1193 & 4814670 & -55657 & -19176 \\
\hline cc-mag-248 & 31.63425 & -110.9726667 & 1193 & 4798434 & -71893 & -40239 \\
\hline cc-mag-249 & 31.63425 & -110.9725972 & 1193 & 4800109 & -70220 & -18484 \\
\hline cc-mag-250 & 31.63425 & -110.9725167 & 1193 & 4800525 & -69805 & -18069 \\
\hline cc-mag-251 & 31.63426667 & -110.9724667 & 1194 & 4793990 & -76343 & -17702 \\
\hline cc-mag-252 & 31.63426667 & -110.9723972 & 1194 & 4780511 & -89824 & -38088 \\
\hline cc-mag-253 & 31.63426667 & -110.9723167 & 1195 & 4792078 & -78258 & -26522 \\
\hline
\end{tabular}




\begin{tabular}{|c|c|c|c|c|c|c|}
\hline cc-mag-254 & 31.63425 & -110.9722306 & 1195 & 4802387 & -67949 & -30905 \\
\hline cc-mag-255 & 31.63425 & -110.9721472 & 1195 & 4804289 & -66047 & -14311 \\
\hline cc-mag-256 & 31.63423056 & -110.9720667 & 1195 & 4804267 & -66069 & -32932 \\
\hline cc-mag-257 & 31.63423056 & -110.9719806 & 1195 & 4792561 & -77778 & -26042 \\
\hline cc-mag-258 & 31.63421667 & -110.9719 & 1196 & 4796747 & -73591 & -34633 \\
\hline cc-mag-259 & 31.63421667 & -110.9718 & 1196 & 4800980 & -69360 & -17624 \\
\hline cc-mag-260 & 31.63421667 & -110.9717167 & 1196 & 4789586 & -80756 & -29020 \\
\hline cc-mag-261 & 31.63423056 & -110.9716472 & 1196 & 4787022 & -83323 & -25742 \\
\hline cc-mag-262 & 31.63423056 & -110.9715806 & 1196 & 4786600 & -83747 & -32011 \\
\hline cc-mag-263 & 31.63425 & -110.9715306 & 1197 & 4792561 & -77787 & -18978 \\
\hline cc-mag-264 & 31.63425 & -110.9714667 & 1197 & 4798925 & -71424 & -19688 \\
\hline cc-mag-265 & 31.63425 & -110.9714 & 1197 & 4799804 & -70547 & -18811 \\
\hline cc-mag-266 & 31.63425 & -110.9713167 & 1197 & 4797810 & -72542 & -20806 \\
\hline cc-mag-267 & 31.63425 & -110.9712306 & 1197 & 4796552 & -73802 & -22066 \\
\hline cc-mag-268 & 31.63425 & -110.9711667 & 1197 & 4800949 & -69405 & -17669 \\
\hline cc-mag-269 & 31.63425 & -110.9710806 & 1197 & 4795733 & -74622 & -22886 \\
\hline cc-mag-270 & 31.63428056 & -110.9710167 & 1197 & 4787695 & -82665 & -23734 \\
\hline cc-mag-271 & 31.63429722 & -110.9709306 & 1197 & 4778776 & -91585 & -34096 \\
\hline cc-mag-272 & 31.63429722 & -110.9708472 & 1197 & 4791489 & -78874 & -27138 \\
\hline cc-mag-273 & 31.63431667 & -110.9707667 & 1198 & 4796588 & -73777 & -15717 \\
\hline cc-mag-274 & 31.63433056 & -110.9706806 & 1198 & 4791162 & -79205 & -22245 \\
\hline cc-mag-275 & 31.63435 & -110.9706 & 1198 & 4800692 & -69677 & -11617 \\
\hline cc-mag-276 & 31.63436667 & -110.9705167 & 1199 & 4800902 & -69469 & -11888 \\
\hline cc-mag-277 & 31.63436667 & -110.9704306 & 1199 & 4797468 & -72904 & -21168 \\
\hline cc-mag-278 & 31.63436667 & -110.9703472 & 1199 & 4807885 & -62489 & -10753 \\
\hline cc-mag-279 & 31.63438056 & -110.9702667 & 1199 & 4810484 & -59892 & -2736 \\
\hline cc-mag-280 & 31.63439722 & -110.9702 & 1199 & 4809451 & -60926 & -2788 \\
\hline cc-mag-281 & 31.63441667 & -110.97015 & 1199 & 4773062 & -97317 & -38508 \\
\hline cc-mag-282 & 31.63443056 & -110.9700806 & 1200 & 4783891 & -86491 & -28910 \\
\hline cc-mag-283 & 31.63443056 & -110.9700306 & 1200 & 4783208 & -87175 & -35439 \\
\hline cc-mag-284 & 31.63445 & -110.9699667 & 1200 & 4779197 & -91189 & -32680 \\
\hline cc-mag-285 & 31.63446667 & -110.9698806 & 1201 & 4782763 & -87624 & -30135 \\
\hline cc-mag-286 & 31.63448056 & -110.9698 & 1201 & 4786210 & -84179 & -27023 \\
\hline cc-mag-287 & 31.63448056 & -110.9697167 & 1201 & 4783090 & -87301 & -35565 \\
\hline cc-mag-288 & 31.63451667 & -110.96965 & 1201 & 4788393 & -82001 & -23045 \\
\hline cc-mag-289 & 31.63455 & -110.9695667 & 1202 & 4788159 & -82239 & -23407 \\
\hline cc-mag-290 & 31.63458056 & -110.9694972 & 1202 & 4781537 & -88864 & -29969 \\
\hline cc-mag-291 & 31.63459722 & -110.9694167 & 1202 & 4779478 & -90924 & -33250 \\
\hline cc-mag-292 & 31.63461667 & -110.9693306 & 1202 & 4785575 & -84831 & -26927 \\
\hline cc-mag-293 & 31.63463056 & -110.96925 & 1202 & 4791907 & -78503 & -21347 \\
\hline cc-mag-294 & 31.63463056 & -110.9691667 & 1202 & 4791665 & -78745 & -27009 \\
\hline cc-mag-295 & 31.63463056 & -110.9690806 & 1203 & 4791948 & -78465 & -26729 \\
\hline cc-mag-296 & 31.63463056 & -110.9689972 & 1202 & 4794590 & -75824 & -24088 \\
\hline cc-mag-297 & 31.63463056 & -110.9689306 & 1202 & 4799172 & -71243 & -19507 \\
\hline cc-mag-298 & 31.63463056 & -110.96885 & 1202 & 4803294 & -67123 & -15387 \\
\hline cc-mag-299 & 31.63461667 & -110.9687667 & 1202 & 4807178 & -63239 & -23756 \\
\hline cc-mag-300 & 31.63459722 & -110.9686972 & 1202 & 4822794 & -47623 & -17422 \\
\hline cc-mag-301 & 31.63459722 & -110.9686472 & 1203 & 4801314 & -69105 & -17369 \\
\hline cc-mag-302 & 31.63458056 & -110.9685806 & 1203 & 4808858 & -61561 & -29085 \\
\hline cc-mag-303 & 31.63461667 & -110.9685 & 1203 & 4794012 & -76412 & -17507 \\
\hline cc-mag-304 & 31.63463056 & -110.96845 & 1203 & 4787648 & -82776 & -24426 \\
\hline cc-mag-305 & 31.63465 & -110.9683806 & 1203 & 4788527 & -81899 & -23534 \\
\hline cc-mag-306 & 31.63465 & -110.9683167 & 1204 & 4791480 & -78946 & -27210 \\
\hline cc-mag-307 & 31.63463056 & -110.9682306 & 1204 & 4793193 & -77235 & -42891 \\
\hline cc-mag-308 & 31.63461667 & -110.9681472 & 1204 & 4795898 & -74531 & -35048 \\
\hline cc-mag-309 & 31.63458056 & -110.9680806 & 1204 & 4806529 & -63898 & -46343 \\
\hline cc-mag-310 & 31.63455 & -110.9680167 & 1204 & 4811449 & -58977 & -39418 \\
\hline
\end{tabular}




\begin{tabular}{|c|c|c|c|c|c|c|}
\hline cc-mag-311 & 31.63451667 & -110.96795 & 1203 & 4808598 & -61828 & -43005 \\
\hline cc-mag-312 & 31.63448056 & -110.9678806 & 1203 & 4811913 & -58512 & -40321 \\
\hline cc-mag-313 & 31.63443056 & -110.9677972 & 1203 & 4820616 & -49808 & -33752 \\
\hline cc-mag-314 & 31.63439722 & -110.9677306 & 1203 & 4821502 & -48920 & -30097 \\
\hline cc-mag-315 & 31.63435 & -110.9676667 & 1203 & 4825803 & -44619 & -31236 \\
\hline cc-mag-316 & 31.63429722 & -110.9676167 & 1202 & 4829748 & -40670 & -30682 \\
\hline cc-mag-317 & 31.63426667 & -110.9675667 & 1202 & 4817740 & -52679 & -36878 \\
\hline cc-mag-318 & 31.63423056 & -110.9675306 & 1201 & 4814612 & -55803 & -45383 \\
\hline cc-mag-319 & 31.63419722 & -110.9675 & 1201 & 4829442 & -40973 & -31236 \\
\hline cc-mag-320 & 31.63416667 & -110.9674667 & 1202 & 4827732 & -42681 & -31513 \\
\hline cc-mag-321 & 31.63413056 & -110.9674167 & 1202 & 4823518 & -46894 & -33241 \\
\hline cc-mag-322 & 31.6341 & -110.9673472 & 1203 & 4827467 & -42943 & -21966 \\
\hline cc-mag-323 & 31.63406667 & -110.9672806 & 1204 & 4824795 & -45613 & -26790 \\
\hline cc-mag-324 & 31.63401667 & -110.9672 & 1204 & 4823656 & -46750 & -31162 \\
\hline cc-mag-325 & 31.63396667 & -110.9671 & 1205 & 4818641 & -51763 & -32940 \\
\hline cc-mag-326 & 31.63391667 & -110.9669972 & 1204 & 4814158 & -56246 & -36970 \\
\hline cc-mag-327 & 31.63386667 & -110.9668972 & 1204 & 4812092 & -58310 & -39487 \\
\hline cc-mag-328 & 31.63381667 & -110.9668 & 1203 & 4816121 & -54279 & -35911 \\
\hline cc-mag-329 & 31.63376667 & -110.9667 & 1202 & 4809936 & -60465 & -41642 \\
\hline cc-mag-330 & 31.63371667 & -110.9666306 & 1201 & 4817496 & -52903 & -39216 \\
\hline cc-mag-331 & 31.63364722 & -110.9665472 & 1201 & 4826320 & -44075 & -31991 \\
\hline cc-mag-332 & 31.63358056 & -110.9664806 & 1201 & 4829747 & -40646 & -30226 \\
\hline cc-mag-333 & 31.63353056 & -110.9663972 & 1200 & 4826329 & -44063 & -28006 \\
\hline cc-mag-334 & 31.6335 & -110.9663306 & 1198 & 4805878 & -64513 & -44238 \\
\hline cc-mag-335 & 31.6335 & -110.9662667 & 1198 & 4804839 & -65554 & -13818 \\
\hline cc-mag-336 & 31.63351667 & -110.9661806 & 1197 & 4800001 & -70394 & -12905 \\
\hline cc-mag-337 & 31.63354722 & -110.9661306 & 1197 & 4798464 & -71935 & -12982 \\
\hline cc-mag-338 & 31.6336 & -110.9660972 & 1196 & 4798204 & -72199 & -13552 \\
\hline cc-mag-339 & 31.63364722 & -110.9660806 & 1195 & 4793247 & -77158 & -18896 \\
\hline cc-mag-340 & 31.6337 & -110.9660667 & 1194 & 4777032 & -93379 & -35274 \\
\hline cc-mag-341 & 31.63374722 & -110.9660667 & 1193 & 4784274 & -86141 & -28571 \\
\hline
\end{tabular}


APPENDIX C: AEROMAGNETIC DATA

\begin{tabular}{|c|c|c|c|c|c|c|c|c|c|}
\hline ID & $\begin{array}{c}\text { Easting } \\
(\mathrm{km})\end{array}$ & $\begin{array}{c}\text { Northing } \\
(\mathrm{km})\end{array}$ & $\begin{array}{l}\text { Elev. } \\
(\mathrm{m})\end{array}$ & $\begin{array}{l}\text { Basemag } \\
\text { IGRF } \\
\text { Corrected } \\
(\mathrm{nT})\end{array}$ & ID & $\begin{array}{c}\text { Easting } \\
(\mathrm{km})\end{array}$ & $\begin{array}{c}\text { Northing } \\
(\mathrm{km})\end{array}$ & $\begin{array}{l}\text { Elev. } \\
(\mathrm{m})\end{array}$ & $\begin{array}{l}\text { Basemag } \\
\text { IGRF } \\
\text { Corrected } \\
\text { (nT) }\end{array}$ \\
\hline cw-a-1 & 500.00699 & 3500.96 & 1312 & -195.73 & $c w-a-51$ & 500.423 & 3500.96 & 1324 & -193.98 \\
\hline$c w-a-2$ & 500.01599 & 3500.96 & 1312 & -195.73 & $c w-a-52$ & 500.431 & 3500.96 & 1324 & -193.84 \\
\hline cw-a-3 & 500.02399 & 3500.96 & 1312 & -195.73 & $c w-a-53$ & 500.44 & 3500.96 & 1325 & -193.69 \\
\hline cw-a-4 & 500.03299 & 3500.96 & 1312 & -195.74001 & cw-a-54 & 500.448 & 3500.96 & 1325 & -193.56 \\
\hline$c w-a-5$ & 500.04001 & 3500.96 & 1312 & -195.75999 & $c w-a-55$ & 500.45599 & 3500.96 & 1326 & -193.47 \\
\hline cw-a-6 & 500.04901 & 3500.96 & 1312 & -195.75 & $c w-a-56$ & 500.46399 & 3500.96 & 1327 & -193.34 \\
\hline cw-a-7 & 500.05701 & 3500.96 & 1312 & -195.75999 & $c w-a-57$ & 500.47198 & 3500.96 & 1327 & -193.24001 \\
\hline cw-a-8 & 500.06601 & 3500.96 & 1312 & -195.75 & cw-a-58 & 500.48001 & 3500.95 & 1328 & -193.13 \\
\hline cw-a-9 & 500.07401 & 3500.96 & 1312 & -195.74001 & cw-a-59 & 500.48901 & 3500.95 & 1328 & -193.02 \\
\hline$c w-a-10$ & 500.082 & 3500.96 & 1312 & -195.73 & $c w-a-60$ & 500.496 & 3500.95 & 1329 & -192.95 \\
\hline cw-a-11 & 500.091 & 3500.96 & 1312 & -195.73 & cw-a-61 & 500.505 & 3500.95 & 1330 & -192.84 \\
\hline cw-a-12 & 500.099 & 3500.96 & 1312 & -195.74001 & $c w-a-62$ & 500.513 & 3500.95 & 1330 & -192.8 \\
\hline cw-a-13 & 500.108 & 3500.96 & 1312 & -195.73 & $c w-a-63$ & 500.521 & 3500.95 & 1331 & -192.75 \\
\hline cw-a-14 & 500.116 & 3500.96 & 1312 & -195.75999 & cw-a-64 & 500.53 & 3500.95 & 1331 & -192.71001 \\
\hline cw-a-15 & 500.12399 & 3500.96 & 1312 & -195.75999 & $c w-a-65$ & 500.53699 & 3500.95 & 1332 & -192.64999 \\
\hline cw-a-16 & 500.13199 & 3500.96 & 1312 & -195.75999 & cw-a-66 & 500.54599 & 3500.95 & 1333 & -192.64 \\
\hline cw-a-17 & 500.14099 & 3500.96 & 1313 & -195.78999 & cw-a-67 & 500.55399 & 3500.95 & 1333 & -192.64 \\
\hline cw-a-18 & 500.14899 & 3500.96 & 1313 & -195.8 & cw-a-68 & 500.56201 & 3500.95 & 1334 & -192.63 \\
\hline cw-a-19 & 500.15799 & 3500.96 & 1313 & -195.8 & cw-a-69 & 500.57001 & 3500.95 & 1335 & -192.66 \\
\hline cw-a-20 & 500.16599 & 3500.96 & 1313 & -195.78999 & cw-a-70 & 500.578 & 3500.95 & 1335 & -192.69 \\
\hline$c w-a-21$ & 500.17401 & 3500.96 & 1313 & -195.78999 & cw-a-71 & 500.586 & 3500.95 & 1336 & -192.69 \\
\hline$c w-a-22$ & 500.18301 & 3500.96 & 1313 & -195.81 & cw-a-72 & 500.59399 & 3500.95 & 1337 & -192.72 \\
\hline$c w-a-23$ & 500.19101 & 3500.97 & 1313 & -195.81 & cw-a-73 & 500.60199 & 3500.95 & 1337 & -192.77 \\
\hline$c w-a-24$ & 500.20001 & 3500.97 & 1313 & -195.78999 & cw-a-74 & 500.61099 & 3500.95 & 1338 & -192.82001 \\
\hline$c w-a-25$ & 500.207 & 3500.97 & 1313 & -195.78 & $\mathrm{cw}-\mathrm{a}-75$ & 500.61801 & 3500.95 & 1339 & -192.89 \\
\hline$c w-a-26$ & 500.216 & 3500.97 & 1313 & -195.75999 & cw-a-76 & 500.62601 & 3500.95 & 1339 & -192.96001 \\
\hline$c w-a-27$ & 500.224 & 3500.97 & 1313 & -195.77 & cw-a-77 & 500.63501 & 3500.95 & 1340 & -193 \\
\hline cw-a-28 & 500.233 & 3500.97 & 1314 & -195.77 & cw-a-78 & 500.64301 & 3500.95 & 1341 & -193.10001 \\
\hline$c w-a-29$ & 500.241 & 3500.96 & 1314 & -195.7 & cw-a-79 & 500.651 & 3500.95 & 1342 & -193.25 \\
\hline$c w-a-30$ & 500.24899 & 3500.96 & 1315 & -195.67999 & cw-a- 80 & 500.659 & 3500.95 & 1342 & -193.38 \\
\hline$c w-a-31$ & 500.25699 & 3500.96 & 1315 & -195.66 & cw-a-81 & 500.66699 & 3500.95 & 1343 & -193.53 \\
\hline cw-a-32 & 500.26599 & 3500.96 & 1315 & -195.67 & cw-a-82 & 500.67499 & 3500.95 & 1344 & -193.69 \\
\hline$c w-a-33$ & 500.27399 & 3500.96 & 1316 & -195.64999 & $c w-a-83$ & 500.68301 & 3500.95 & 1344 & -193.89 \\
\hline$c w-a-34$ & 500.28299 & 3500.96 & 1316 & -195.66 & cw-a-84 & 500.69101 & 3500.95 & 1345 & -194.06 \\
\hline$c w-a-35$ & 500.29001 & 3500.96 & 1317 & -195.64999 & $c w-a-85$ & 500.69901 & 3500.95 & 1346 & -194.3 \\
\hline$c w-a-36$ & 500.29901 & 3500.96 & 1317 & -195.60001 & cw-a-86 & 500.707 & 3500.95 & 1346 & -194.53999 \\
\hline cw-a-37 & 500.30701 & 3500.96 & 1317 & -195.50999 & cw-a-87 & 500.715 & 3500.95 & 1347 & -194.82001 \\
\hline$c w-a-38$ & 500.31601 & 3500.96 & 1318 & -195.39999 & cw-a-88 & 500.72299 & 3500.95 & 1348 & -195.12 \\
\hline$c w-a-39$ & 500.32401 & 3500.96 & 1318 & -195.28999 & cw-a-89 & 500.73099 & 3500.95 & 1349 & -195.42999 \\
\hline$c w-a-40$ & 500.332 & 3500.96 & 1319 & -195.22 & cw-a-90 & 500.73901 & 3500.95 & 1349 & -195.78 \\
\hline$c w-a-41$ & 500.34 & 3500.96 & 1319 & -195.14 & cw-a-91 & 500.74701 & 3500.95 & 1350 & -196.13 \\
\hline$c w-a-42$ & 500.349 & 3500.96 & 1319 & -195.05 & cw-a-92 & 500.755 & 3500.95 & 1351 & -196.53999 \\
\hline$c w-a-43$ & 500.35699 & 3500.96 & 1320 & -194.97 & cw-a-93 & 500.763 & 3500.95 & 1352 & -196.94 \\
\hline$c w-a-44$ & 500.366 & 3500.96 & 1320 & -194.87 & cw-a-94 & 500.771 & 3500.95 & 1353 & -197.36 \\
\hline$c w-a-45$ & 500.37299 & 3500.96 & 1320 & -194.77 & cw-a-95 & 500.77802 & 3500.95 & 1353 & -197.78999 \\
\hline$c w-a-46$ & 500.38199 & 3500.96 & 1321 & -194.67999 & cw-a-96 & 500.78699 & 3500.95 & 1354 & -198.25 \\
\hline$c w-a-47$ & 500.39001 & 3500.96 & 1321 & -194.56 & cw-a-97 & 500.79501 & 3500.95 & 1355 & -198.69 \\
\hline cw-a-48 & 500.39899 & 3500.96 & 1322 & -194.41 & cw-a-98 & 500.80301 & 3500.95 & 1356 & -199.14 \\
\hline
\end{tabular}




\begin{tabular}{|c|c|c|c|c|c|c|c|c|c|}
\hline cw-a-49 & 500.40701 & 3500.96 & 1322 & -194.27 & cw-a-99 & 500.811 & 3500.95 & 1356 & -199.63 \\
\hline cw-a-50 & 500.41501 & 3500.96 & 1323 & -194.11 & cw-a-100 & 500.81799 & 3500.95 & 1357 & -200.12 \\
\hline cw-a-101 & 500.82599 & 3500.95 & 1358 & -200.63 & cw-a-156 & 501.25699 & 3500.97 & 1383 & -223.46001 \\
\hline cw-a-102 & 500.83401 & 3500.95 & 1359 & -201.13 & cw-a-157 & 501.26501 & 3500.97 & 1383 & -223.71001 \\
\hline cw-a-103 & 500.84201 & 3500.95 & 1360 & -201.67 & cw-a-158 & 501.27301 & 3500.97 & 1383 & -223.91 \\
\hline cw-a-104 & 500.85001 & 3500.95 & 1360 & -202.17 & cw-a-159 & 501.28101 & 3500.97 & 1384 & -224.17999 \\
\hline cw-a-105 & 500.858 & 3500.95 & 1361 & -202.7 & cw-a-160 & 501.28799 & 3500.97 & 1384 & -224.41 \\
\hline cw-a-106 & 500.866 & 3500.95 & 1362 & -203.28999 & cw-a-161 & 501.29599 & 3500.97 & 1384 & -224.64999 \\
\hline cw-a-107 & 500.87399 & 3500.95 & 1363 & -203.86 & cw-a-162 & 501.30399 & 3500.97 & 1385 & -224.88 \\
\hline cw-a-108 & 500.88199 & 3500.95 & 1363 & -204.41 & cw-a-163 & 501.31201 & 3500.97 & 1385 & -225.13 \\
\hline cw-a-109 & 500.89001 & 3500.95 & 1364 & -204.98 & cw-a-164 & 501.32001 & 3500.97 & 1385 & -225.36 \\
\hline cw-a-110 & 500.897 & 3500.95 & 1364 & -205.56 & cw-a-165 & 501.327 & 3500.97 & 1385 & -225.61 \\
\hline cw-a-111 & 500.905 & 3500.95 & 1365 & -206.09 & cw-a-166 & 501.33499 & 3500.97 & 1386 & -225.84 \\
\hline cw-a-112 & 500.91299 & 3500.95 & 1366 & -206.64999 & cw-a-167 & 501.34299 & 3500.97 & 1386 & -226.03999 \\
\hline cw-a-113 & 500.92099 & 3500.96 & 1366 & -207.19 & cw-a-168 & 501.35101 & 3500.97 & 1386 & -226.21001 \\
\hline cw-a-114 & 500.92899 & 3500.96 & 1367 & -207.73 & cw-a-169 & 501.35901 & 3500.97 & 1387 & -226.42 \\
\hline cw-a-115 & 500.936 & 3500.96 & 1367 & -208.25 & cw-a-170 & 501.366 & 3500.97 & 1387 & -226.60001 \\
\hline cw-a-116 & 500.944 & 3500.96 & 1368 & -208.75 & cw-a-171 & 501.37399 & 3500.97 & 1387 & -226.78 \\
\hline cw-a-117 & 500.952 & 3500.96 & 1369 & -209.27 & cw-a-172 & 501.38199 & 3500.97 & 1387 & -226.96001 \\
\hline cw-a-118 & 500.95999 & 3500.96 & 1369 & -209.78 & cw-a-173 & 501.39001 & 3500.97 & 1387 & -227.16 \\
\hline cw-a-119 & 500.96799 & 3500.96 & 1370 & -210.27 & cw-a-174 & 501.39801 & 3500.97 & 1388 & -227.34 \\
\hline cw-a-120 & 500.97501 & 3500.96 & 1370 & -210.77 & cw-a-175 & 501.405 & 3500.97 & 1388 & -227.53999 \\
\hline cw-a-121 & 500.983 & 3500.96 & 1371 & -211.24001 & cw-a-176 & 501.41299 & 3500.97 & 1388 & -227.74001 \\
\hline cw-a-122 & 500.991 & 3500.96 & 1372 & -211.73 & cw-a-177 & 501.42099 & 3500.97 & 1388 & -227.96001 \\
\hline cw-a-123 & 500.99899 & 3500.96 & 1372 & -212.19 & cw-a-178 & 501.42899 & 3500.97 & 1388 & -228.16 \\
\hline cw-a-124 & 501.00699 & 3500.96 & 1373 & -212.63 & cw-a-179 & 501.43701 & 3500.97 & 1389 & -228.38 \\
\hline cw-a-125 & 501.01501 & 3500.96 & 1373 & -213.09 & cw-a-180 & 501.444 & 3500.97 & 1389 & -228.58 \\
\hline cw-a-126 & 501.022 & 3500.96 & 1374 & -213.50999 & cw-a-181 & 501.452 & 3500.97 & 1389 & -228.78 \\
\hline cw-a-127 & 501.03 & 3500.96 & 1375 & -213.97 & cw-a-182 & 501.45999 & 3500.97 & 1389 & -228.98 \\
\hline cw-a-128 & 501.03799 & 3500.96 & 1375 & -214.42 & cw-a-183 & 501.46799 & 3500.97 & 1389 & -229.16 \\
\hline cw-a-129 & 501.04599 & 3500.96 & 1375 & -214.81 & cw-a-184 & 501.47601 & 3500.97 & 1390 & -229.34 \\
\hline cw-a-130 & 501.05399 & 3500.96 & 1375 & -215.2 & cw-a-185 & 501.483 & 3500.97 & 1390 & -229.53999 \\
\hline cw-a-131 & 501.06201 & 3500.96 & 1376 & -215.63 & cw-a-186 & 501.491 & 3500.97 & 1390 & -229.72 \\
\hline cw-a-132 & 501.069 & 3500.96 & 1376 & -216.03 & cw-a-187 & 501.49899 & 3500.97 & 1390 & -229.91 \\
\hline cw-a-133 & 501.077 & 3500.97 & 1376 & -216.41 & cw-a-188 & 501.50699 & 3500.97 & 1390 & -230.08 \\
\hline cw-a-134 & 501.08499 & 3500.97 & 1376 & -216.78 & cw-a-189 & 501.51501 & 3500.97 & 1390 & -230.25 \\
\hline cw-a-135 & 501.09299 & 3500.97 & 1377 & -217.16 & cw-a-190 & 501.52301 & 3500.97 & 1390 & -230.45 \\
\hline cw-a-136 & 501.10101 & 3500.97 & 1377 & -217.52 & cw-a-191 & 501.53101 & 3500.97 & 1390 & -230.63 \\
\hline cw-a-137 & 501.10901 & 3500.97 & 1377 & -217.88 & cw-a-192 & 501.539 & 3500.97 & 1390 & -230.8 \\
\hline cw-a-138 & 501.116 & 3500.97 & 1377 & -218.24001 & cw-a-193 & 501.547 & 3500.97 & 1390 & -230.96001 \\
\hline cw-a-139 & 501.12399 & 3500.97 & 1378 & -218.60001 & cw-a-194 & 501.55499 & 3500.97 & 1390 & -231.09 \\
\hline cw-a-140 & 501.13199 & 3500.97 & 1378 & -218.94 & cw-a-195 & 501.56201 & 3500.97 & 1390 & -231.27 \\
\hline cw-a-141 & 501.14001 & 3500.97 & 1378 & -219.27 & cw-a-196 & 501.57001 & 3500.97 & 1390 & -231.42 \\
\hline cw-a-142 & 501.14801 & 3500.97 & 1378 & -219.59 & cw-a-197 & 501.578 & 3500.97 & 1390 & -231.61 \\
\hline cw-a-143 & 501.155 & 3500.97 & 1379 & -219.91 & cw-a-198 & 501.586 & 3500.97 & 1390 & -231.78 \\
\hline cw-a-144 & 501.16299 & 3500.97 & 1379 & -220.28 & cw-a-199 & 501.59399 & 3500.97 & 1390 & -231.92999 \\
\hline cw-a-145 & 501.17099 & 3500.97 & 1379 & -220.58 & $c w-a-200$ & 501.60101 & 3500.97 & 1390 & -232.12 \\
\hline cw-a-146 & 501.17899 & 3500.97 & 1379 & -220.86 & cw-a-201 & 501.60901 & 3500.97 & 1390 & -232.3 \\
\hline cw-a-147 & 501.18701 & 3500.97 & 1380 & -221.13 & cw-a-202 & 501.617 & 3500.97 & 1390 & -232.48 \\
\hline cw-a-148 & 501.19501 & 3500.97 & 1380 & -221.39999 & $c w-a-203$ & 501.625 & 3500.97 & 1390 & -232.66 \\
\hline cw-a-149 & 501.202 & 3500.97 & 1380 & -221.67 & cw-a-204 & 501.633 & 3500.97 & 1390 & -232.8 \\
\hline$c w-a-150$ & 501.20999 & 3500.97 & 1381 & -221.91 & $c w-a-205$ & 501.64001 & 3500.97 & 1390 & -232.99001 \\
\hline cw-a-151 & 501.21799 & 3500.97 & 1381 & -222.17999 & cw-a-206 & 501.64801 & 3500.97 & 1390 & -233.12 \\
\hline cw-a-152 & 501.22601 & 3500.97 & 1381 & -222.42999 & cw-a-207 & 501.65601 & 3500.97 & 1391 & -233.27 \\
\hline cw-a-153 & 501.23401 & 3500.97 & 1382 & -222.73 & cw-a-208 & 501.664 & 3500.97 & 1390 & -233.42 \\
\hline cw-a-154 & 501.242 & 3500.97 & 1382 & -222.98 & cw-a-209 & 501.672 & 3500.97 & 1390 & -233.53 \\
\hline cw-a-155 & 501.24899 & 3500.97 & 1382 & -223.23 & cw-a-210 & 501.67999 & 3500.97 & 1390 & -233.69 \\
\hline
\end{tabular}




\begin{tabular}{|c|c|c|c|c|c|c|c|c|c|}
\hline cw-a-211 & 501.68799 & 3500.97 & 1390 & -233.8 & $c w-a-262$ & 502.09299 & 3500.95 & 1395 & -229.12 \\
\hline cw-a-212 & 501.69601 & 3500.97 & 1390 & -233.92999 & cw-a-263 & 502.10101 & 3500.95 & 1396 & -229 \\
\hline cw-a-213 & 501.70401 & 3500.97 & 1390 & -234.05 & $c w-a-264$ & 502.10901 & 3500.95 & 1396 & -228.91 \\
\hline cw-a-214 & 501.71201 & 3500.97 & 1390 & -234.14999 & $c w-a-265$ & 502.117 & 3500.95 & 1396 & -228.82001 \\
\hline cw-a-215 & 501.71899 & 3500.97 & 1390 & -234.27 & $c w-a-266$ & 502.125 & 3500.95 & 1396 & -228.78999 \\
\hline cw-a-216 & 501.72699 & 3500.97 & 1390 & -234.35001 & cw-a-267 & 502.133 & 3500.95 & 1397 & -228.78999 \\
\hline cw-a-217 & 501.73499 & 3500.97 & 1390 & -234.41 & cw-a-268 & 502.14099 & 3500.95 & 1397 & -228.75999 \\
\hline cw-a-218 & 501.74301 & 3500.97 & 1390 & -234.49001 & cw-a-269 & 502.14899 & 3500.95 & 1398 & -228.78 \\
\hline cw-a-219 & 501.75101 & 3500.97 & 1390 & -234.57001 & cw-a-270 & 502.15701 & 3500.95 & 1398 & -228.8 \\
\hline cw-a-220 & 501.759 & 3500.97 & 1390 & -234.59 & cw-a-271 & 502.16501 & 3500.95 & 1398 & -228.88 \\
\hline cw-a-221 & 501.767 & 3500.97 & 1390 & -234.64999 & cw-a-272 & 502.173 & 3500.95 & 1399 & -229 \\
\hline cw-a-222 & 501.77499 & 3500.97 & 1390 & -234.67 & cw-a-273 & 502.181 & 3500.95 & 1399 & -229.11 \\
\hline$c w-a-223$ & 501.78299 & 3500.97 & 1390 & -234.67 & cw-a-274 & 502.189 & 3500.95 & 1400 & -229.21001 \\
\hline cw-a-224 & 501.79099 & 3500.97 & 1390 & -234.67 & cw-a-275 & 502.19699 & 3500.96 & 1400 & -229.37 \\
\hline cw-a-225 & 501.798 & 3500.97 & 1390 & -234.7 & cw-a-276 & 502.20499 & 3500.96 & 1401 & -229.5 \\
\hline cw-a-226 & 501.806 & 3500.97 & 1390 & -234.67 & cw-a-277 & 502.21301 & 3500.96 & 1401 & -229.72 \\
\hline cw-a-227 & 501.814 & 3500.97 & 1390 & -234.66 & cw-a-278 & 502.22101 & 3500.96 & 1402 & -229.94 \\
\hline cw-a-228 & 501.82199 & 3500.97 & 1390 & -234.59 & cw-a-279 & 502.229 & 3500.96 & 1402 & -230.19 \\
\hline cw-a-229 & 501.82999 & 3500.96 & 1390 & -234.53999 & cw-a-280 & 502.237 & 3500.96 & 1403 & -230.45 \\
\hline cw-a-230 & 501.83801 & 3500.96 & 1390 & -234.47 & cw-a-281 & 502.245 & 3500.96 & 1403 & -230.67999 \\
\hline cw-a-231 & 501.84601 & 3500.96 & 1390 & -234.36 & cw-a-282 & 502.25299 & 3500.96 & 1404 & -230.97 \\
\hline cw-a-232 & 501.854 & 3500.96 & 1390 & -234.27 & cw-a-283 & 502.26099 & 3500.96 & 1404 & -231.25 \\
\hline cw-a-233 & 501.862 & 3500.96 & 1390 & -234.17 & cw-a-284 & 502.26901 & 3500.96 & 1405 & -231.57001 \\
\hline cw-a-234 & 501.87 & 3500.96 & 1390 & -234.05 & $c w-a-285$ & 502.276 & 3500.96 & 1405 & -231.89 \\
\hline cw-a-235 & 501.87799 & 3500.96 & 1390 & -233.92 & $c w-a-286$ & 502.285 & 3500.96 & 1406 & -232.19 \\
\hline cw-a-236 & 501.88599 & 3500.96 & 1391 & -233.78 & cw-a-287 & 502.293 & 3500.96 & 1406 & -232.53 \\
\hline cw-a-237 & 501.89401 & 3500.96 & 1391 & -233.63 & cw-a-288 & 502.30099 & 3500.96 & 1407 & -232.85001 \\
\hline cw-a-238 & 501.90201 & 3500.96 & 1391 & -233.52 & cw-a-289 & 502.30899 & 3500.96 & 1407 & -233.25 \\
\hline$c w-a-239$ & 501.91 & 3500.96 & 1391 & -233.37 & $c w-a-290$ & 502.31601 & 3500.96 & 1407 & -233.59 \\
\hline cw-a-240 & 501.91699 & 3500.96 & 1391 & -233.23 & cw-a-291 & 502.32401 & 3500.96 & 1408 & -233.96001 \\
\hline cw-a-241 & 501.92599 & 3500.96 & 1391 & -233.05 & cw-a-292 & 502.332 & 3500.96 & 1408 & -234.36 \\
\hline cw-a-242 & 501.93399 & 3500.96 & 1391 & -232.92 & cw-a-293 & 502.341 & 3500.96 & 1409 & -234.78 \\
\hline$c w-a-243$ & 501.94199 & 3500.96 & 1391 & -232.73 & cw-a-294 & 502.349 & 3500.96 & 1409 & -235.2 \\
\hline cw-a-244 & 501.95001 & 3500.96 & 1391 & -232.55 & cw-a-295 & 502.35599 & 3500.96 & 1409 & -235.61 \\
\hline cw-a-245 & 501.957 & 3500.96 & 1392 & -232.34 & cw-a-296 & 502.36401 & 3500.96 & 1410 & -236.03999 \\
\hline cw-a-246 & 501.965 & 3500.96 & 1392 & -232.14999 & cw-a-297 & 502.37201 & 3500.96 & 1410 & -236.48 \\
\hline cw-a-247 & 501.97299 & 3500.96 & 1392 & -231.92999 & cw-a-298 & 502.38 & 3500.96 & 1411 & -236.89999 \\
\hline cw-a-248 & 501.98199 & 3500.96 & 1392 & -231.74001 & cw-a-299 & 502.38901 & 3500.96 & 1411 & -237.34 \\
\hline cw-a-249 & 501.98999 & 3500.96 & 1392 & -231.5 & cw-a-300 & 502.396 & 3500.96 & 1411 & -237.77 \\
\hline$c w-a-250$ & 501.99701 & 3500.96 & 1393 & -231.28 & cw-a-301 & 502.40399 & 3500.96 & 1412 & -238.21001 \\
\hline cw-a-251 & 502.005 & 3500.96 & 1393 & -231.05 & cw-a-302 & 502.41199 & 3500.97 & 1412 & -238.62 \\
\hline$c w-a-252$ & 502.013 & 3500.96 & 1393 & -230.86 & cw-a-303 & 502.42001 & 3500.97 & 1413 & -239.07001 \\
\hline$c w-a-253$ & 502.021 & 3500.96 & 1393 & -230.62 & cw-a-304 & 502.42801 & 3500.97 & 1413 & -239.5 \\
\hline$c w-a-254$ & 502.03 & 3500.96 & 1393 & -230.42999 & cw-a-305 & 502.436 & 3500.97 & 1413 & -239.91 \\
\hline cw-a-255 & 502.03699 & 3500.96 & 1394 & -230.25 & cw-a-306 & 502.444 & 3500.97 & 1414 & -240.36 \\
\hline cw-a-256 & 502.04501 & 3500.96 & 1394 & -230.03999 & cw-a-307 & 502.452 & 3500.97 & 1414 & -240.77 \\
\hline$c w-a-257$ & 502.05301 & 3500.96 & 1394 & -229.89 & cw-a-308 & 502.45999 & 3500.97 & 1415 & -241.21001 \\
\hline cw-a-258 & 502.061 & 3500.96 & 1394 & -229.7 & cw-a-309 & 502.46799 & 3500.97 & 1415 & -241.62 \\
\hline cw-a-259 & 502.069 & 3500.96 & 1395 & -229.52 & $c w-a-310$ & 502.47601 & 3500.97 & 1416 & -242.02 \\
\hline$c w-a-260$ & 502.077 & 3500.96 & 1395 & -229.38 & cw-a-311 & 502.48401 & 3500.97 & 1416 & -242.46001 \\
\hline cw-a-261 & 502.08499 & 3500.95 & 1395 & -229.25 & cw-a-312 & 502.492 & 3500.97 & 1417 & -242.88 \\
\hline rr-a-1 & 499.53601 & 3506.8799 & 1369 & -119.23 & rr-a-56 & 498.94601 & 3506.9299 & 1311 & -171.55 \\
\hline rr-a-2 & 499.52499 & 3506.8799 & 1368 & -119.75 & rr-a-57 & 498.935 & 3506.9299 & 1310 & -171.73 \\
\hline rr-a-3 & 499.51401 & 3506.8799 & 1366 & -120.31 & rr-a-58 & 498.92401 & 3506.9299 & 1309 & -171.89999 \\
\hline
\end{tabular}




\begin{tabular}{|c|c|c|c|c|c|c|c|c|c|}
\hline rr-a-4 & 499.504 & 3506.8799 & 1365 & -120.91 & rr-a-59 & 498.914 & 3506.9299 & 1309 & -172.00999 \\
\hline rr-a-5 & 499.49301 & 3506.8799 & 1364 & -121.58 & rr-a-60 & 498.90302 & 3506.9299 & 1308 & -172.09 \\
\hline rr-a-6 & 499.48199 & 3506.8799 & 1363 & -122.25 & rr-a-61 & 498.892 & 3506.9299 & 1307 & -172.11 \\
\hline rr-a-7 & 499.47101 & 3506.8899 & 1362 & -123.04 & rr-a-62 & 498.88101 & 3506.9299 & 1306 & -172.12 \\
\hline rr-a-8 & 499.461 & 3506.8899 & 1361 & -123.84 & rr-a-63 & 498.87 & 3506.9299 & 1305 & -172.07001 \\
\hline rr-a-9 & 499.45001 & 3506.8899 & 1360 & -124.72 & rr-a-64 & 498.85999 & 3506.9299 & 1304 & -172.00999 \\
\hline rr-a-10 & 499.44 & 3506.8899 & 1359 & -125.63 & rr-a-65 & 498.849 & 3506.9299 & 1303 & -171.97 \\
\hline rr-a-11 & 499.42899 & 3506.8899 & 1358 & -126.59 & rr-a-66 & 498.83801 & 3506.9299 & 1302 & -171.89 \\
\hline rr-a-12 & 499.418 & 3506.8899 & 1357 & -127.62 & rr-a-67 & 498.827 & 3506.9299 & 1302 & -171.73 \\
\hline rr-a-13 & 499.40701 & 3506.8899 & 1356 & -128.59 & rr-a-68 & 498.81699 & 3506.9299 & 1301 & -171.53 \\
\hline rr-a-14 & 499.397 & 3506.8899 & 1355 & -129.67 & rr-a-69 & 498.80701 & 3506.9299 & 1301 & -171.28 \\
\hline rr-a-15 & 499.38599 & 3506.8899 & 1354 & -130.72 & rr-a-70 & 498.79599 & 3506.9299 & 1300 & -171 \\
\hline rr-a-16 & 499.375 & 3506.8899 & 1353 & -131.84 & rr-a-71 & 498.785 & 3506.9299 & 1300 & -170.67999 \\
\hline rr-a-17 & 499.36401 & 3506.8999 & 1351 & -132.97 & rr-a-72 & 498.77399 & 3506.9299 & 1299 & -170.36 \\
\hline rr-a-18 & 499.353 & 3506.8999 & 1350 & -134.12 & rr-a-73 & 498.763 & 3506.9299 & 1299 & -170.00999 \\
\hline rr-a-19 & 499.34299 & 3506.8999 & 1349 & -135.34 & rr-a-74 & 498.75299 & 3506.9299 & 1298 & -169.73 \\
\hline rr-a-20 & 499.332 & 3506.8999 & 1348 & -136.53999 & rr-a-75 & 498.742 & 3506.9299 & 1298 & -169.47 \\
\hline rr-a-21 & 499.32101 & 3506.8999 & 1347 & -137.77 & rr-a-76 & 498.73199 & 3506.9199 & 1297 & -169.21001 \\
\hline rr-a-22 & 499.31 & 3506.8999 & 1346 & -139.02 & rr-a-77 & 498.72101 & 3506.9199 & 1296 & -168.95 \\
\hline rr-a-23 & 499.29901 & 3506.8999 & 1345 & -140.3 & rr-a-78 & 498.70999 & 3506.9199 & 1296 & -168.7 \\
\hline rr-a-24 & 499.289 & 3506.8999 & 1344 & -141.53999 & rr-a-79 & 498.70001 & 3506.9199 & 1295 & -168.45 \\
\hline rr-a-25 & 499.27802 & 3506.8999 & 1343 & -142.82001 & rr-a-80 & 498.689 & 3506.9199 & 1295 & -168.24001 \\
\hline rr-a-26 & 499.26801 & 3506.9099 & 1342 & -144.07001 & rr-a-81 & 498.67801 & 3506.9199 & 1294 & -168.05 \\
\hline rr-a-27 & 499.25699 & 3506.9099 & 1341 & -145.34 & rr-a-82 & 498.668 & 3506.9199 & 1294 & -167.86 \\
\hline rr-a-28 & 499.246 & 3506.9099 & 1340 & -146.61 & rr-a-83 & 498.65701 & 3506.9199 & 1293 & -167.66 \\
\hline rr-a-29 & 499.23599 & 3506.9099 & 1339 & -147.85001 & rr-a-84 & 498.647 & 3506.9199 & 1293 & -167.45 \\
\hline rr-a-30 & 499.22501 & 3506.9099 & 1338 & -149.12 & rr-a-85 & 498.63599 & 3506.9199 & 1292 & -167.25 \\
\hline rr-a-31 & 499.21399 & 3506.9099 & 1337 & -150.36 & rr-a-86 & 498.625 & 3506.9199 & 1292 & -167.07001 \\
\hline rr-a-32 & 499.203 & 3506.9099 & 1335 & -151.63 & rr-a-87 & 498.61401 & 3506.9199 & 1291 & -166.89 \\
\hline rr-a-33 & 499.19199 & 3506.9099 & 1334 & -152.89 & rr-a-88 & 498.604 & 3506.9199 & 1291 & -166.67999 \\
\hline rr-a-34 & 499.18201 & 3506.9099 & 1333 & -154.16 & rr-a-89 & 498.59399 & 3506.9199 & 1291 & -166.5 \\
\hline rr-a-35 & 499.17099 & 3506.9099 & 1332 & -155.38 & rr-a-90 & 498.58301 & 3506.9199 & 1291 & -166.35001 \\
\hline rr-a-36 & 499.16 & 3506.9099 & 1331 & -156.59 & rr-a-91 & 498.573 & 3506.9099 & 1291 & -166.13 \\
\hline rr-a-37 & 499.14899 & 3506.9099 & 1330 & -157.75 & rr-a-92 & 498.56201 & 3506.9099 & 1290 & -165.92999 \\
\hline rr-a-38 & 499.138 & 3506.9099 & 1329 & -158.89 & rr-a-93 & 498.55099 & 3506.9099 & 1290 & -165.72 \\
\hline rr-a-39 & 499.12799 & 3506.9199 & 1328 & -160 & rr-a-94 & 498.54099 & 3506.9099 & 1290 & -165.53 \\
\hline rr-a-40 & 499.117 & 3506.9199 & 1327 & -161.08 & rr-a-95 & 498.53101 & 3506.9099 & 1290 & -165.3 \\
\hline rr-a-41 & 499.10599 & 3506.9199 & 1326 & -162.10001 & rr-a-96 & 498.51999 & 3506.9099 & 1290 & -165.10001 \\
\hline rr-a-42 & 499.09601 & 3506.9199 & 1325 & -163.12 & rr-a-97 & 498.51001 & 3506.9099 & 1289 & -164.88 \\
\hline rr-a-43 & 499.08499 & 3506.9199 & 1323 & -164.05 & rr-a-98 & 498.49899 & 3506.9099 & 1289 & -164.63 \\
\hline rr-a-44 & 499.07501 & 3506.9199 & 1322 & -164.99001 & rr-a-99 & 498.48901 & 3506.9099 & 1289 & -164.37 \\
\hline rr-a-45 & 499.064 & 3506.9199 & 1321 & -165.86 & rr-a-100 & 498.478 & 3506.9099 & 1289 & -164.12 \\
\hline rr-a-46 & 499.05301 & 3506.9199 & 1320 & -166.67 & rr-a-101 & 498.46799 & 3506.8999 & 1289 & -163.92999 \\
\hline rr-a-47 & 499.04199 & 3506.9199 & 1319 & -167.42999 & rr-a-102 & 498.457 & 3506.8999 & 1288 & -163.67999 \\
\hline rr-a-48 & 499.03101 & 3506.9199 & 1318 & -168.09 & rr-a-103 & 498.44601 & 3506.8999 & 1288 & -163.48 \\
\hline rr-a-49 & 499.021 & 3506.9199 & 1318 & -168.75 & rr-a-104 & 498.43701 & 3506.8999 & 1288 & -163.25999 \\
\hline rr-a-50 & 499.01001 & 3506.9199 & 1317 & -169.32001 & rr-a-105 & 498.42599 & 3506.8999 & 1288 & -163.07001 \\
\hline rr-a-51 & 498.99899 & 3506.9199 & 1316 & -169.83 & rr-a-106 & 498.41501 & 3506.8999 & 1288 & -162.83 \\
\hline rr-a-52 & 498.98801 & 3506.9199 & 1315 & -170.25 & rr-a-107 & 498.405 & 3506.8999 & 1288 & -162.61 \\
\hline rr-a-53 & 498.97699 & 3506.9299 & 1314 & -170.66 & rr-a-108 & 498.39401 & 3506.8999 & 1288 & -162.37 \\
\hline rr-a-54 & 498.96701 & 3506.9299 & 1313 & -171 & rr-a-109 & 498.38501 & 3506.8999 & 1288 & -162.17 \\
\hline rr-a-55 & 498.95599 & 3506.9299 & 1312 & -171.32001 & rr-a-110 & 498.37399 & 3506.8899 & 1288 & -161.91 \\
\hline rr-a-111 & 498.36401 & 3506.8899 & 1288 & -161.67999 & rr-a-166 & 497.80701 & 3506.8601 & 1289 & -158.56 \\
\hline rr-a-112 & 498.353 & 3506.8899 & 1288 & -161.44 & rr-a-167 & 497.797 & 3506.8601 & 1289 & -158.71001 \\
\hline rr-a-113 & 498.34299 & 3506.8899 & 1288 & -161.2 & rr-a-168 & 497.78699 & 3506.8601 & 1289 & -158.82001 \\
\hline rr-a-114 & 498.33301 & 3506.8899 & 1288 & -161.00999 & rr-a-169 & 497.77701 & 3506.8601 & 1289 & -158.96001 \\
\hline rr-a-115 & 498.323 & 3506.8899 & 1288 & -160.75999 & rr-a-170 & 497.767 & 3506.8601 & 1289 & -159.11 \\
\hline
\end{tabular}




\begin{tabular}{|c|c|c|c|c|c|c|c|c|c|}
\hline rr-a-116 & 498.31201 & 3506.8899 & 1288 & -160.55 & rr-a-171 & 497.75699 & 3506.8601 & 1289 & -159.28 \\
\hline rr-a-117 & 498.302 & 3506.8899 & 1288 & -160.32001 & rr-a-172 & 497.74799 & 3506.8601 & 1289 & -159.39999 \\
\hline rr-a-118 & 498.29099 & 3506.8899 & 1288 & -160.08 & rr-a-173 & 497.73801 & 3506.8601 & 1289 & -159.59 \\
\hline rr-a-119 & 498.28201 & 3506.8799 & 1288 & -159.88 & rr-a-174 & 497.728 & 3506.8601 & 1289 & -159.75 \\
\hline $\mathrm{rr}-\mathrm{a}-120$ & 498.271 & 3506.8799 & 1288 & -159.67 & rr-a-175 & 497.71799 & 3506.8601 & 1289 & -159.94 \\
\hline rr-a-121 & 498.26099 & 3506.8799 & 1288 & -159.5 & rr-a-176 & 497.70801 & 3506.8601 & 1289 & -160.09 \\
\hline rr-a-122 & 498.25 & 3506.8799 & 1288 & -159.36 & rr-a-177 & 497.698 & 3506.8601 & 1289 & -160.25 \\
\hline rr-a-123 & 498.23999 & 3506.8799 & 1288 & -159.2 & rr-a-178 & 497.68799 & 3506.8601 & 1289 & -160.45 \\
\hline rr-a-124 & 498.23001 & 3506.8799 & 1288 & -159.07001 & rr-a-179 & 497.67899 & 3506.8601 & 1289 & -160.63 \\
\hline rr-a-125 & 498.22 & 3506.8799 & 1288 & -158.98 & rr-a-180 & 497.66901 & 3506.8601 & 1289 & -160.82001 \\
\hline rr-a-126 & 498.20901 & 3506.8799 & 1288 & -158.89999 & rr-a-181 & 497.659 & 3506.8601 & 1289 & -161.03 \\
\hline rr-a-127 & 498.19901 & 3506.8799 & 1288 & -158.78 & rr-a-182 & 497.64899 & 3506.8601 & 1289 & -161.22 \\
\hline rr-a-128 & 498.189 & 3506.8701 & 1288 & -158.66 & rr-a-183 & 497.63901 & 3506.8601 & 1289 & -161.39999 \\
\hline rr-a-129 & 498.17899 & 3506.8701 & 1288 & -158.59 & rr-a-184 & 497.63 & 3506.8601 & 1289 & -161.60001 \\
\hline rr-a-130 & 498.16901 & 3506.8701 & 1288 & -158.52 & rr-a-185 & 497.62 & 3506.8601 & 1289 & -161.78999 \\
\hline rr-a-131 & 498.159 & 3506.8701 & 1288 & -158.45 & rr-a-186 & 497.60999 & 3506.8601 & 1289 & -161.98 \\
\hline $\mathrm{rr}-\mathrm{a}-132$ & 498.14801 & 3506.8701 & 1288 & -158.44 & rr-a-187 & 497.60001 & 3506.8601 & 1289 & -162.22 \\
\hline rr-a-133 & 498.138 & 3506.8701 & 1287 & -158.36 & rr-a-188 & 497.591 & 3506.8601 & 1289 & -162.41 \\
\hline rr-a-134 & 498.129 & 3506.8701 & 1287 & -158.3 & rr-a-189 & 497.582 & 3506.8601 & 1289 & -162.61 \\
\hline rr-a-135 & 498.11801 & 3506.8701 & 1287 & -158.25 & rr-a-190 & 497.57199 & 3506.8601 & 1288 & -162.87 \\
\hline rr-a-136 & 498.108 & 3506.8701 & 1287 & -158.14999 & rr-a-191 & 497.56201 & 3506.8601 & 1288 & -163.09 \\
\hline rr-a-137 & 498.09799 & 3506.8701 & 1287 & -158.02 & rr-a-192 & 497.552 & 3506.8601 & 1288 & -163.32001 \\
\hline rr-a-138 & 498.08701 & 3506.8701 & 1287 & -157.95 & rr-a-193 & 497.54199 & 3506.8701 & 1288 & -163.53 \\
\hline rr-a-139 & 498.078 & 3506.8701 & 1287 & -157.84 & rr-a-194 & 497.53299 & 3506.8701 & 1287 & -163.77 \\
\hline rr-a-140 & 498.06699 & 3506.8601 & 1287 & -157.73 & & & & & \\
\hline rr-a-141 & 498.05701 & 3506.8601 & 1287 & -157.67999 & & & & & \\
\hline rr-a-142 & 498.047 & 3506.8601 & 1287 & -157.58 & & & & & \\
\hline rr-a-143 & 498.03699 & 3506.8601 & 1286 & -157.52 & & & & & \\
\hline rr-a-144 & 498.02701 & 3506.8601 & 1286 & -157.46001 & & & & & \\
\hline rr-a-145 & 498.017 & 3506.8601 & 1286 & -157.42999 & & & & & \\
\hline rr-a-146 & 498.00601 & 3506.8601 & 1286 & -157.39999 & & & & & \\
\hline rr-a-147 & 497.996 & 3506.8601 & 1286 & -157.39999 & & & & & \\
\hline rr-a-148 & 497.98599 & 3506.8601 & 1286 & -157.45 & & & & & \\
\hline rr-a-149 & 497.97699 & 3506.8601 & 1287 & -157.44 & & & & & \\
\hline rr-a-150 & 497.96701 & 3506.8601 & 1287 & -157.45 & & & & & \\
\hline rr-a-151 & 497.95599 & 3506.8601 & 1287 & -157.44 & & & & & \\
\hline rr-a-152 & 497.94601 & 3506.8601 & 1287 & -157.46001 & & & & & \\
\hline rr-a-153 & 497.936 & 3506.8601 & 1287 & -157.49001 & & & & & \\
\hline rr-a-154 & 497.927 & 3506.8601 & 1287 & -157.50999 & & & & & \\
\hline rr-a-155 & 497.91699 & 3506.8601 & 1287 & -157.56 & & & & & \\
\hline rr-a-156 & 497.90601 & 3506.8601 & 1288 & -157.59 & & & & & \\
\hline rr-a-157 & 497.896 & 3506.8601 & 1288 & -157.66 & & & & & \\
\hline rr-a-158 & 497.88599 & 3506.8601 & 1288 & -157.71001 & & & & & \\
\hline rr-a-159 & 497.87701 & 3506.8601 & 1288 & -157.78999 & & & & & \\
\hline rr-a-160 & 497.867 & 3506.8601 & 1288 & -157.89 & & & & & \\
\hline rr-a-161 & 497.85599 & 3506.8601 & 1288 & -157.97 & & & & & \\
\hline rr-a-162 & 497.84601 & 3506.8601 & 1288 & -158.07001 & & & & & \\
\hline rr-a-163 & 497.836 & 3506.8601 & 1288 & -158.17 & & & & & \\
\hline rr-a-164 & 497.827 & 3506.8601 & 1289 & -158.31 & & & & & \\
\hline rr-a-165 & 497.81699 & 3506.8601 & 1289 & -158.44 & & & & & \\
\hline cc-a-1 & 500.24701 & 3499.95 & 1356 & -140.85001 & cc-a-56 & 500.67001 & 3499.95 & 1380 & -151.45 \\
\hline cc-a-2 & 500.254 & 3499.95 & 1356 & -140.97 & cc-a-57 & 500.677 & 3499.95 & 1380 & -151.85001 \\
\hline cc-a-3 & 500.26199 & 3499.95 & 1357 & -141.09 & cc-a-58 & 500.685 & 3499.96 & 1381 & -152.27 \\
\hline cc-a-4 & 500.26999 & 3499.95 & 1358 & -141.21001 & cc-a-59 & 500.69199 & 3499.96 & 1381 & -152.7 \\
\hline cc-a-5 & 500.27802 & 3499.95 & 1358 & -141.33 & cc-a-60 & 500.70001 & 3499.96 & 1381 & -153.14 \\
\hline cc-a-6 & 500.28601 & 3499.95 & 1359 & -141.42999 & cc-a-61 & 500.70801 & 3499.96 & 1381 & -153.55 \\
\hline cc-a-7 & 500.293 & 3499.95 & 1360 & -141.56 & cc-a-62 & 500.715 & 3499.96 & 1382 & -154 \\
\hline
\end{tabular}




\begin{tabular}{|c|c|c|c|c|c|c|c|c|c|}
\hline cc-a- 8 & 500.30099 & 3499.95 & 1360 & -141.64 & cc-a-63 & 500.72299 & 3499.96 & 1382 & -154.46001 \\
\hline cc-a-9 & 500.30899 & 3499.95 & 1361 & -141.75 & cc-a-64 & 500.73099 & 3499.96 & 1382 & -154.92 \\
\hline cc-a-10 & 500.31699 & 3499.95 & 1362 & -141.85001 & cc-a-65 & 500.73801 & 3499.96 & 1382 & -155.42 \\
\hline cc-a-11 & 500.32401 & 3499.95 & 1362 & -141.97 & cc-a-66 & 500.746 & 3499.96 & 1382 & -155.89999 \\
\hline cc-a-12 & 500.332 & 3499.95 & 1363 & -142.05 & cc-a-67 & 500.75299 & 3499.96 & 1383 & -156.39 \\
\hline cc-a-13 & 500.33899 & 3499.95 & 1363 & -142.16 & cc-a-68 & 500.76099 & 3499.96 & 1383 & -156.89999 \\
\hline cc-a-14 & 500.34698 & 3499.95 & 1364 & -142.25999 & cc-a-69 & 500.76901 & 3499.96 & 1383 & -157.44 \\
\hline cc-a-15 & 500.35501 & 3499.95 & 1364 & -142.38 & cc-a-70 & 500.77701 & 3499.96 & 1383 & -157.94 \\
\hline cc-a-16 & 500.36301 & 3499.95 & 1365 & -142.48 & cc-a-71 & 500.785 & 3499.96 & 1383 & -158.49001 \\
\hline cc-a-17 & 500.37 & 3499.95 & 1365 & -142.59 & cc-a-72 & 500.79199 & 3499.96 & 1383 & -159.06 \\
\hline cc-a-18 & 500.37799 & 3499.95 & 1366 & -142.7 & cc-a-73 & 500.79999 & 3499.96 & 1383 & -159.64 \\
\hline cc-a-19 & 500.38599 & 3499.95 & 1367 & -142.82001 & cc-a-74 & 500.80801 & 3499.96 & 1383 & -160.21001 \\
\hline cc-a-20 & 500.39301 & 3499.95 & 1367 & -142.92999 & cc-a-75 & 500.81601 & 3499.96 & 1383 & -160.82001 \\
\hline cc-a-21 & 500.401 & 3499.95 & 1368 & -143.07001 & cc-a-76 & 500.823 & 3499.96 & 1382 & -161.47 \\
\hline cc-a-22 & 500.40799 & 3499.95 & 1368 & -143.16 & cc-a-77 & 500.83099 & 3499.96 & 1382 & -162.07001 \\
\hline cc-a-23 & 500.41599 & 3499.95 & 1369 & -143.32001 & cc-a-78 & 500.83801 & 3499.96 & 1382 & -162.72 \\
\hline cc-a-24 & 500.42401 & 3499.95 & 1369 & -143.45 & cc-a-79 & 500.84601 & 3499.96 & 1382 & -163.38 \\
\hline cc-a-25 & 500.43201 & 3499.95 & 1370 & -143.60001 & cc-a- 80 & 500.854 & 3499.96 & 1382 & -164.07001 \\
\hline$c c-a-26$ & 500.44 & 3499.95 & 1370 & -143.74001 & cc-a- 81 & 500.862 & 3499.96 & 1382 & -164.75 \\
\hline cc-a-27 & 500.44699 & 3499.95 & 1371 & -143.87 & cc-a- 82 & 500.86899 & 3499.96 & 1382 & -165.48 \\
\hline cc-a-28 & 500.45499 & 3499.95 & 1372 & -144 & cc-a-83 & 500.87701 & 3499.96 & 1382 & -166.24001 \\
\hline cc-a-29 & 500.46301 & 3499.95 & 1372 & -144.16 & cc-a- 84 & 500.88501 & 3499.96 & 1382 & -166.98 \\
\hline cc-a-30 & 500.47 & 3499.95 & 1372 & -144.32001 & cc-a-85 & 500.89301 & 3499.96 & 1382 & -167.78999 \\
\hline cc-a-31 & 500.478 & 3499.95 & 1373 & -144.50999 & cc-a-86 & 500.901 & 3499.96 & 1382 & -168.59 \\
\hline cc-a-32 & 500.48499 & 3499.95 & 1373 & -144.7 & cc-a-87 & 500.90799 & 3499.96 & 1382 & -169.38 \\
\hline cc-a-33 & 500.49301 & 3499.95 & 1373 & -144.88 & cc-a- 88 & 500.91599 & 3499.96 & 1381 & -170.23 \\
\hline cc-a-34 & 500.50101 & 3499.95 & 1374 & -145.06 & cc-a-89 & 500.92401 & 3499.97 & 1381 & -171.11 \\
\hline cc-a-35 & 500.509 & 3499.95 & 1374 & -145.25999 & cc-a-90 & 500.93201 & 3499.97 & 1381 & -171.99001 \\
\hline cc-a-36 & 500.51599 & 3499.95 & 1374 & -145.5 & cc-a-91 & 500.94 & 3499.97 & 1380 & -172.89 \\
\hline cc-a-37 & 500.52399 & 3499.95 & 1375 & -145.73 & cc-a-92 & 500.94699 & 3499.97 & 1380 & -173.82001 \\
\hline cc-a-38 & 500.53101 & 3499.95 & 1375 & -145.92999 & cc-a-93 & 500.95499 & 3499.97 & 1379 & -174.73 \\
\hline cc-a-39 & 500.539 & 3499.95 & 1375 & -146.16 & cc-a-94 & 500.96301 & 3499.97 & 1378 & -175.7 \\
\hline cc-a-40 & 500.547 & 3499.95 & 1376 & -146.39999 & cc-a-95 & 500.97101 & 3499.97 & 1378 & -176.66 \\
\hline cc-a-41 & 500.55499 & 3499.95 & 1376 & -146.67999 & cc-a-96 & 500.979 & 3499.97 & 1377 & -177.64 \\
\hline cc-a-42 & 500.56201 & 3499.95 & 1376 & -146.92999 & cc-a-97 & 500.98599 & 3499.97 & 1376 & -178.63 \\
\hline cc-a-43 & 500.57001 & 3499.95 & 1377 & -147.23 & cc-a-98 & 500.99399 & 3499.97 & 1376 & -179.67 \\
\hline cc-a-44 & 500.577 & 3499.95 & 1377 & -147.47 & cc-a-99 & 501.00201 & 3499.97 & 1375 & -180.71001 \\
\hline cc-a-45 & 500.58499 & 3499.95 & 1377 & -147.73 & cc-a-100 & 501.01001 & 3499.97 & 1374 & -181.77 \\
\hline cc-a-46 & 500.59299 & 3499.95 & 1378 & -148.05 & cc-a-101 & 501.01801 & 3499.97 & 1374 & -182.83 \\
\hline cc-a-47 & 500.60001 & 3499.95 & 1378 & -148.34 & cc-a-102 & 501.026 & 3499.97 & 1373 & -183.91 \\
\hline cc-a-48 & 500.608 & 3499.95 & 1378 & -148.64 & cc-a-103 & 501.034 & 3499.97 & 1372 & -184.96001 \\
\hline cc-a-49 & 500.616 & 3499.95 & 1379 & -148.98 & cc-a-104 & 501.04199 & 3499.97 & 1372 & -186.05 \\
\hline cc-a-50 & 500.62399 & 3499.95 & 1379 & -149.32001 & cc-a-105 & 501.04999 & 3499.97 & 1371 & -187.14 \\
\hline cc-a-51 & 500.63101 & 3499.95 & 1379 & -149.63 & cc-a-106 & 501.05801 & 3499.97 & 1371 & -188.24001 \\
\hline cc-a-52 & 500.638 & 3499.95 & 1379 & -149.96001 & cc-a-107 & 501.065 & 3499.97 & 1370 & -189.34 \\
\hline cc-a-53 & 500.646 & 3499.95 & 1380 & -150.31 & cc-a-108 & 501.073 & 3499.97 & 1369 & -190.42999 \\
\hline cc-a-54 & 500.65399 & 3499.95 & 1380 & -150.71001 & cc-a-109 & 501.08099 & 3499.97 & 1369 & -191.49001 \\
\hline cc-a-55 & 500.66199 & 3499.95 & 1380 & -151.10001 & cc-a-110 & 501.08899 & 3499.97 & 1368 & -192.58 \\
\hline cc-a-111 & 501.09799 & 3499.97 & 1367 & -193.64999 & cc-a-166 & 501.548 & 3499.97 & 1362 & -215.03999 \\
\hline cc-a-112 & 501.10501 & 3499.97 & 1367 & -194.7 & cc-a-167 & 501.556 & 3499.97 & 1363 & -215.09 \\
\hline cc-a-113 & 501.11301 & 3499.97 & 1366 & -195.71001 & cc-a-168 & 501.564 & 3499.97 & 1363 & -215.16 \\
\hline cc-a-114 & 501.12201 & 3499.97 & 1365 & -196.73 & cc-a-169 & 501.573 & 3499.97 & 1364 & -215.27 \\
\hline cc-a-115 & 501.13 & 3499.97 & 1365 & -197.73 & cc-a-170 & 501.58099 & 3499.97 & 1364 & -215.45 \\
\hline cc-a-116 & 501.138 & 3499.97 & 1364 & -198.7 & cc-a-171 & 501.58899 & 3499.97 & 1365 & -215.56 \\
\hline cc-a-117 & 501.146 & 3499.97 & 1364 & -199.63 & cc-a-172 & 501.59698 & 3499.97 & 1365 & -215.73 \\
\hline cc-a-118 & 501.15399 & 3499.97 & 1363 & -200.53999 & cc-a-173 & 501.60501 & 3499.97 & 1366 & -215.92 \\
\hline cc-a-119 & 501.16199 & 3499.97 & 1362 & -201.39 & cc-a-174 & 501.61301 & 3499.97 & 1366 & -216.11 \\
\hline
\end{tabular}




\begin{tabular}{|c|c|c|c|c|c|c|c|c|c|}
\hline cc-a-120 & 501.17001 & 3499.97 & 1362 & -202.25 & cc-a-175 & 501.62201 & 3499.97 & 1367 & -216.3 \\
\hline cc-a-121 & 501.17899 & 3499.97 & 1361 & -203.07001 & cc-a-176 & 501.63 & 3499.97 & 1367 & -216.53999 \\
\hline cc-a-122 & 501.186 & 3499.97 & 1360 & -203.86 & cc-a-177 & 501.638 & 3499.97 & 1368 & -216.8 \\
\hline cc-a-123 & 501.194 & 3499.97 & 1360 & -204.62 & cc-a-178 & 501.646 & 3499.97 & 1368 & -217.03 \\
\hline cc-a-124 & 501.203 & 3499.97 & 1359 & -205.32001 & cc-a-179 & 501.65399 & 3499.97 & 1369 & -217.31 \\
\hline cc-a-125 & 501.211 & 3499.97 & 1359 & -206.02 & cc-a-180 & 501.66199 & 3499.97 & 1369 & -217.56 \\
\hline cc-a-126 & 501.21899 & 3499.97 & 1358 & -206.7 & cc-a-181 & 501.67099 & 3499.97 & 1370 & -217.85001 \\
\hline cc-a-127 & 501.22699 & 3499.97 & 1357 & -207.3 & cc-a-182 & 501.67801 & 3499.97 & 1370 & -218.14 \\
\hline cc-a-128 & 501.23499 & 3499.97 & 1357 & -207.92999 & cc-a-183 & 501.68701 & 3499.97 & 1371 & -218.41 \\
\hline cc-a-129 & 501.24301 & 3499.97 & 1356 & -208.48 & cc-a-184 & 501.69501 & 3499.97 & 1371 & -218.67999 \\
\hline cc-a-130 & 501.25201 & 3499.97 & 1356 & -209.06 & cc-a-185 & 501.703 & 3499.97 & 1372 & -218.95 \\
\hline cc-a-131 & 501.26001 & 3499.97 & 1356 & -209.57001 & cc-a-186 & 501.711 & 3499.97 & 1373 & -219.23 \\
\hline cc-a-132 & 501.26801 & 3499.97 & 1356 & -210.08 & cc-a-187 & 501.71899 & 3499.97 & 1373 & -219.50999 \\
\hline cc-a-133 & 501.276 & 3499.97 & 1356 & -210.53 & cc-a-188 & 501.72699 & 3499.97 & 1373 & -219.75 \\
\hline cc-a-134 & 501.284 & 3499.97 & 1356 & -210.98 & cc-a-189 & 501.73599 & 3499.97 & 1374 & -220.03999 \\
\hline cc-a-135 & 501.293 & 3499.97 & 1356 & -211.37 & cc-a-190 & 501.74399 & 3499.97 & 1375 & -220.28999 \\
\hline cc-a-136 & 501.30099 & 3499.97 & 1356 & -211.78999 & cc-a-191 & 501.75201 & 3499.96 & 1375 & -220.52 \\
\hline cc-a-137 & 501.30899 & 3499.97 & 1355 & -212.14 & cc-a-192 & 501.76001 & 3499.96 & 1376 & -220.7 \\
\hline cc-a-138 & 501.31699 & 3499.97 & 1355 & -212.48 & cc-a-193 & 501.76801 & 3499.96 & 1376 & -220.92999 \\
\hline cc-a-139 & 501.32599 & 3499.97 & 1355 & -212.8 & cc-a-194 & 501.776 & 3499.96 & 1377 & -221.11 \\
\hline cc-a-140 & 501.33401 & 3499.97 & 1355 & -213.11 & cc-a-195 & 501.784 & 3499.96 & 1378 & -221.27 \\
\hline cc-a-141 & 501.34201 & 3499.97 & 1355 & -213.39 & cc-a-196 & 501.79199 & 3499.96 & 1378 & -221.46001 \\
\hline cc-a-142 & 501.35001 & 3499.97 & 1355 & -213.64 & cc-a-197 & 501.79999 & 3499.96 & 1379 & -221.57001 \\
\hline cc-a-143 & 501.35901 & 3499.97 & 1355 & -213.84 & cc-a-198 & 501.80801 & 3499.96 & 1379 & -221.66 \\
\hline cc-a-144 & 501.367 & 3499.97 & 1355 & -214.05 & cc-a-199 & 501.81601 & 3499.96 & 1380 & -221.73 \\
\hline cc-a-145 & 501.375 & 3499.97 & 1355 & -214.21001 & cc-a-200 & 501.82401 & 3499.96 & 1381 & -221.82001 \\
\hline cc-a-146 & 501.384 & 3499.97 & 1355 & -214.35001 & cc-a-201 & 501.83301 & 3499.96 & 1381 & -221.82001 \\
\hline cc-a-147 & 501.39099 & 3499.97 & 1355 & -214.47 & cc-a-202 & 501.84 & 3499.96 & 1382 & -221.84 \\
\hline cc-a-148 & 501.39999 & 3499.97 & 1354 & -214.56 & cc-a-203 & 501.84799 & 3499.96 & 1383 & -221.87 \\
\hline cc-a-149 & 501.40799 & 3499.97 & 1354 & -214.64999 & cc-a-204 & 501.85699 & 3499.96 & 1383 & -221.86 \\
\hline cc-a-150 & 501.41599 & 3499.97 & 1355 & -214.67999 & cc-a-205 & 501.86499 & 3499.96 & 1384 & -221.85001 \\
\hline cc-a-151 & 501.42499 & 3499.97 & 1355 & -214.7 & cc-a-206 & 501.87299 & 3499.96 & 1384 & -221.84 \\
\hline cc-a-152 & 501.43301 & 3499.97 & 1356 & -214.74001 & cc-a-207 & 501.88101 & 3499.96 & 1385 & -221.77 \\
\hline cc-a-153 & 501.44101 & 3499.97 & 1356 & -214.81 & cc-a-208 & 501.88901 & 3499.96 & 1386 & -221.73 \\
\hline cc-a-154 & 501.44901 & 3499.97 & 1357 & -214.81 & cc-a-209 & 501.897 & 3499.96 & 1386 & -221.69 \\
\hline cc-a-155 & 501.45801 & 3499.97 & 1357 & -214.84 & cc-a-210 & 501.905 & 3499.96 & 1387 & -221.61 \\
\hline cc-a-156 & 501.466 & 3499.97 & 1358 & -214.82001 & cc-a-211 & 501.91299 & 3499.96 & 1388 & -221.53 \\
\hline cc-a-157 & 501.474 & 3499.97 & 1358 & -214.82001 & cc-a-212 & 501.92001 & 3499.96 & 1389 & -221.49001 \\
\hline cc-a-158 & 501.48199 & 3499.97 & 1359 & -214.81 & cc-a-213 & 501.92801 & 3499.96 & 1389 & -221.42 \\
\hline cc-a-159 & 501.48999 & 3499.97 & 1359 & -214.82001 & cc-a-214 & 501.93701 & 3499.96 & 1390 & -221.34 \\
\hline cc-a-160 & 501.49899 & 3499.97 & 1360 & -214.77 & cc-a-215 & 501.94501 & 3499.95 & 1391 & -221.28999 \\
\hline cc-a-161 & 501.50699 & 3499.97 & 1360 & -214.78 & cc-a-216 & 501.953 & 3499.95 & 1392 & -221.17 \\
\hline cc-a-162 & 501.51501 & 3499.97 & 1361 & -214.8 & cc-a-217 & 501.95999 & 3499.95 & 1393 & -221.09 \\
\hline cc-a-163 & 501.52301 & 3499.97 & 1361 & -214.85001 & cc-a-218 & 501.96799 & 3499.95 & 1393 & -221.02 \\
\hline cc-a-164 & 501.53101 & 3499.97 & 1362 & -214.89 & cc-a-219 & 501.97601 & 3499.95 & 1394 & -221 \\
\hline cc-a-165 & 501.54001 & 3499.97 & 1362 & -214.96001 & cc-a-220 & 501.98401 & 3499.95 & 1395 & -220.97 \\
\hline cc-a-221 & 501.992 & 3499.95 & 1396 & -220.96001 & cc-a-276 & 502.41699 & 3499.95 & 1440 & -223.81 \\
\hline cc-a-222 & 502 & 3499.95 & 1397 & -220.92999 & cc-a-277 & 502.42401 & 3499.95 & 1441 & -223.88 \\
\hline cc-a-223 & 502.008 & 3499.95 & 1397 & -220.91 & cc-a-278 & 502.431 & 3499.95 & 1441 & -223.95 \\
\hline cc-a-224 & 502.01599 & 3499.95 & 1398 & -220.92 & cc-a-279 & 502.439 & 3499.95 & 1442 & -223.99001 \\
\hline cc-a-225 & 502.02399 & 3499.95 & 1399 & -220.88 & cc-a-280 & 502.44699 & 3499.96 & 1443 & -224.07001 \\
\hline cc-a-226 & 502.03201 & 3499.95 & 1400 & -220.86 & cc-a-281 & 502.45401 & 3499.96 & 1444 & -224.16 \\
\hline cc-a-227 & 502.039 & 3499.95 & 1401 & -220.88 & cc-a-282 & 502.461 & 3499.96 & 1444 & -224.25 \\
\hline cc-a-228 & 502.047 & 3499.95 & 1401 & -220.88 & cc-a-283 & 502.46899 & 3499.96 & 1445 & -224.33 \\
\hline cc-a-229 & 502.05499 & 3499.95 & 1402 & -220.89999 & cc-a-284 & 502.47699 & 3499.96 & 1446 & -224.39 \\
\hline cc-a-230 & 502.06299 & 3499.95 & 1403 & -220.92 & cc-a-285 & 502.48401 & 3499.96 & 1446 & -224.5 \\
\hline cc-a-231 & 502.07101 & 3499.95 & 1404 & -220.92999 & cc-a-286 & 502.492 & 3499.96 & 1447 & -224.60001 \\
\hline
\end{tabular}




\begin{tabular}{|c|c|c|c|c|c|c|c|c|c|}
\hline cc-a-232 & 502.078 & 3499.95 & 1405 & -220.92999 & cc-a-287 & 502.49899 & 3499.96 & 1448 & -224.67 \\
\hline cc-a-233 & 502.086 & 3499.95 & 1406 & -220.96001 & cc-a-288 & 502.50699 & 3499.96 & 1448 & -224.75 \\
\hline cc-a-234 & 502.09399 & 3499.95 & 1407 & -220.94 & cc-a-289 & 502.51401 & 3499.96 & 1449 & -224.84 \\
\hline cc-a-235 & 502.10199 & 3499.95 & 1407 & -220.98 & cc-a-290 & 502.522 & 3499.96 & 1449 & -224.94 \\
\hline cc-a-236 & 502.10999 & 3499.95 & 1408 & -221.00999 & cc-a-291 & 502.53 & 3499.96 & 1449 & -225.03 \\
\hline cc-a-237 & 502.117 & 3499.95 & 1409 & -221.03999 & cc-a-292 & 502.53699 & 3499.96 & 1450 & -225.12 \\
\hline cc-a-238 & 502.125 & 3499.95 & 1410 & -221.06 & cc-a-293 & 502.54401 & 3499.96 & 1450 & -225.24001 \\
\hline cc-a-239 & 502.133 & 3499.95 & 1411 & -221.10001 & cc-a-294 & 502.552 & 3499.96 & 1450 & -225.28999 \\
\hline cc-a-240 & 502.14099 & 3499.95 & 1412 & -221.09 & cc-a-295 & 502.56 & 3499.96 & 1450 & -225.39 \\
\hline cc-a-241 & 502.14899 & 3499.95 & 1413 & -221.13 & cc-a-296 & 502.56699 & 3499.96 & 1450 & -225.49001 \\
\hline cc-a-242 & 502.15601 & 3499.95 & 1413 & -221.17 & cc-a-297 & 502.57401 & 3499.96 & 1450 & -225.60001 \\
\hline cc-a-243 & 502.164 & 3499.95 & 1414 & -221.21001 & cc-a-298 & 502.582 & 3499.96 & 1450 & -225.7 \\
\hline cc-a-244 & 502.172 & 3499.95 & 1415 & -221.27 & cc-a-299 & 502.59 & 3499.96 & 1450 & -225.84 \\
\hline cc-a-245 & 502.17999 & 3499.95 & 1416 & -221.31 & cc-a-300 & 502.59698 & 3499.96 & 1450 & -225.92999 \\
\hline cc-a-246 & 502.18799 & 3499.95 & 1417 & -221.37 & cc-a-301 & 502.60501 & 3499.96 & 1450 & -226.03 \\
\hline cc-a-247 & 502.19501 & 3499.95 & 1418 & -221.41 & cc-a-302 & 502.612 & 3499.96 & 1451 & -226.14 \\
\hline cc-a-248 & 502.203 & 3499.95 & 1419 & -221.48 & cc-a-303 & 502.62 & 3499.96 & 1451 & -226.25 \\
\hline cc-a-249 & 502.211 & 3499.95 & 1420 & -221.55 & cc-a-304 & 502.62799 & 3499.96 & 1451 & -226.37 \\
\hline cc-a-250 & 502.21899 & 3499.95 & 1420 & -221.64 & cc-a-305 & 502.63501 & 3499.96 & 1451 & -226.47 \\
\hline cc-a-251 & 502.22601 & 3499.95 & 1421 & -221.69 & cc-a-306 & 502.64301 & 3499.96 & 1451 & -226.60001 \\
\hline cc-a-252 & 502.23401 & 3499.95 & 1422 & -221.78999 & cc-a-307 & 502.64999 & 3499.96 & 1451 & -226.71001 \\
\hline cc-a-253 & 502.241 & 3499.95 & 1423 & -221.86 & cc-a-308 & 502.65799 & 3499.96 & 1451 & -226.82001 \\
\hline cc-a-254 & 502.24899 & 3499.95 & 1423 & -221.97 & cc-a-309 & 502.66501 & 3499.96 & 1451 & -226.95 \\
\hline cc-a-255 & 502.25699 & 3499.95 & 1424 & -222.03999 & cc-a-310 & 502.673 & 3499.96 & 1451 & -227.03999 \\
\hline cc-a-256 & 502.26501 & 3499.95 & 1425 & -222.13 & cc-a-311 & 502.681 & 3499.97 & 1451 & -227.17999 \\
\hline cc-a-257 & 502.272 & 3499.95 & 1426 & -222.23 & cc-a-312 & 502.68799 & 3499.97 & 1451 & -227.34 \\
\hline cc-a-258 & 502.28 & 3499.95 & 1427 & -222.32001 & cc-a-313 & 502.69601 & 3499.97 & 1450 & -227.46001 \\
\hline cc-a-259 & 502.28699 & 3499.95 & 1427 & -222.42 & cc-a-314 & 502.70401 & 3499.97 & 1450 & -227.59 \\
\hline cc-a-260 & 502.29501 & 3499.95 & 1428 & -222.5 & cc-a-315 & 502.711 & 3499.97 & 1450 & -227.73 \\
\hline cc-a-261 & 502.30301 & 3499.95 & 1429 & -222.57001 & cc-a-316 & 502.71899 & 3499.97 & 1450 & -227.84 \\
\hline cc-a-262 & 502.31 & 3499.95 & 1430 & -222.64999 & cc-a-317 & 502.72601 & 3499.97 & 1450 & -227.98 \\
\hline cc-a-263 & 502.31799 & 3499.95 & 1430 & -222.7 & cc-a-318 & 502.73401 & 3499.97 & 1449 & -228.09 \\
\hline cc-a-264 & 502.32599 & 3499.95 & 1431 & -222.8 & cc-a-319 & 502.742 & 3499.97 & 1449 & -228.2 \\
\hline cc-a-265 & 502.33301 & 3499.95 & 1432 & -222.89999 & cc-a-320 & 502.75 & 3499.97 & 1449 & -228.33 \\
\hline cc-a-266 & 502.341 & 3499.95 & 1433 & -222.99001 & cc-a-321 & 502.75699 & 3499.97 & 1449 & -228.42 \\
\hline cc-a-267 & 502.34799 & 3499.95 & 1434 & -223.07001 & cc-a-322 & 502.76501 & 3499.97 & 1449 & -228.53999 \\
\hline cc-a-268 & 502.35599 & 3499.95 & 1434 & -223.2 & cc-a-323 & 502.772 & 3499.97 & 1448 & -228.7 \\
\hline cc-a-269 & 502.36401 & 3499.95 & 1435 & -223.31 & cc-a-324 & 502.78 & 3499.97 & 1448 & -228.84 \\
\hline cc-a-270 & 502.371 & 3499.95 & 1436 & -223.41 & cc-a-325 & 502.78799 & 3499.97 & 1448 & -228.99001 \\
\hline cc-a-271 & 502.379 & 3499.95 & 1437 & -223.50999 & cc-a-326 & 502.79599 & 3499.97 & 1448 & -229.14999 \\
\hline cc-a-272 & 502.38599 & 3499.95 & 1437 & -223.61 & cc-a-327 & 502.80301 & 3499.97 & 1447 & -229.3 \\
\hline cc-a-273 & 502.39401 & 3499.95 & 1438 & -223.66 & cc-a-328 & 502.811 & 3499.97 & 1447 & -229.37 \\
\hline cc-a-274 & 502.401 & 3499.95 & 1439 & -223.73 & cc-a-329 & 502.81799 & 3499.97 & 1447 & -229.49001 \\
\hline cc-a-275 & 502.409 & 3499.95 & 1439 & -223.8 & cc-a-330 & 502.82599 & 3499.97 & 1447 & -229.61 \\
\hline cc-a-331 & 502.83401 & 3499.97 & 1446 & -229.72 & & & & & \\
\hline cc-a-332 & 502.84201 & 3499.97 & 1446 & -229.83 & & & & & \\
\hline cc-a-333 & 502.849 & 3499.97 & 1445 & -229.92999 & & & & & \\
\hline cc-a-334 & 502.85699 & 3499.97 & 1445 & -230.00999 & & & & & \\
\hline cc-a-335 & 502.86499 & 3499.97 & 1444 & -230.13 & & & & & \\
\hline cc-a-336 & 502.87299 & 3499.97 & 1444 & -230.25 & & & & & \\
\hline cc-a-337 & 502.88101 & 3499.97 & 1443 & -230.34 & & & & & \\
\hline cc-a-338 & 502.88901 & 3499.97 & 1443 & -230.42999 & & & & & \\
\hline cc-a-339 & 502.896 & 3499.97 & 1442 & -230.55 & & & & & \\
\hline cc-a-340 & 502.90399 & 3499.97 & 1442 & -230.64999 & & & & & \\
\hline cc-a-341 & 502.91199 & 3499.98 & 1442 & -230.75999 & & & & & \\
\hline cc-a-342 & 502.92001 & 3499.98 & 1441 & -230.89 & & & & & \\
\hline cc-a-343 & 502.92801 & 3499.98 & 1441 & -230.97 & & & & & \\
\hline
\end{tabular}




$\begin{array}{cccrr}\text { cc-a-344 } & 502.936 & 3499.98 & 1440 & -231.06 \\ \text { cc-a-345 } & 502.94299 & 3499.98 & 1440 & -231.14999 \\ \text { cc-a-346 } & 502.95099 & 3499.98 & 1439 & -231.2 \\ \text { cc-a-347 } & 502.95901 & 3499.98 & 1439 & -231.28999 \\ \text { cc-a-348 } & 502.96701 & 3499.98 & 1438 & -231.36 \\ \text { cc-a-349 } & 502.97501 & 3499.98 & 1438 & -231.42999 \\ \text { cc-a-350 } & 502.983 & 3499.98 & 1438 & -231.52 \\ \text { cc-a-351 } & 502.991 & 3499.98 & 1437 & -231.57001 \\ \text { cc-a-352 } & 502.99799 & 3499.98 & 1437 & -231.62 \\ \text { cc-a-353 } & 503.00699 & 3499.98 & 1436 & -231.61 \\ \text { cc-a-354 } & 503.01501 & 3499.98 & 1436 & -231.63 \\ \text { cc-a-355 } & 503.02301 & 3499.98 & 1436 & -231.64 \\ \text { cc-a-356 } & 503.03101 & 3499.98 & 1435 & -231.67 \\ \text { cc-a-357 } & 503.03799 & 3499.98 & 1435 & -231.7 \\ \text { cc-a-358 } & 503.047 & 3499.98 & 1434 & -231.72 \\ \text { cc-a-359 } & 503.05499 & 3499.98 & 1434 & -231.75 \\ \text { cc-a-360 } & 503.06299 & 3499.98 & 1434 & -231.82001 \\ \text { cc-a-361 } & 503.07101 & 3499.98 & 1433 & -231.88 \\ \text { cc-a-362 } & 503.078 & 3499.98 & 1433 & -231.91 \\ \text { cc-a-363 } & 503.08701 & 3499.98 & 1432 & -231.91 \\ \text { cc-a-364 } & 503.095 & 3499.98 & 1432 & -231.92999 \\ \text { cc-a-365 } & 503.103 & 3499.98 & 1432 & -231.92999 \\ \text { cc-a-366 } & 503.11099 & 3499.98 & 1431 & -231.98 \\ \text { cc-a-367 } & 503.11899 & 3499.98 & 1431 & -232.02 \\ \text { cc-a-368 } & 503.12701 & 3499.98 & 1430 & -232.03999 \\ \text { cc-a-369 } & 503.13501 & 3499.98 & 1430 & -232.08 \\ \text { cc-a-370 } & 503.14301 & 3499.98 & 1430 & -232.14 \\ \text { cc-a-371 } & 503.151 & 3499.98 & 1430 & -232.17 \\ \text { cc-a-372 } & 503.159 & 3499.98 & 1430 & -232.22 \\ \text { cc-a-373 } & 503.16699 & 3499.98 & 1430 & -232.24001 \\ \text { cc-a-374 } & 503.17499 & 3499.98 & 1429 & -232.25999 \\ \text { cc-a-375 } & 503.18399 & 3499.98 & 1429 & -232.25 \\ \text { cc-a-376 } & 503.19199 & 3499.98 & 1429 & -232.23 \\ \text { cc-a-377 } & 503.20001 & 3499.98 & 1429 & -232.23 \\ \text { cc-a-378 } & 503.20801 & 3499.98 & 1429 & -232.24001 \\ \text { cc-a-379 } & 503.216 & 3499.98 & 1429 & -232.22 \\ \text { cc-a-380 } & 503.224 & 3499.98 & 1429 & -232.24001 \\ \text { cc-a-381 } & 503.233 & 3499.98 & 1429 & -232.22 \\ \text { cc-a-382 } & 503.23999 & 3499.98 & 1428 & -232.17999 \\ \text { cc-a-383 } & 503.24899 & 3499.98 & 1428 & -232.14\end{array}$

